\title{
Untersuchung endokriner Effekte von Benzophenon-2 und $17 \beta$-Estradiol in estrogen-rezeptiven Organen
}

\author{
Dissertation \\ zur Erlangung des Doktorgrades \\ der Mathematisch-Naturwissenschaftlichen Fakultäten \\ der Georg-August-Universität zu Göttingen
}

vorgelegt von

Christiane Schlecht

aus Blankenburg/Harz 
D 7

Referent: Prof. Dr. R. Hardeland

Korreferent: Prof. Dr. D. Doenecke

Tag der mündlichen Prüfung: 03.05.2006 
Gewidmet meiner „Familie“ 


\section{Abkürzungsverzeichnis}

In dieser Arbeit wurden die internationalen SI-Einheiten und davon abgeleitete Einheiten mit SI-Präfixen verwendet.

$3 \mathrm{MC}$

Abb.

AF-1

AF-2

AhR

ANOVA

ATP

BP

BrdU

BSA

bzw.

$\mathrm{C}$

C3

cAMP

cDNA

CED

CES

cpm

CREB

CTP

$\mathrm{Da}$

DDT

DES

dest

DI/II

DMEM

DMSO

DNA
3-Methylcholanthren

Abbildung

Liganden-unabhängige Transaktivierungsfunktion

Liganden-abhängige Transaktivierungsfunktion

Arylhydrocarbon-Rezeptor

analysis of variance

Adenosintriphosphat

Benzophenon

5-Bromo-2'deoxyuridin

bovines Serumalbumin

beziehungsweise

Cytidin

Komplement-Protein 3

cyclisches Adenosinmonophosphat

komplementäre DNA

kritische Effekt-Dosis

kritische Effekt-Größe

counts per minute

cAMP-responsives Element-bindendes Protein

Cytidintriphosphat

Dalton

Dichlordiphenyltrichlorethan

Diethylstilbestrol

destilliert

Typ I/II 5'-Deiodase

dulbecco's modified eagle's medium

Dimethylsulfoxid

Desoxyribonukleinsäure 


\begin{tabular}{|c|c|}
\hline DNase & Desoxyribonuklease \\
\hline $\mathrm{DPN}$ & Diarylpropionitril, ER $\beta$-Agonist \\
\hline $\mathrm{E} 2$ & $17 \beta$-Estradiol \\
\hline $\mathrm{E} 2 \mathrm{~V}$ & $17 \beta$-Estradiolvalerat \\
\hline EAC & endokrin aktive Chemikalie \\
\hline EC50 & Konzentration, bei der die halbmaximale Wirkung erreicht wird \\
\hline ECLIA & Elektrochemilumineszenz-Immunoassay \\
\hline EDTA & Ethylendiamintetraacetat \\
\hline ELISA & enzyme-linked immunosorbent assay \\
\hline ER & Estrogen-Rezeptor \\
\hline ERE & Estrogen-responsives Element \\
\hline EROD & Ethoxyresorufin-O-deethylase \\
\hline $\mathrm{EtOH}$ & Ethanol \\
\hline FAM & 6-Carboxy-fluorescein \\
\hline FCS & fötales Kälberserum \\
\hline FSH & follikelstimulierendes Hormon \\
\hline fT3; fT4 & freies $\mathrm{T} 3$, freies $\mathrm{T} 4$ \\
\hline $\mathrm{G}$ & Guanosin \\
\hline $\mathrm{GH}$ & Wachstumshormon \\
\hline GnRH & Gonadotropin-Releasing-Hormon \\
\hline GTP & Guanosintriphosphat \\
\hline HDL & high density lipoprotein \\
\hline $\mathrm{HE}$ & Hämatoxylin-Eosin \\
\hline HEPES & 2-(4-(2-Hydoxyethyl)-1-piperazinyl)ethansulfonat \\
\hline HPG & Hypothalamus-Hypophyse-Gonaden \\
\hline HPLC & high performance liquid chromatography \\
\hline HPT & Hypothalamus-Hypophyse-Schilddrüse \\
\hline HRE & Hormon-responsives Element \\
\hline HRP & Meerrettichperoxidase \\
\hline ICI 182,780; ICI & Estrogen-Rezeptor-Antagonist \\
\hline $\operatorname{Ig}$ & Immunoglobulin \\
\hline IGF-1 & insulin-like growth factor 1 \\
\hline
\end{tabular}




\begin{tabular}{|c|c|}
\hline $\mathrm{Kg}$ & Körpergewicht \\
\hline LDL & low density lipoprotein \\
\hline LH & luteinisierendes Hormon \\
\hline LOAEL & lowest observed adverse effect level \\
\hline MAP & mitogen activated protein \\
\hline $\mathrm{MBH}$ & mediobasaler Hypothalamus \\
\hline mRNA & messenger-RNA \\
\hline MS & Massenspektrometrie \\
\hline MTT & 3-(4,5-Dimethyl-2-thiazolyl)-2,5-diphenyl-2H-tetrazolium bromid \\
\hline $\mathrm{N}-\mathrm{CoR}$ & nuclear receptor corepressor \\
\hline NIS & Natrium/Iodid-Symporter \\
\hline NOAEL & no observed adverse effect level \\
\hline OD & optische Dichte \\
\hline OECD & Organisation für wirtschaftliche Zusammenarbeit und Entwicklung \\
\hline ovx & ovariektomiert \\
\hline PBS & Phosphat-gepufferte Saline \\
\hline PCB & polychlorierte Biphenyle \\
\hline PCR & Polymerase-Kettenreaktion \\
\hline Pen/Strep & Penicillin/Streptomycin \\
\hline $\mathrm{pH}$ & negativer dekadischer Logarithmus der Wasserstoffionenkonzentration \\
\hline PKM & Permanentkultur-Medium \\
\hline PPT & Propylpyrazoltriol, ER $\alpha$-Agonist \\
\hline PRL & Prolaktin \\
\hline PTU & 6-n-Propyl-2-thiouracil \\
\hline QSAR & Quantitative Struktur-Aktivitäts-Beziehung \\
\hline RBA & Rezeptorbindungsassay \\
\hline REA & Repressor der ER-Aktivität \\
\hline RIA & Radioimmunoassay \\
\hline RLB & Reporter-Lysis-Puffer \\
\hline RNA & Ribonukleinsäure \\
\hline RNase & Ribonuklease \\
\hline RT & reverse Transkription \\
\hline
\end{tabular}




\begin{tabular}{|c|c|}
\hline RTD-PCR & real time detection-PCR \\
\hline SDS & Sodiumdodecylculfat \\
\hline SEM & Standardfehler des Mittelwertes \\
\hline SERM & selektiver Estrogen-Rezeptor-Modulator \\
\hline SHR & Steroidhormonrezeptoren \\
\hline SMRT & silencing mediator of retinoid and thyroid hormone receptor \\
\hline $\mathrm{SRC}$ & Steroid-Rezeptor-Koaktivator \\
\hline Swi/Snf & Chromatin-remodulierender Komplex \\
\hline $\mathrm{T} 3$ & Triiodthyronin \\
\hline $\mathrm{T} 4$ & Thyroxin \\
\hline Tab. & Tabelle \\
\hline TAMRA & 6-Carboxy-tetramethyl-rhodamin \\
\hline TERP-1 & truncated estrogen receptor product \\
\hline TPO & Schilddrüsenperoxidase \\
\hline TRAP/DRIP & Mediator zwischen Hormon-Rezeptor und Transkriptionsapparat \\
\hline TRH & TSH-Releasing-Hormon \\
\hline Tris & Tris(hydroxymethyl)aminomethan \\
\hline TSH & Thyroidea-stimulierendes Hormon \\
\hline UF & Unsicherheitsfaktor \\
\hline Upm & Umdrehungen pro Minute \\
\hline UTP & Uridintriphosphat \\
\hline UV & ultraviolett \\
\hline Velc & Velcorin \\
\hline z.B. & zum Beispiel \\
\hline
\end{tabular}




\section{Inhaltsverzeichnis}

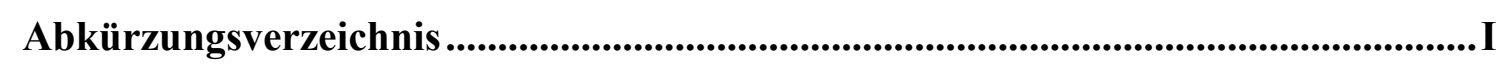

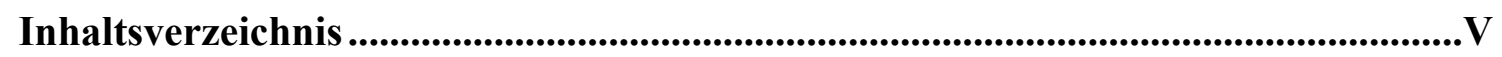

1 Einleitung......................................................................................................................... 1

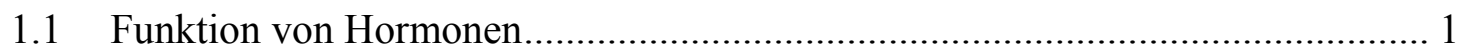

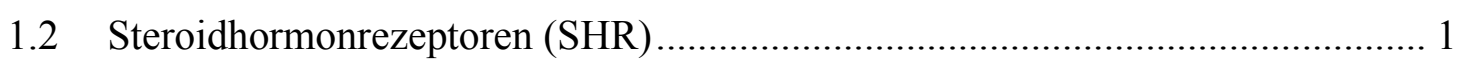

1.2.1 Aufbau von SHR..................................................................................................

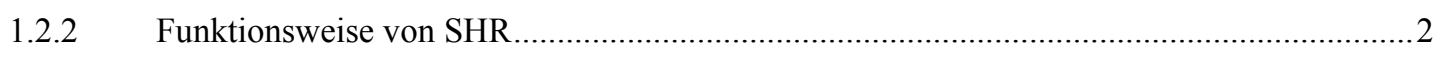

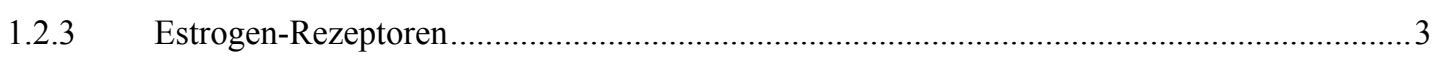

1.3 Einflüsse von endokrin aktiven Chemikalien auf das Hormonsystem ................. 4

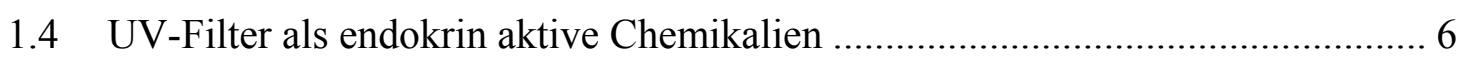

1.5 OECD-Protokoll zur Identifikation von EACs................................................ 8

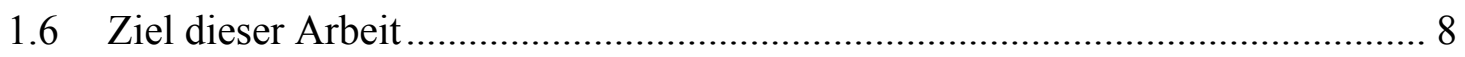

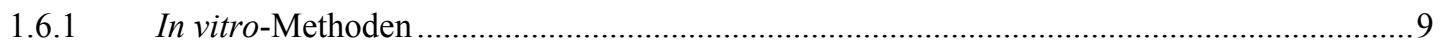

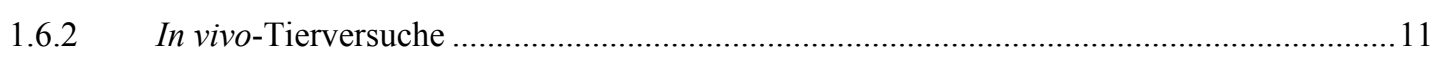

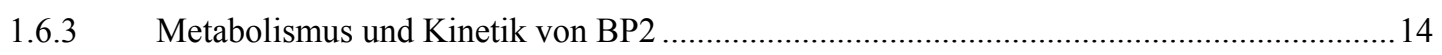

1.6.4 Erstellen einer Dosis-Wirkungsbeziehung für ausgewählte Parameter.................................. 14

2 Material und Methoden............................................................................ 15

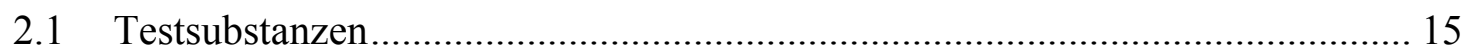

2.2 Sonstige Chemikalien und Verbrauchsmaterialien........................................... 16

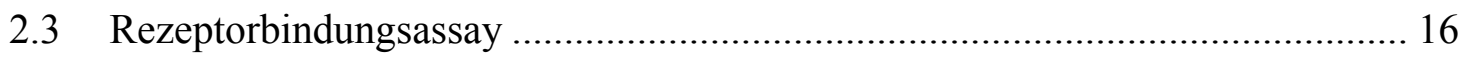

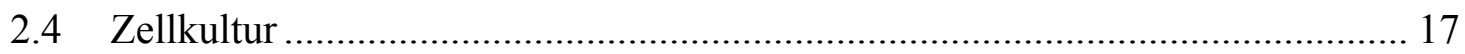

2.4.1 Proliferationstest (BrdU-Assay, E-screen) ................................................................... 18

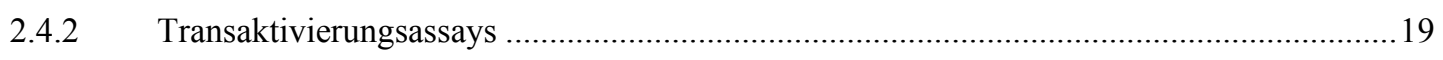

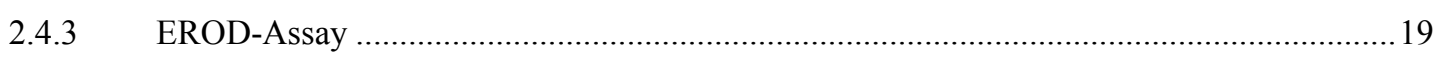

2.4.3.1 Proteinbestimmung nach Bradford (1976) ......................................................................2

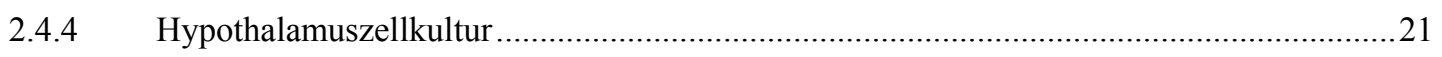

2.4.4.1 Bestimmung von GnRH im Zellkulturüberstand .............................................................2

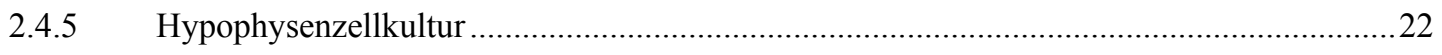

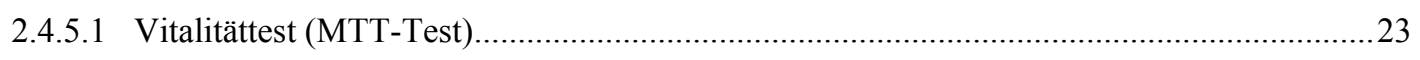

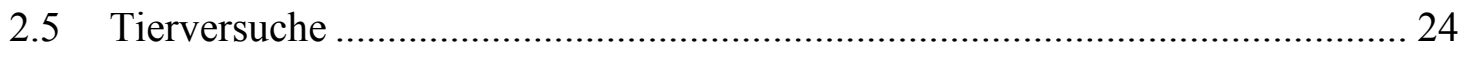

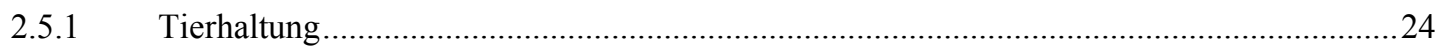

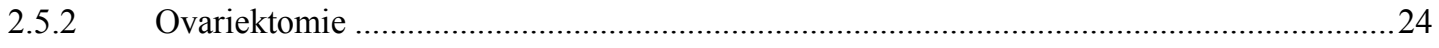




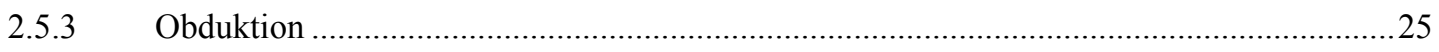

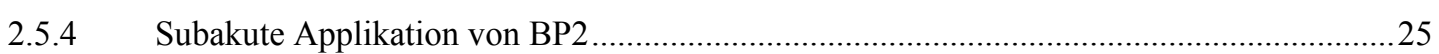

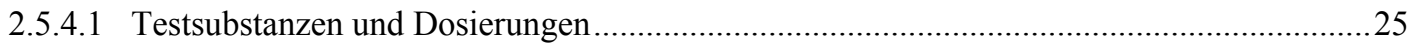

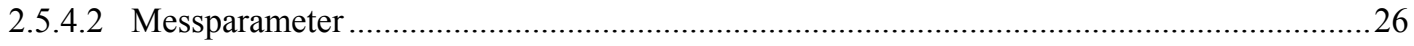

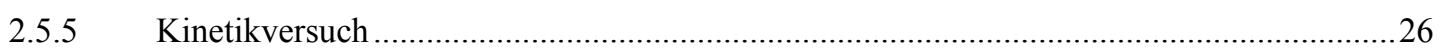

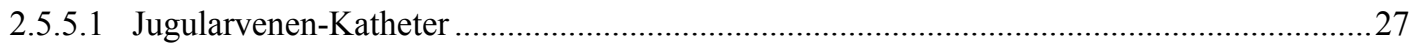

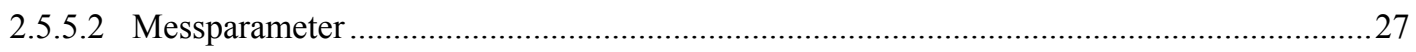

2.6 Serum Analyse.................................................................................... 28

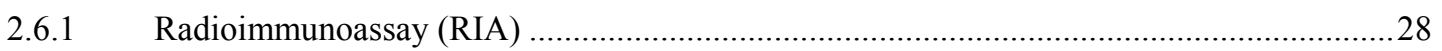

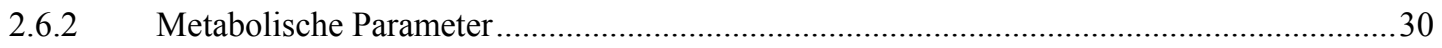

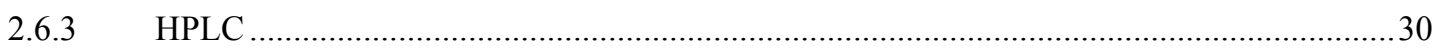

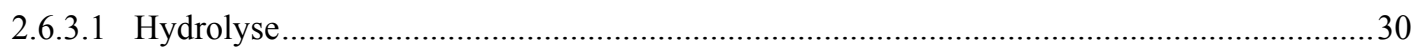

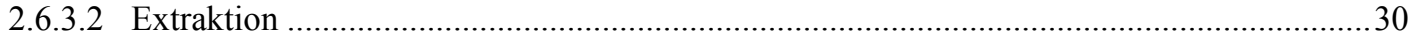

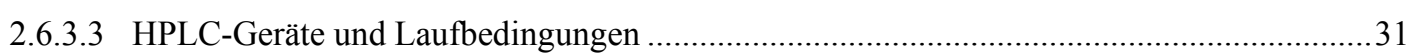

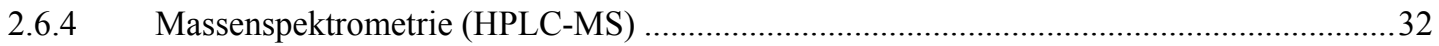

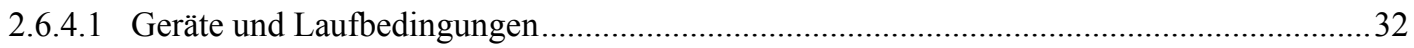

2.7 Molekularbiologische Arbeiten ....................................................................... 33

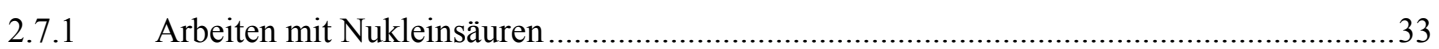

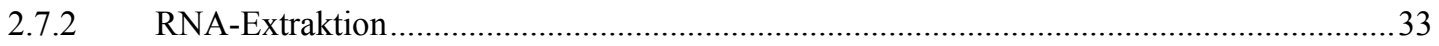

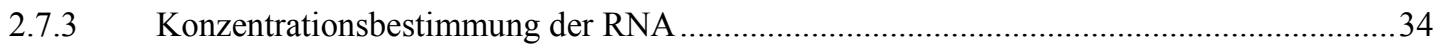

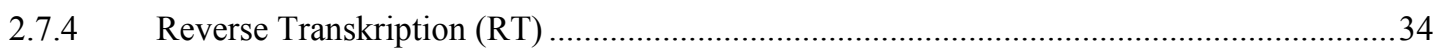

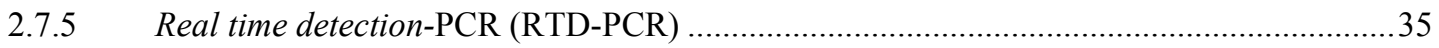

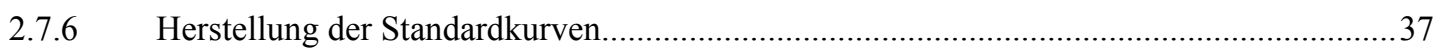

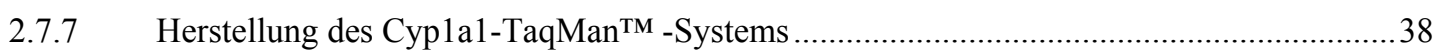

2.8 Proteinarbeiten...................................................................................... 39

2.8.1 Analyse der Proteinexpression des Natrium/Iodid-Symporters ......................................39

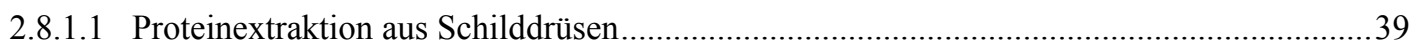

2.8.1.2 SDS-Polyacrylamid-Gelelektrophorese (SDS-PAGE) ...................................................40

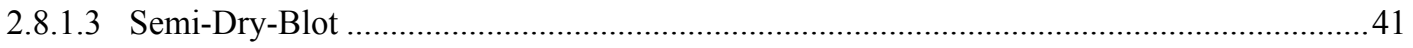

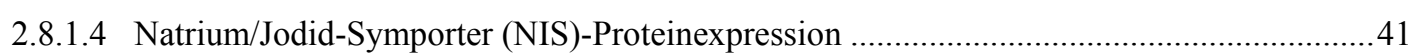

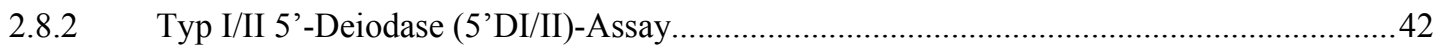

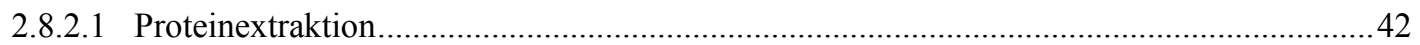

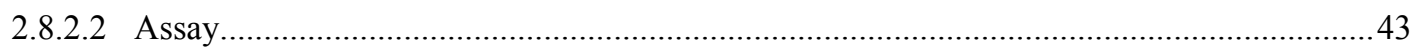

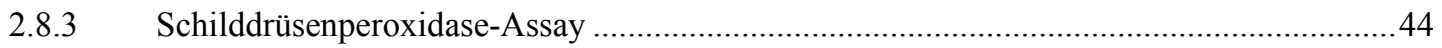

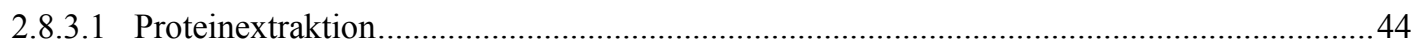

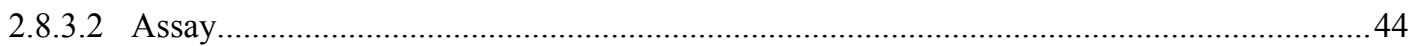

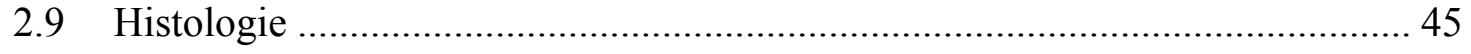

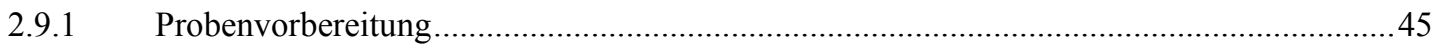




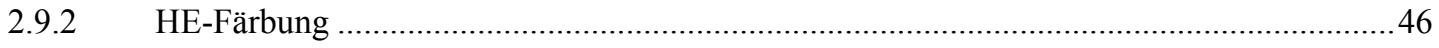

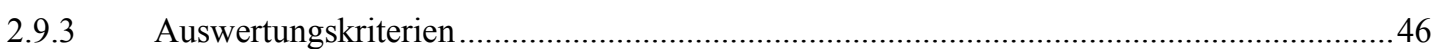

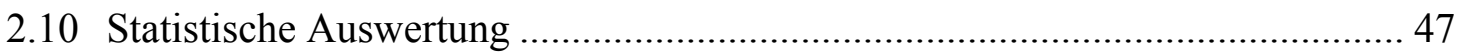

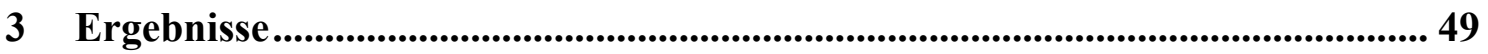

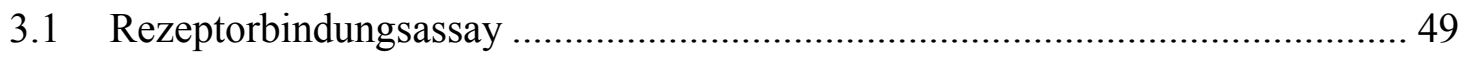

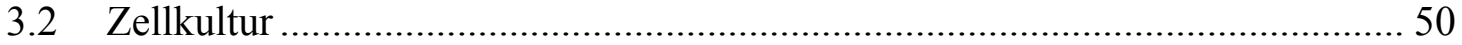

3.2.1 Proliferationstest mit MCF-7-Zellen (E-Screen) ..........................................................50

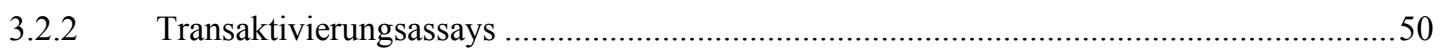

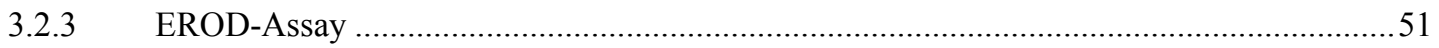

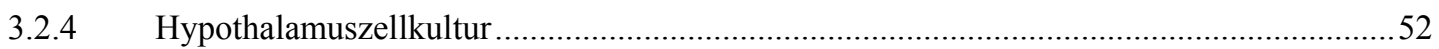

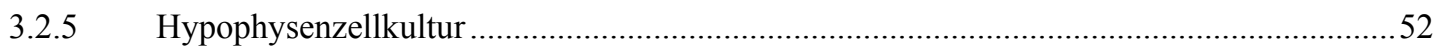

3.2.5.1 Viabilitätsbestimmung mittels MTT-Test..................................................................53

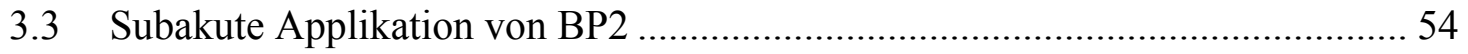

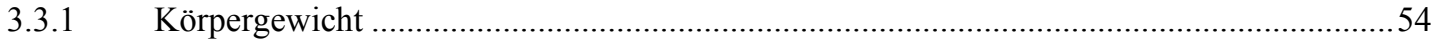

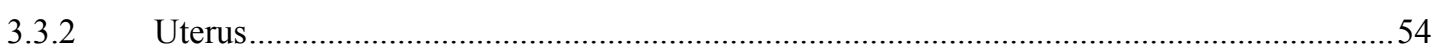

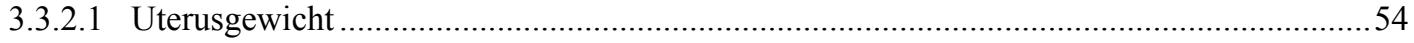

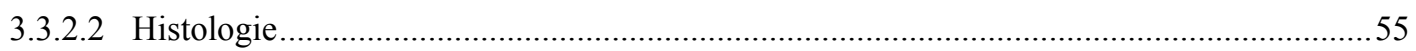

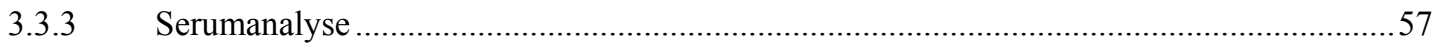

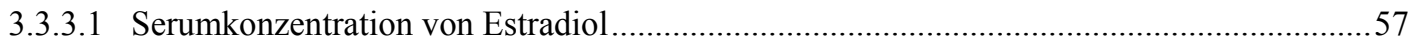

3.3.3.2 Serumkonzentration von Benzophenon-2 ....................................................................5

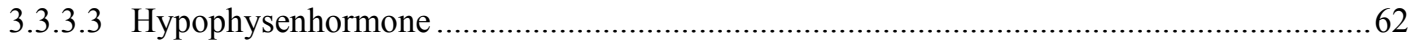

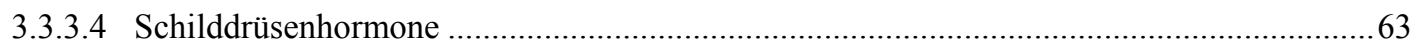

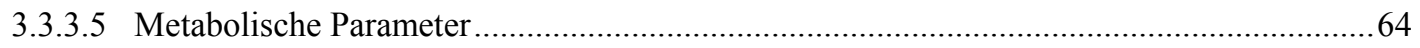

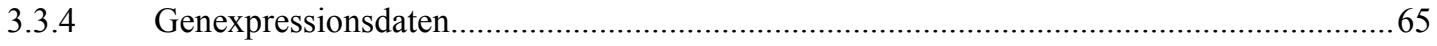

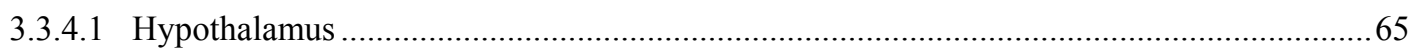

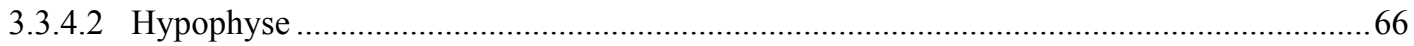

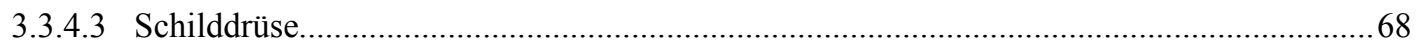

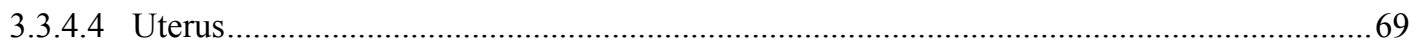

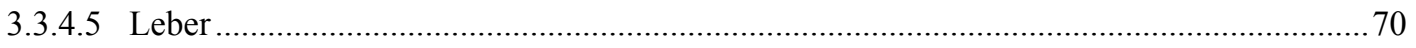

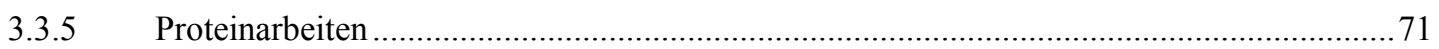

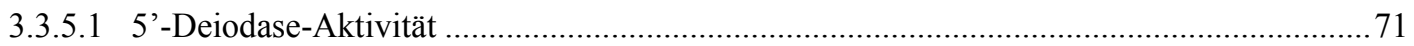

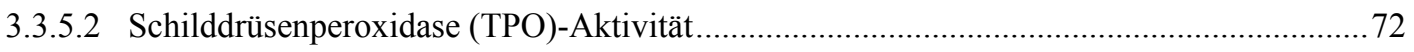

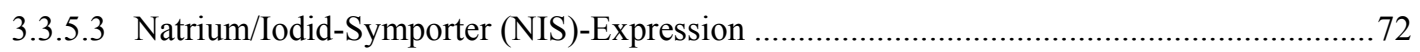

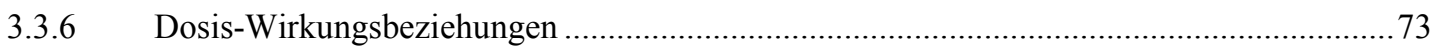

3.4 Kinetikversuch ..................................................................... 75

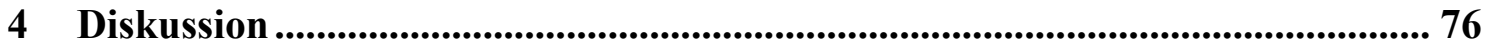


4.1 Bestätigung der estrogenen Aktivität von BP2 durch screening-Methoden ...... 76

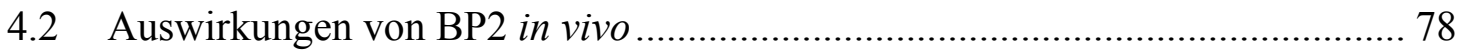

4.2.1 Auswirkungen von BP2 auf metabolische Parameter ........................................................78

4.2.2 Beeinflussung des ER $\alpha / E R \beta$-Status durch BP2 ….........................................................

4.2.3 Auswirkungen von BP2 auf die HPG-Achse ................................................................... 82

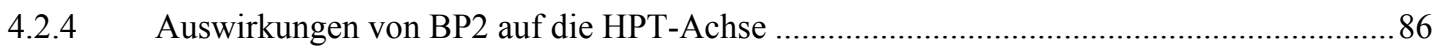

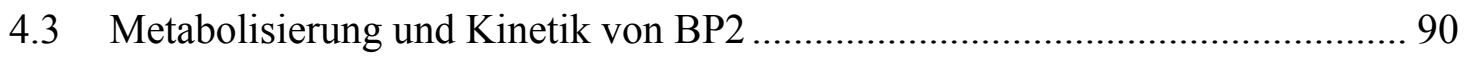

4.4 Dosis-Wirkungsbeziehung und Risiko-Bewertung ....................................... 93

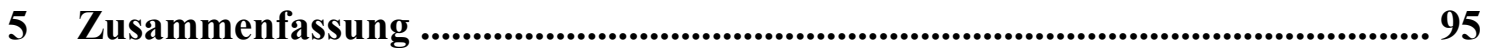

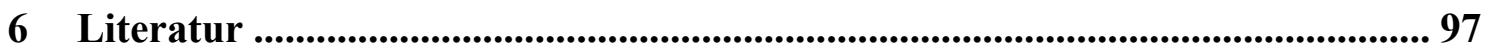

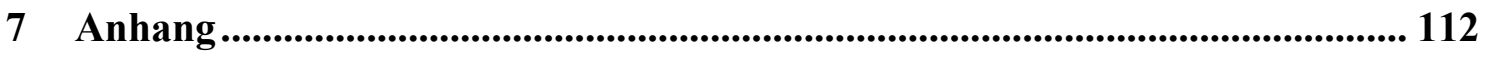

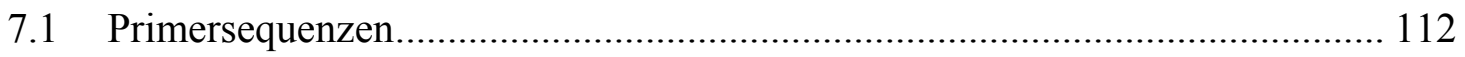




\section{Einleitung}

\subsection{Funktion von Hormonen}

Viele essentielle Funktionen des menschlichen Körpers werden durch Hormone gesteuert. Diese Botenstoffe sind unter anderem an der Regulation des Wachstums, der Reproduktion, des Stoffwechsels, des Elektrolyt- und Wasserhaushaltes und der Immunabwehr beteiligt. Aufgrund ihrer Struktur lassen sich Hormone in Aminosäurederivate (z.B. Thyroxin), Peptidhormone (z.B. Releasing-Hormone des Hypothalamus und stimulierende Hormone der Hypophyse) und Steroidhormone (z.B. Sexualhormone und Cortisol) einteilen.

Die Spezifität der Hormone wird dabei durch Rezeptoren gewährleistet, welche nach der Bindung des Hormons die Signale in der Zielzelle, zum Beispiel durch die Aktivierung von Signaltransduktionskaskaden (hauptsächlich bei hydrophilen Hormonen) oder durch die Regulation der Transkription (hauptsächlich bei lipophilen Hormonen), weiterleiten.

\subsection{Steroidhormonrezeptoren}

Zusammen mit Schilddrüsen-, Retinolsäure- und Vitamin D-Rezeptoren und einer Reihe von Rezeptoren ohne bekannte physiologische Liganden (Orphan-Rezeptoren) werden Steroidhormonrezeptoren (SHR) zur Superfamilie der Kernrezeptoren gezählt. Alle Mitglieder dieser Superfamilie zeichnen sich durch eine gemeinsame Grundstruktur aus (Evans 1988; Giguere et al. 1988; Gronemeyer et al. 1995).

Steroidhormonrezeptoren umfassen neben den Estrogen- und Androgen-Rezeptoren auch die Progesteron-, Glukokortikoid- und Mineralokortikoid-Rezeptoren. 


\subsubsection{Aufbau von Steroidhormonrezeptoren}

Steroidhormonrezeptoren sind modular aus mehreren Domänen aufgebaut (Beato et al. 1995). Diese Domänen haben bestimmte Funktionen und sind zwischen den einzelnen Rezeptoren teilweise hochkonserviert (siehe Abbildung 1-1).

N-terminal liegt die A/B-Domäne, welche die Liganden-unabhängige Transaktivierungsfunktion AF-1 enthält. Es folgt die DNA-bindende Domäne (C-Domäne), die Ligandenbindungsdomäne (E-Domäne) und c-terminal die Liganden-abhängige Transaktivierungsfunktion AF-2.

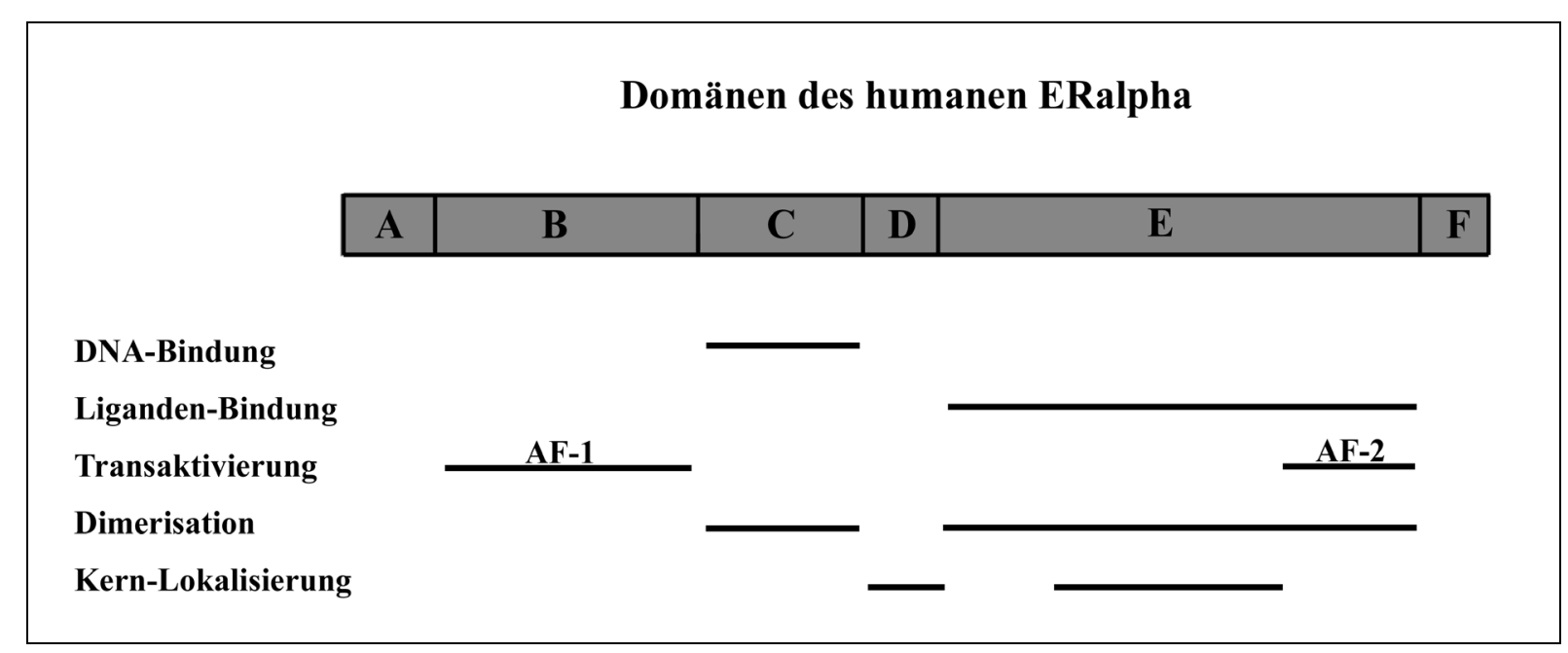

Abbildung 1-1:Aufbau und Funktionen der Domänen des humanen Estrogen-Rezeptor $\alpha$. Modifiziert nach (Reid et al. 2002)

\subsubsection{Funktionsweise von Steroidhormonrezeptoren}

Die Rezeptoren liegen ohne Ligand in einem Komplex mit Heat shock-Proteinen vor (Landel et al. 1995). Durch die Bindung eines Liganden wird eine Konformationsänderung ausgelöst, welche dazu führt, dass die assoziierten Proteine den Komplex verlassen (Rachez et al. 2001). Durch die Konformationsänderung des Proteins werden außerdem die Dimerisation der Rezeptoren und die Bindung an das entsprechende Hormon-responsive Element (HRE) des Genes ermöglicht (Paech et al. 1997).

Das an die DNA gebundene Rezeptor-Dimer kann anschließend durch die Rekrutierung verschiedener Kofaktoren (z.B. Koaktivatoren wie SRC-1, SRC-2 und TRAP/DRIP, Korepressoren wie N-CoR oder SMRT [Nilsson et al. 2001] und Modulatoren der 
Chromatinstruktur wie Swi/Snf [Collingwood et al. 1999]) die Transkription des Zielgens induzieren bzw. reprimieren. Die Rekrutierung der Kofaktoren ist dabei abhängig von dem gebundenen Liganden und der dadurch verursachten Konformationsänderung des Proteins, wobei die Position der Helix 12 (AF-2) den entscheidenden Ausschlag zwischen Induktion und Repression gibt (Brzozowski et al. 1997; Pike et al. 1999).

Neben der klassischen Transkriptionsregulierung wurden für Estrogene weitere mögliche Wirkmechanismen beschrieben. Dazu zählen zum Beispiel die Phosphorylierung von CREB (Zhou et al. 1996), die Aktivierung von MAP-Kinasen (Migliaccio et al. 1996), die Beeinflussung des cAMP- und Kalziumspiegels in der Zelle (Morley et al. 1992; Aronica et al. 1994; Collins et al. 1999), die Modifikation der DNA-Methylierung und die Modifikation der Aktivität von anderen Transkriptionsfaktoren. Diese schnellen, nicht-genomischen Effekte werden möglicherweise durch Estrogen-Rezeptoren in der Zellmembran vermittelt (Pappas et al. 1995; Collins et al. 1999).

\subsubsection{Estrogen-Rezeptoren}

$\mathrm{Zu}$ den SHR gehören die Estrogen-Rezeptoren (ER). 1986 wurde die Klonierung eines humanen Estrogen-Rezeptors (ER, später ER $\alpha$ ) beschrieben (Green et al. 1986). Bis zur Entdeckung eines zweiten Estrogen-Rezeptors (ER $\beta) 1996$ in der Prostata und im Ovar von Ratten (Kuiper et al. 1996) ging man davon aus, dass nur ein Rezeptor die Hormonwirkung vermittelte.

Inzwischen sind zusätzlich von beiden Rezeptoren verschiedene Isoformen bekannt (Friend et al. 1995; Zhang et al. 1996; Chu et al. 1997; Leygue et al. 1998; Maruyama et al. 1998). Allerdings herrscht über deren Funktion noch Unklarheit. Es wird angenommen, dass diese Isoformen einen regulierenden Einfluss auf die Signaltransduktion der Estrogene haben (Murphy et al. 1998). Die ER $\alpha$-Isoform TERP-1 stimuliert zum Beispiel die transkriptionelle Aktivität des ER $\alpha$ durch Titration des Repressorproteins REA (Lin et al. 2003). Beide ERs sind in der Lage Homodimere und auch Heterodimere mit einigen Isoformen zu bilden.

Über das Zusammenwirken der beiden Estrogen-Rezeptoren gibt es bislang keine gesicherten Erkenntnisse. Eine Möglichkeit stellt die „Yin/Yang“-Theorie dar, nach der ER $\beta$ die durch ER $\alpha$ aktivierte Transkription moduliert oder in Geweben ohne ER $\alpha$-Expression die Aufgaben von ER $\alpha$ übernimmt (Liu et al. 2002; Lindberg et al. 2003). Inzwischen wird zusätzlich davon ausgegangen, dass das Verhältnis der beiden Rezeptoren eine entscheidende Rolle bei 


\section{Einleitung}

Umsetzung des Hormonsignals in Proliferation oder Differenzierung spielt. In HepG2-Zellen wurde nachgewiesen, dass für die Proliferation die Interaktion des Transkriptionsfaktors AF-1 mit ER $\alpha$ wichtig ist (Flouriot et al. 2000), außerdem konnte gezeigt werden, dass E2 in ER $\alpha$-knockout-Mäusen keine Gewichtszunahme bzw. Proliferation des Uterus bewirken konnte (Couse et al. 1995). Andererseits konnte die durch Estrogen induzierte Differenzierung im murinen Ovidukt durch den E2-Antagonisten ICI 182,780 gehemmt werden (Okada et al. 2004), war aber in ER $\alpha$-knockout-Mäusen trotzdem möglich, was auf eine Signaltransduktion unter Beteiligung von ER $\beta$ schließen lässt.

\subsection{Einflüsse von endokrin aktiven Chemikalien auf das Hormonsystem}

Es ist bekannt, dass exogene, also körperfremde, Substanzen an vielen Punkten in die Regulationswege von Hormonregelkreisläufen eingreifen können (Degen et al. 1999). $\mathrm{Zu}$ diesen exogenen Substanzen gehören neben natürlich vorkommenden Substanzen wie z.B. Phyto- und Mykoestrogenen auch Xenobiotika. Diese Substanzen sind anthropogenen Ursprungs, wie zum Beispiel polychlorierte Biphenyle (PCB), und reichern sich teilweise aufgrund ihrer lipophilen Struktur und ihrer hohen Halbwertszeit in bestimmten Lebensräumen oder Geweben an (Cooke et al. 1982; Hooper et al. 1990). Man spricht bei diesen Substanzen von endokrin aktiven Chemikalien (EAC).

Es gibt vielfältige Möglichkeiten der Interaktion einer EAC mit einem Hormonsystem:

- Imitation der Wirkung eines hormonellen Agonisten bzw. Antagonisten. Dabei sind auch diverse Mischformen möglich (Landel et al. 1994).

- Hemmung der hormonellen Regulation durch Blockierung des Rezeptors, der Kofaktoren oder Bindestellen des Rezeptors. Auch die indirekte Induktion des Rezeptorabbaus durch Ubiquitinierung wurde beschrieben (Wormke et al. 2003).

- Modifikation von Produktion, Sekretion, Transport oder Metabolismus eines endogenen Hormons (Morinaga et al. 2004).

Mittlerweile umgibt sich der Mensch mit über 100.000 Chemikalien (Fent 2003), von denen viele noch nicht auf eine mögliche Toxizität und die meisten noch nicht auf eine mögliche endokrine Aktivität getestet wurden. Bei Vergleichen der strukturellen Eigenschaften von 58.000 Industriechemikalien mit den strukturellen Eigenschaften von ER-Liganden mittels des QSAR-Programms (Quantitative Struktur-Aktivitäts-Beziehung) sind 6000 der 
untersuchten Substanzen als mögliche ER-Liganden identifiziert worden (Hong et al. 2002) Dass diese Substanzen einen negativen Einfluss auf die menschliche Gesundheit haben könnten, wurde anhand mehrerer Kriterien diskutiert:

- Spermienqualität: In der Zeitspanne von 1938 bis 1990 wurde ein Rückgang der Spermienzahl pro $\mathrm{ml}$ um rund $50 \%$ in westlichen Industrienationen beobachtet (Carlsen et al. 1992). Dieser Trend wurde inzwischen von mehreren Studien bestätigt (Auger et al. 1995; Swan et al. 1997; Swan et al. 2000). Außerdem konnte gezeigt werden, dass Söhne von Frauen, welche mit Diethylstilbestrol (DES) behandelt wurden, eine um etwa 1/3 reduzierte Spermiendichte aufwiesen (Bonde et al. 1998). DES ist ein starkes Estradiolanalogon, welches in den 50er bis 70er Jahren in den USA zur Prävention von Schwangerschaftsabbrüchen sowie als „Pille danach“ verschrieben wurde.

- Hodenkarzinome: Es konnte gezeigt werden, dass die pränatale Exposition gegenüber DES zu einem um den Faktor 2,6 erhöhten Risiko eines Hodenkarzinoms führt (Toppari et al. 1996).

- Prostatakarzinome: Das Risiko an Prostatakrebs zu erkranken, erhöhte sich signifikant bei Anwendern von hormonell wirksamen Pestiziden (Morrison et al. 1993; KellerByrne et al. 1997; Dich et al. 1998; Fleming et al. 1999; Parker et al. 1999). Es wurde außerdem ein Zusammenhang zwischen einem hohen Estrogenspiegel der Mutter während der Schwangerschaft und Prostataneoplasien bei männlichen Nachkommen vermutet (Santti et al. 1994).

- Brustkrebs: In den letzten Jahrzehnten wurde ein Anstieg der Inzidenz der Estrogensensiblen Tumore beobachtet. Es wird diskutiert, ob die Ursache in der Exposition gegenüber Xenobiotika wie zum Beispiel Dichlordiphenyltrichlorethan (DDT) liegt (Krieger et al. 1994; Hoyer et al. 1998; Dorgan et al. 1999; Laden et al. 2001).

- Vaginalkarzinome: In den 70er Jahren zeigten sich bei den Töchtern von mit DES behandelten Müttern Langzeitfolgen. Es konnte eine stark erhöhte Krebsinzidenz in der Vagina festgestellt werden (Herbst et al. 1971). Bei über $90 \%$ der betroffenen Frauen entwickelten sich vaginale Fehlbildungen (Herbst 1987) und bei 0,1\% wurde eine sehr seltene Art von vaginalen Adenokarzinomen gefunden (Newbold 1995).

All diese Untersuchungen sind ein Indiz für die adverse Beeinflussung endokriner Systeme durch Xenobiotika, die eine weitere Untersuchung dieser Substanzen nötig machen, da die 
genauen Ursachen und Mechanismen in den vielen Fällen noch nicht endgültig aufgeklärt werden konnten.

\subsection{UV-Filter als endokrin aktive Chemikalien}

Durch die zunehmende Sonnenexposition des Menschen kommt dem Schutz der Haut vor der kurzwelligen UVA (320 - $400 \mathrm{~nm}$ )- und UVB (290 - $320 \mathrm{~nm}$ )-Strahlung des Sonnenlichtes eine immer größere Bedeutung zu.

Durch die energiereichere UVB-Strahlung wird die Melatoninbildung in den Melanocyten angeregt, wodurch einerseits die gewünschte Hautbräunung erreicht wird, andererseits ist UVB-Strahlung auch für Entzündungsreaktionen (Sonnenbrand, Photoallergien) verantwortlich. Zusammen mit UVA-Strahlung ist sie außerdem für die Hautalterung und die Entstehung von Tumoren durch Schädigung der DNA verantwortlich (Brash et al. 1991; Stege 2001) und wurde als karzinogen für den Menschen eingestuft (IARC 1992).

Um diesen Schäden vorzubeugen, werden unter anderem chemische UV-Filter eingesetzt, die in Sonnenlotionen und auch zunehmend in anderen Kosmetika wie Lippenstiften, Cremes und Haarpflegemitteln verwendet werden. Diese Substanzen ziehen im Gegensatz zu physikalischen UV-Filtern wie Titandioxid oder Zinkoxid in die Haut ein und absorbieren aufgrund ihrer kondensierten und häufig aromatischen $\pi$-Bindungssysteme die hochenergetische UV-Strahlung, um sie in Form von Wärme wieder abzugeben.

Eine Klasse der sehr heterogenen Gruppe der UV-Filter sind die Benzophenone. 12 Derivate der Grundstruktur Benzophenon (BP1 bis BP12) sind als UV-Filter im Gebrauch. Im europäischen Raum wird 2,2',4,4'-Tetrahydroxybenzophenon (BP2) zum Produktschutz Plastik- und Gummierzeugnissen beigefügt und darf im asiatischen Raum als UV Schutz mit bis $\mathrm{zu} 10 \%$ Gehalt benutzt werden. In Europa ist BP2 nicht auf der Positivliste für Sonnenschutzmittel (Council Directive 76/768/EEC) aufgeführt, darf aber in Kosmetika für den alleinigen Zweck des Produktschutzes beigefügt werden. Das kantonale Laboratorium Basel konnte in Aftershaves bis zu 0,24 \% BP2 feststellen (Bericht 58 vom 31.12.2003, erhältlich unter http://www.kantonslabor-bs.ch/infos_berichte.cfm).

Durch neuere Untersuchungen ist das vierfach hydroxylierte BP2 als mögliche EAC in Verdacht geraten. BP2 wurde positiv im ER $\alpha$-Reportergenassay sowie im uterotrophen Assay getestet (Yamasaki et al. 2003). 


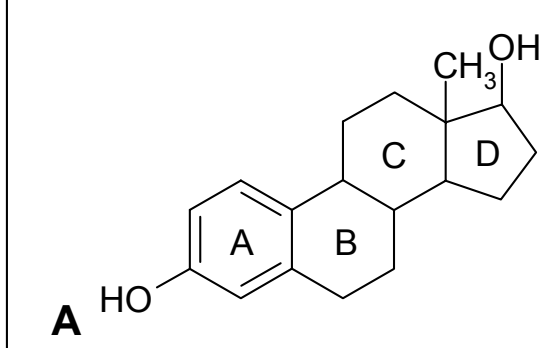

B<smiles>O=C(c1ccc(O)cc1O)c1ccc(O)cc1O</smiles>

Abbildung 1-2: Strukturformeln von 17ß-Estradiol (A) und Benzophenon-2 (B).

Untersuchungen der Kristallstruktur des Ligand-Rezeptor-Komplexes sowie Strukturvergleiche bekannter ER-Liganden haben eine Reihe von Merkmalen ergeben, die für eine Bindung an das aktive Zentrum der ERs von Bedeutung sind. Kernmerkmal ist eine 3'-Hydroxylgruppe an einem Phenylring, wie sie am A-Ring des 17ß-Estradiol (E2) vorhanden ist. Eine sterische Behinderung an der ortho-Position verhindert häufig eine Interaktion. Des Weiteren weisen Liganden ein Hydroxylanalogon zur 17ß-Hydroxylgruppe des E2 auf. Die Bindetasche des ER lässt nur Liganden mit einer zu E2 vergleichbaren Größe zu (Anstead et al. 1997). Die beiden Hydroxylgruppen sind durch Bildung von Wasserstoffbrücken für die Bindung und das Auslösen der Konformationsänderung des ER wichtig (Brzozowski et al. 1997).

Bei dem Vergleich von 517 Chemikalien, die einen transaktivierenden Einfluss in einem yeast-two-hybrid-Assay gezeigt haben, wurde ein mit Hydroxylgruppen in ortho- und para-Position substituierter Phenylring wie in der untersuchten Substanz BP2 als Hauptstrukturmerkmal von ER-Liganden identifiziert (Nishihara et al. 2000).

Es ist also davon auszugehen, dass BP2 selbst ein EAC ist. Das Gefahrenpotential, das von BP2 möglicherweise ausgeht, sowie mögliche andere Effekte sind noch gänzlich unerforscht. 


\subsection{OECD-Protokoll zur Identifikation von endokrin aktive Chemikalien}

Es wurde erkannt, dass man anhand von in vitro-Assays zwar eine Aussage zu Mechanismen und speziellen biologischen Endpunkten machen kann, das endokrine Potential einer Chemikalie in vivo lässt sich damit jedoch nicht abschätzen. Die Organisation für wirtschaftliche Zusammenarbeit und Entwicklung (OECD) hat deshalb ein Programm zur Validierung des uterotrophen Assays initiiert, um ein Testsystem zur Identifikation von estrogenen EACs zu etablieren (Kanno et al. 2003; Owens et al. 2003). In diesem in vivoAssay wird die Estrogenität einer Testsubstanz anhand der Zunahme des Uterusgewichtes in kastrierten, weiblichen Ratten untersucht (ausführlich beschrieben in Abschnitt 1.6.2).

Dabei beschränkt man sich aber auf einen einzigen biologischen Endpunkt, der estrogenen Wirkung im Reproduktionstrakt, dem Uterusgewicht. Seit der Beschreibung von Tamoxifen existiert das ,selektiver Estrogen-Rezeptor-Modulator (SERM)-Konzept“. Das heißt, dass eine potentiell estrogene Substanz organspezifisch eine agonistische oder antagonistische Wirkung entfalten kann. Dies beruht auf der Liganden-spezifischen Konformationsänderung des Rezeptors und der damit verbundenen Rekrutierung von gewebespezifisch exprimierten Kofaktoren. Der uterotrophe Assay kann deshalb nur rein estrogene Substanzen identifizieren, selektive ER $\alpha$ - und ER $\beta$-Agonisten sowie SERMs können mit dieser Methode durchaus übersehen werden. Nicht ER-vermittelte Effekte in endokrinen Systemen werden in diesem Modell ebenfalls nicht erfasst. Dass eine Substanz mehrere Rezeptoren und damit endokrine Systeme beeinflussen kann, wird anhand des Beispiels Prochloraz deutlich. Diese Substanz wirkt als Antagonist auf Estrogen- und Androgen-Rezeptor und als Agonist auf den Arylhydrocarbon-Rezeptor (AhR) (Vinggaard et al. 2006).

\subsection{Ziel dieser Arbeit}

Es soll die endokrine Wirkung des UV-Filters Benzophenon-2 untersucht werden. Über die Methoden des in vitro-screenings hinaus wird der uterotrophe Assay in einer erweiterten Form angewandt, um die Auswirkungen einer BP2-Behandlung auf die Organe der Hypothalamus-Hypophyse-Gonaden (HPG)-Achse sowie der Hypothalamus-HypophyseSchilddrüsen (HPT)-Achse und auf metabolische Parameter zu erfassen. Damit soll untersucht werden, ob BP2 über die in der Literatur postulierte rein estrogene Wirkung noch über andere endokrine Aktivitäten verfügt, die bislang nicht beachtet wurden.

Des Weiteren soll eine mögliche Metabolisierung von BP2 in vivo überprüft werden. 


\section{Einleitung}

Aus den Ergebnissen der untersuchten Parameter soll eine Dosis-Wirkungsbeziehung erstellt werden, die als Grundlage für eine Risiko-Bewertung verwendet werden kann.

Dazu werden verschiedene in vivo- und in vitro-Testsysteme eingesetzt, deren Grundlagen im Folgenden näher beschrieben werden.

\subsubsection{In vitro-Methoden}

Zunächst soll die estrogene Aktivität von BP2 durch in vitro-Versuche bestätigt werden.

- Rezeptorbindungsassay (RBA): Im RBA können Substanzen identifiziert werden, die mit radioaktiv markiertem Estradiol um Bindestellen an rekombinantem ER $\alpha$ oder ER $\beta$ bzw. in der klassischen Variante in uterinem Cytosol konkurrieren (Danzo 1997). Da Estrogene ihre Wirkung hauptsächlich über die ERs vermitteln, eignet sich dieser Assay zur Erfassung potentieller estrogener Chemikalien. Ob durch die Bindung der Substanz eine agonistische oder antagonistische Aktivität vermittelt wird und über die Stärke der Transaktivierung, kann mit diesem Assay nichts ausgesagt werden.

- Proliferationsassay (E-screen): Die Zellen der Brustkrebszelllinie MCF-7 reagieren auf Estradiol mit vermehrtem Wachstum (Soto et al. 1995). Die Rate der Proliferation ist proportional zur Menge bzw. zur Aktivität des Estrogens. Ähnlich wie im RBA wird hier die Testsubstanz auf ihre Fähigkeit zur Induktion eines biologischen Endpunktes getestet.

- Transaktivierungsassay: Dieser Assay nutzt die Zelllinie MCF-7, welche mit einem durch ein Estrogen-responsives Element (ERE) reguliertem Reportergen (Luciferase) stabil transfiziert wurde (Gomez et al. 2005). Damit kann die Fähigkeit zur Transaktivierung von ER-regulierten Zielgenen anhand der induzierten Luciferase gemessen werden. Im Gegensatz zum E-screen wird hier ein spezifischer Mechanismus überprüft. 
- Ethoxyresorufindeethylase-Assay (EROD-Assay): Viele Xenobiotika verstärken ihre eigene Degradation und Exkretion durch die Induktion der Enzyme der Biotransformation in der Leber (Ebert et al. 2005). In der Hepatomzelllinie H4IIE kann die Aktivität eines der an der Phase-I der Biotransformation beteiligten Enzyme, der EROD, gemessen werden (Whyte et al. 2004). Damit erhält man einen Anhaltspunkt für die mögliche Kinetik der Substanz in vivo. Die Enzymaktivität wird über eine vermehrte Transaktivierung durch den Arylhydrocarbon-Rezeptor (AhR) verstärkt (Denison et al. 2002). AhR-Agonisten sind zudem in der Lage über den AhR einen antagonistischen Einfluss auf die Signaltransduktion der Estrogene auszuüben. Dies kann durch die Induktion der E2-Degradation, durch Induktion des Proteasom-abhängigen Abbaus der ERs, durch die Inhibition der E2-induzierten Transkription durch überlappende responsive Elemente auf der DNA oder auch durch die Konkurrenz um Kofaktoren geschehen (Safe et al. 2003).

- Hypothalamuszellkultur: Der Einfluss der Testsubstanzen auf die hypothalamische Gonadotropin-Releasing-Hormon (GnRH)-Sekretion soll mittels der murinen Hypothalamuszellinie GT1-7 untersucht werden (Bowe et al. 2003). GnRH wird pulsatil sezerniert und über das portale Gefäßsystem zur Hypophyse transportiert, wo es die Sekretion des luteinisierenden Hormons ( $\mathrm{LH}$ ) und des follikelstimulierenden Hormons (FSH) bewirkt (Page 1983; Knobil 1990; Levine 1997).

- Hypophysenzellkultur: Durch die Inkubation von primären Ratten-Hypophysenzellen mit den Testsubstanzen soll der Einfluss auf die Sekretion des Thyroideastimulierenden Hormons (TSH) und LH untersucht werden. LH wird von den gonadotrophen Zellen der Adenohypophyse nach Stimulation mit GnRH sezerniert. TSH wird nach Stimulation durch TRH (TSH-Releasing-Hormon) von den thyreotrophen Zellen der Adenohypophyse sezerniert. In vitro reagieren die Zellen einer primären Hypophysenzellkultur auf eine Belastung mit estrogenen Substanzen mit einer Induktion der Sekretion von LH und TSH (Menon et al. 1985; Emons et al. 1988). Die Hormone können im Zellüberstand gemessen werden (Bieglmayer et al. 1980; Ortmann et al. 1999). 


\subsubsection{In vivo-Tierversuche}

In vitro-Assays sind schnell, kostengünstig und erlauben durch die Untersuchung definierter Endpunkte Aussagen zu Mechanismen. In vivo-Tierversuche dagegen berücksichtigen Parameter des intakten Organismus wie Aufnahme, Verteilung, Metabolisierung, Akkumulation und Exkretion der Testsubstanz. Eine Einschätzung des endokrinen Potentials auf einen Organismus ist nur in Tiermodellen möglich.

- Uterotropher Assay: Der uterotrophe Assay basiert auf der Regulation des Uteruswachstums im natürlichen Zyklus der Ratte durch Estrogene. Das endogene Estradiol spielt eine entscheidende Rolle bei der Regulation des weiblichen Zyklus. Bei Ratten machen die durch Estrogen regulierten Organe Vagina, Cervix und Uterus einen rapiden Zyklus von Wachstum und Regression durch. Der Zyklus der Ratte dauert dabei nur 4 bis 5 Tage (Smith et al. 1975).

Ein Ansteigen des Estrogenspiegels löst eine Kaskade von molekularen und zellulären Prozessen aus. Zu Beginn führt die Aktivierung der ERs durch Estradiol zu vermehrter Expression einiger Estrogen-regulierter Gene. Die Expression anderer Gene wiederum wird herunterreguliert (Clark et al. 1983). Diese molekulare Umstrukturierung in der frühen Phase (bis $6 \mathrm{~h}$ nach Exposition) führt zu morphologischen Veränderungen in den Geweben von Vagina, Cervix und Uterus in der späten Phase (bis $24 \mathrm{~h}$ nach Exposition). Die mitotische Aktivität im Uterus nimmt zu und erreicht nach ca. 24 Stunden nach der Exposition durch Estradiol ein Maximum (Kaye et al. 1971). Nach zwei bis drei Tagen manifestiert sich ein estrogener Effekt im Ansteigen des Uterusgewichtes auf das 2- bis 4 fache.

Die Stimulation durch natürliche Estrogene entfällt in immaturen oder ovariektomierten Tieren fast vollständig, so dass estrogene Einflüsse (Einlagerung von Flüssigkeit und erhöhte Zellproliferation) von Testsubstanzen schnell sichtbar werden. Daher ist die ovariektomierte Ratte das ideale Modell zur Untersuchung estrogener Substanzen. Da das Protokoll des klassischen uterotrophen Assays (Allen et al. 1937) nur die Auswertung des Uterusgewichtes vorsieht (Yuan 1991), werden andere mögliche Endpunkte nicht erfasst. Es wird deshalb ein erweiterter Assay durchgeführt, bei dem auch verschiedene andere Organe und Parameter (siehe unten) betrachtet werden. 
- ER $\alpha$ - und ERß-Expression: Estrogene vermitteln ihre Wirkung hauptsächlich über die ERs (siehe oben). Die Regulation der ERs ist hoch komplex (Reid et al. 2002) und noch nicht vollständig aufgeklärt. Es gibt jedoch Untersuchungen, die zeigen, dass die ERs gewebespezifisch einer Autoregulation unterliegen (Castles et al. 1997; Tena-Sempere et al. 2004). Neben anderen Faktoren wie der zellulären Ausstattung an Kofaktoren und Transkriptionsfaktoren und der Beschaffenheit der Promotoren der Zielgene (Weihua et al. 2003) ist die Affinität der Liganden und das Expressionsmuster der ERs entscheidend für die Umsetzung des estrogenen Signals (Fowler et al. 2005). Deshalb wird in verschiedenen Organen die Genexpressionen von ER $\alpha$ und ER $\beta$ bestimmt.

- Genexpression estrogener Marker: Verschiedene Gene werden in ihrer Transkription durch Estrogene direkt oder indirekt beeinflusst. Um zu untersuchen, ob BP2 eine ähnliche Regulation der Transkription verursacht, soll die mRNA-Menge verschiedener Markergene durch Real Time Detection-PCR (RTD-PCR) gemessen werden.

Truncated estrogen receptor product (TERP)-1: TERP-1 ist eine in den lactotrophen Zellen der Hypophyse exprimierte ER $\alpha$-Isoform, welcher die Exons 1 bis 4 fehlen (Friend et al. 1995). Die Regulation der Transkription erfolgt durch ein ERE im Zusammenspiel mit einer Bindestelle für den Hypophysen-spezifischen Transkriptionsfaktor Pit-1 (Schausi et al. 2003). Estrogene haben auf die Transkription von TERP-1 einen stimulierenden Einfluss (Schreihofer et al. 2000).

Insulin-like growth factor (IGF)-1: IGF-1 ist ein Peptid, welches die anabole und mitogene Wirkung von GH vermittelt. Es wird in der Leber und lokal in den Zielorganen exprimiert. Murphy et al. beschrieben eine erhöhte Transkription von IGF1 im Uterus nach der Applikation von E2 (Murphy et al. 1987). In der Leber wurde eine verringerte Genexpression nach E2-Gabe beobachtet (Krattenmacher et al. 1994).

Komplement-Protein (C) 3: Die Proteine des Komplement-Systems spielen eine Rolle bei der Immunabwehr, indem sie Immunkomplexe solubilisieren, Zellen und Pathogene lysieren, die Phagozytose von Pathogenen verstärken und Entzündungsreaktionen auslösen. Die Komplementproteine bilden eine proteolytischen Kaskade, in der jedes Spaltungsprodukt als Protease des nächsten Substrates wirkt. Die Expression von C3 wird durch eine Sequenz von drei EREs im Promotor kontrolliert (Fan et al. 1996) und ist somit direkt durch Estrogene aktivierbar (Sundstrom et al. 1989). 
- Metabolische Parameter: Untersuchungen haben gezeigt, dass Estrogene einen indirekten Einfluss auf die Funktion der Leber haben, so werden die Plasma Konzentrationen von Cholesterol, HDL und LDL (high bzw. low density lipoprotein) durch Steroidhormone modifiziert (Sacks et al. 1990; Walsh et al. 1991). Die molekulare Grundlage dafür ist noch nicht aufgeklärt, allerdings spielt der Signaltransduktionsweg der Estrogene dabei eine entscheidende Rolle (Nanjee et al. 1990). Aus epidemiologischen Studien wird deutlich, dass der Einfluss von Steroiden auf den Metabolismus auch Auswirkungen auf Herzgefäßerkrankungen hat (Colvin et al. 1993).

- Hypothalamus-Hypophyse-Gonaden (HPG)-Achse: Im Hypothalamus erfolgt die Produktion und Sekretion verschiedener Releasing-Hormone (z.B. GnRH) in das Pfortadersystem, welches für die Signalweiterleitung zum Hypophysenvorderlappen verantwortlich ist. In der Hypophyse bewirken diese Hormone die Sekretion von glandotropen Hormonen (z. B. LH) oder Hormonen, welche direkt auf bestimmte Körperzellen wirken wie z.B. GH (Wachstumshormon). Effekte von BP2 auf die Sekretion dieser Hormone können direkt über die Bestimmung der Serumspiegel von LH, PRL und GH gemessen werden. Außerdem erfolgt die Bestimmung der Genexpression der Untereinheiten von LH. Einflüsse von BP2 auf die GnRH-Sekretion werden durch Inkubation hypothalamischer Zellen mit der Testsubstanz gemessen.

- Hypothalamus-Hypophyse-Schildrüsen (HPT)-Achse: Der Hypothalamus sezerniert neben den oben genannten Hormonen zusätzlich TRH, das in der Hypophyse die Freisetzung von TSH stimuliert. TSH steigert die Sekretion von T3 und T4 durch die Schilddrüse. Wie alle Hormonkreisläufe unterliegt auch die Funktion der Schilddrüse einer strikten Kontrolle durch feedback-Regulationen, welche in diesem Fall die Schilddrüsenhormone T3 und T4 auf Hypophyse und Hypothalamus ausüben. In diesem Versuch wird die Genexpression von TRH im Hypothalamus und der Untereinheiten von TSH in der Hypophyse mit RTD-PCR bestimmt. Zusätzlich werden die Serumspiegel von TSH, freiem und gesamten T3 und T4 bestimmt. Der Einfluss von BP2 auf die Schilddrüsenfunktion wird anhand der Natrium/Iodid-Symporter (NIS)Proteinexpression und der Schilddrüsenperoxidase (TPO)-Aktivität in der Schilddrüse 
sowie der 5'-Deiodase-Aktivität in der Leber untersucht. Diese Proteine sind wichtig bei der Produktion der Schilddrüsenhormone T3 und T4 (NIS und TPO) beziehungsweise bei deren Abbau (5'-Deiodase).

\subsubsection{Metabolismus und Kinetik von BP2}

Für den UV-Filter BP3 konnte gezeigt werden, dass die Substanz nach der Absorption im Organismus metabolisiert wird (Takatori et al. 2003). Dabei wurde nachgewiesen, dass die eigentlich endokrin aktive Substanz nicht das verabreichte BP3 war, sondern der Metabolit BP1, welcher um ein Vielfaches potenter als BP3 ist. Für das chemisch verwandte BP2 sind bislang keine Daten zur Kinetik vorhanden, deshalb wird die Kinetik anhand eines zusätzlichen in vivo-Versuches untersucht.

- Serumanalyse: Nach der Auftrennung von Serum- und Urinproben mittels HPLC kann die Menge der Substanz in der Probe mit einem UV-Photometer bestimmt werden. So kann der zeitliche Verlauf der Absorption und Exkretion von BP2 gemessen werden. Des Weiteren ist es möglich, mittels Massenspektrometrie, eventuell vorhandene Metabolite zu identifizieren.

\subsubsection{Erstellen einer Dosis-Wirkungsbeziehung für ausgewählte Parameter}

Das Erstellen einer Dosis-Wirkungsbeziehung ist der Kernpunkt bei der Untersuchung und Bewertung von Einflüssen durch Xenobiotika. Nachdem eine Substanz als endokrin aktive Chemikalie identifiziert wurde (Yamasaki et al. 2003; Schlecht et al. 2004), muss der Einfluss auf endokrine Regulationsmechanismen von Organismen untersucht werden.

Aus in vitro-Analysen ist es unmöglich, auf das Potential einer Testsubstanz zur Interaktion mit der exponierten Population, in diesem Fall den Menschen, zu schließen. Dies kann nur auf der Basis eines in vivo-Versuches in einem geeigneten Modell geschehen. Die Laborratte ist ein weltweit anerkanntes Modell zur Extrapolation von Effekten auf den Menschen (Gies et al. 2001).

Dafür wird anhand einiger ausgewählter Parameter mittels des sog. Benchmark Approaches der Schwellenwert, das heißt die Dosis, bei der die Wirkung auf den Parameter einsetzt, ermittelt. Dieser Schwellenwert bildet dann die Grundlage für eine Risiko-Bewertung 


\section{Material und Methoden}

\subsection{Testsubstanzen}

Benzophenon-2 (BP2) (UVINUL D-50), Chargennummer 6021881 wurde von BASF (Burgbernheim) bezogen.

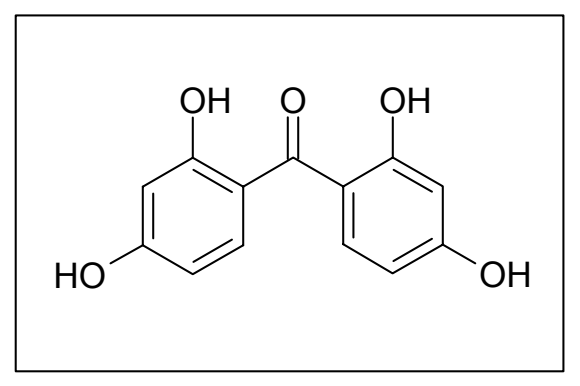

Abbildung 2-1: Strukturformel von Benzophenon-2

Substanzname: 2,2',4,4'-Tetrahydroxybenzophenon

Summenformel: $\mathrm{C}_{13} \mathrm{H}_{10} \mathrm{O}_{5}$

Molare Masse: $246,217 \mathrm{~g} / \mathrm{mol}$

CAS-Nummer: $131-55-5$

$\beta$-Estradiol 17-valerat (E2V) (Kat. Nr.: E1631, Chargennummer 087H0141) wurde von Sigma (Schnelldorf) bezogen.

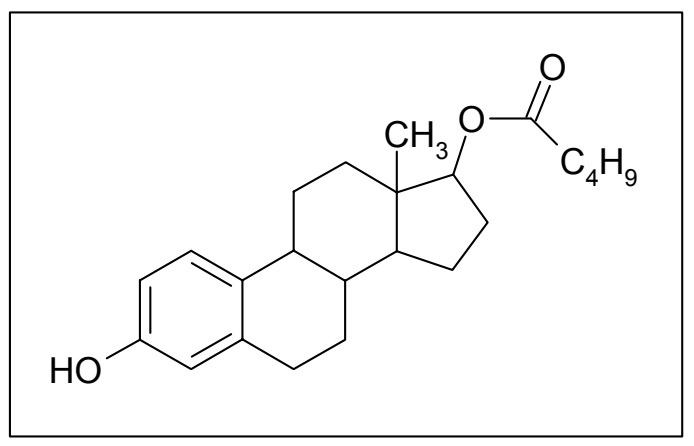

Abbildung 2-2: Strukturformel von $\beta$-Estradiol 17-valerat

Substanzname: Estra-1,3,5(10)-trien-3,17-diol (17-beta)-, 17-pentanoat

Summenformel: $\mathrm{C}_{23} \mathrm{H}_{32} \mathrm{O}_{3}$

Molare Masse: 356,50 g/mol

CAS Nummer: 979-32-8 


\subsection{Sonstige Chemikalien und Verbrauchsmaterialien}

Chemikalien wurden, soweit nicht anders angegeben, von den Firmen Bachem (Weil am Rhein), Merck (Darmstadt), Roth (Karlsruhe) und Sigma (Schnelldorf) bezogen. Es wurden Chemikalien der höchsten erhältlichen Reinheitsstufe verwendet. Verbrauchsmaterialien wurden, soweit nicht anders angegeben, von den Firmen Eppendorf (Hamburg), Greiner (Frickenhausen), Nunc (Wiesbaden) und Sarstedt (Nümbrecht) bezogen.

\subsection{Rezeptorbindungsassay}

Der Rezeptorbindungsassay beruht auf der Konkurrenz von radioaktiv markiertem Estradiol (Tracer) und der zu untersuchenden Substanz um Bindungsstellen im Cytosol. Nach der Abtrennung des ungebundenen Tracers ist die Menge des messbaren, radioaktiv markierten Tracers umgekehrt proportional zur Menge der Testsubstanz im Ansatz.

- Ansatz: $5 \mu$ l Probe oder Standard in $70 \%$ Ethanol (EtOH)

$200 \mu 1$ Cytosol (aus Schweineuterus, laboreigene Herstellung)

$50 \mu 1^{125} \mathrm{~J}$-markiertes Estradiol (etwa $25.000 \mathrm{cpm}$ )

$350 \mu 1$ Assay-Puffer

Die Ansätze wurden gevortext und über Nacht bei $4^{\circ} \mathrm{C}$ inkubiert. Anschließend wurden die Proben auf Eis mit $500 \mu$ l Aktivkohle-Lösung versetzt, 15 Minuten inkubiert, gevortext und 25 Minuten bei 2000 g abzentrifugiert. Der Überstand wurde in Zählröhrchen dekantiert und 10 Minuten im Gamma-Counter (Wizard 1470, Wallac [Perkin-Elmer], Rodgau-Jügesheim) gezählt. Analog zu den Proben wurden die spezifische Bindung (Assay-Puffer + Protein + Tracer), die unspezifische Bindung (Assay-Puffer + Tracer) sowie eine Standardkurve mit 7 Punkten im Bereich von $8 \mathrm{pM}$ bis $20 \mathrm{nM}$ jeweils als Doppelbestimmung mitgeführt. Zusätzlich wurde die Totalaktivität (Assay-Puffer + Tracer ohne Aktivkohle-Fällung) bestimmt. Die Auswertung erfolgte mit dem Programm RIA-CALC Ver.2.7 (Wallac).

- Assay-Puffer 3,2 g Tris

$$
0,504 \text { g EDTA (Merck) }
$$

auf $\mathrm{pH}$ 7,4 einstellen und auf $900 \mathrm{ml} \mathrm{mit} \mathrm{H}_{2} \mathrm{O}_{\text {dest }}$ auffüllen

1 g BSA (Serva, Heidelberg)

100 ml Glycerol (Sigma) 
- Aktivkohle-Lösung 3,2 g Tris

0,504 g EDTA (Merck)

auf pH 7,4 einstellen und auf $900 \mathrm{ml} \mathrm{mit} \mathrm{H}_{2} \mathrm{O}_{\text {dest }}$ auffüllen

5 g Dextran (Pharmacia Biotech, Freiburg)

5 g Aktivkohle (Sigma)

- Standardpräparat

17ß-Estradiol (Sigma)

- Tracer

$16 \alpha-\left[{ }^{125} \mathrm{I}\right]$ iodo-3, 17 $\beta$-Estradiol, 8, $14 \mathrm{TBq} / \mathrm{mmol}$

(Kat.Nr.:NEX 144L, Perkin Elmer, Rodgau-Jügesheim)

\subsection{Zellkultur}

Alle Zellen wurden, soweit nicht anders angegeben, in einem Cytoperm 2-Inkubator (Heraeus, Hanau) bei $37^{\circ} \mathrm{C}, 10 \% \mathrm{CO}_{2}$ und $95 \%$ relativer Luftfeuchtigkeit inkubiert und wurden täglich mikroskopisch beurteilt, um Kontaminationen auszuschließen.

Die Kulturen wurden in $75 \mathrm{~cm}^{2}$-Flaschen kultiviert. Alle zwei bis drei Tage wurde ein Mediumwechsel vorgenommen.

Die Kulturen wurden einmal pro Woche subkultiviert. Dazu wurde das Medium abgesaugt und nach einem Waschschritt mit PBS durch $6 \mathrm{ml}$ Trypsinlösung ersetzt. Die Flaschen wurden maximal 5 Minuten bei $37^{\circ} \mathrm{C}$ inkubiert, bis sich die Zellen vom Flaschenboden lösten. Anschließend wurde die Zellsuspension in $10 \mathrm{ml}$ Permanentkultur-Medium (PKM) gegeben und die Flasche wurde einmal mit Medium nachgespült. Die Zellen wurden sedimentiert (300 g, 10 Minuten) und einmal mit PKM gewaschen. Abschließend wurden die Zellen mit einer Neubauer-Zählkammer (Brand, Wertheim) gezählt und erneut ausgesät. Die Kulturen wurden maximal bis Passage 20 benutzt, um Veränderungen der Zellen auszuschließen (Whyte et al. 2004).

Zur Herstellung von Kryokulturen wurden Zellen einer möglichst frühen Passage mit einer Dichte von $1 * 10^{6}$ Zellen/ml in $10 \%$ DMSO in FCS zunächst über Nacht bei $-70^{\circ} \mathrm{C}$ in einer Styroporbox und anschließend in flüssigem Stickstoff eingefroren.

Um eine neue Kultur aus Kryokulturen anzulegen, wurde ein Kryoröhrchen unter fließend warmem Wasser angetaut und der Inhalt sofort in $15 \mathrm{ml}$ PKM überführt. Die Zellen wurden sedimentiert und einmal mit PKM gewaschen, bevor die Zellen in $75 \mathrm{~cm}^{2}$-Flaschen ausgesät wurden. 
Allen Medien wurde vor der Verwendung jeweils $1 \%$ Pen/Strep (10.000 U Penicillin/ml, $10 \mathrm{mg}$ Streptomycin/ml in einer 0,85 \% Kochsalzlösung, Gibco, Karlsruhe) zugegeben.

- Permanentkulturmedium (PKM)

- Trypsin-EDTA

- PBS
500 ml DMEM (Kat.Nr.:41965-039), Gibco

$50 \mathrm{ml}$ Fetal Bovine Serum, (Kat.Nr:S0115) Biochrom,

Berlin

$5 \mathrm{ml}$ MEM Sodium Pyruvat $100 \mathrm{mM}$, Gibco

$0.05 \%$ Trypsin, (Kat.Nr.:25300-054), Gibco

10x (Kat.Nr: 14200-067), Gibco

\subsubsection{Proliferationstest (BrdU-Assay, E-screen)}

Mit diesem Assay kann der Einbau von 5-Bromo-2'deoxyuridin (BrdU), einem PyrimidinAnalogon, in die DNA von proliferierenden Zellen gemessen werden. Dazu wird das eingebaute $\mathrm{BrdU}$ mit einem Antikörper markiert und anschließend durch eine Substratreaktion photometrisch quantifiziert.

Der Test wurde mit einem Kit der Firma Roche (Cell Proliferation ELISA BrdU, Roche, Mannheim) durchgeführt.

Die MCF7-Zellen (ACC 115; DSMZ, Braunschweig) wurden mit einer Dichte von 10.000 Zellen/well in steroidfreiem PKM ausgesät und $24 \mathrm{~h}$ inkubiert. Anschließend wurden $20 \mu \mathrm{l}$ der 10fach konzentrierten Substanzen zugegeben. Nach einer 24stündigen Inkubation wurden $20 \mu 1100 \mu \mathrm{M}$ BrdU-Lösung zugegeben und es wurde für weitere $2 \mathrm{~h}$ inkubiert. Das Medium wurde anschließend abgesaugt und die Zellen wurden mit $200 \mu 1$ well FixDenat-Lösung für 30 Minuten fixiert. Um den Hintergrund zu reduzieren, wurden nach dem Absaugen der Fixierungslösung $200 \mu 1$ well Blocking Reagent für ELISA (Roche) zupipettiert. Nach einer 30minütigen Inkubation bei Raumtemperatur wurde die Lösung abgesaugt; $100 \mu 1 /$ well der Antikörperlösung (1:100 Verdünnung der Stammlösung) wurden zugegeben und 90 Minuten bei Raumtemperatur inkubiert. Anschließend wurden die Platten 3-mal mit jeweils $200 \mu 1 /$ well Waschlösung gewaschen (ELISA-Washer, Tecan, Crailsheim). Nach der Zugabe von $100 \mu 1 /$ well Substratlösung wurden die Platten bei Raumtemperatur inkubiert, bis eine ausreichende Blaufärbung zu beobachten war (etwa 5 Minuten). Zum Abstoppen der Reaktion wurden $25 \mu 11 \mathrm{M} \mathrm{H}_{2} \mathrm{SO}_{4}$ in jedes well pipettiert. Die Absorption der Proben wurde bei $450 \mathrm{~nm}$ und bei einer Referenzwellenlänge von $690 \mathrm{~nm}$ (Spectra, Tecan) gemessen. 
- PKM steroidfrei

$500 \mathrm{ml}$ DMEM w/o Phenol Red (Kat.Nr:11880-028), Gibco

$50 \mathrm{ml}$ Fetal Bovine Serum, charcoal stripped (Kat.Nr:S3113),

Biochrom

$5 \mathrm{ml}$ Glutamine (200 mM), Gibco

$5 \mathrm{ml}$ MEM Sodium Pyruvat $100 \mathrm{mM}$, Gibco

\subsubsection{Transaktivierungsassays}

Mit diesem Assay wurde die Fähigkeit von BP2 zur spezifischen Transaktivierung der Luciferase-Expression durch ER $\alpha$ oder ER $\beta$ gemessen. Dazu wurden MCF-7-Zellen, welche stabil mit einem Luciferase-Gen unter der Kontrolle eines EREs transfiziert wurden (MELN), zusätzlich mit einem Plasmid transfiziert, welches entweder ER $\alpha(M E L N-E R \alpha)$ oder ER $\beta$ (MELN-ER $\beta$ ) überexprimiert (Gomez et al. 2005).

Die Zellen wurden in $150 \mu \mathrm{l}$ steroidfreiem PKM mit einer Dichte von 10.000 Zellen/well in weißen 96-well-Platten (Becton-Dickinson, Heidelberg) ausgesät. Die Zellen wurden anschließend mit BP2 in Konzentrationen zwischen $1 * 10^{-8} \mathrm{M}$ und $1 * 10^{-5} \mathrm{M}$ sowie dem Lösungsmittel Ethanol in der höchsten verwendeten Konzentration für $16 \mathrm{~h}$ belastet.

Für die Messung der Luciferase-Aktivität wurden das Medium gegen $50 \mu 1$ steroidfreies PKM mit 0,3 mM Luciferin ausgetauscht. Die Luciferase-Aktivität in den intakten Zellen wurde mit einem Trilux-Wallac Luminometer (Perkin-Elmer) gemessen.

\subsubsection{EROD-Assay}

Im EROD-Assay wird die Aktivität der Ethoxyresorufin-O-deethylase (EROD) gemessen. Dieses Enzym ist neben Arylhydrocarbonhydroxylase und P450-Oxygenase ein Produkt des Cypla1-Gens, welches posttranslational prozessiert wird. Die Expression des Cyp1a1-Gens wird durch den Liganden-gebundenen Arylhydrocarbon-Rezeptor (AhR) aktiviert. Das entstehende Enzym ist in der Lage Ethoxyresorufin zu Resorufin zu spalten, welches seinerseits bei $530 \mathrm{~nm}$ zur Fluoreszenz angeregt werden kann. 
<smiles>CCOc1ccc2c(c1)OC1CC(=O)C=CC1=N2</smiles>

7-Ethoxyresorufin
7-Ethoxyresorufin-

O-deethylase

(EROD) (c)

Resorufin

Abbildung 2-3: Durch die 7-Ethoxyresorufin-O-deethylase katalysierte Reaktion.

Der EROD-Assay wurde mit Hepatomzellen der Ratte (H4IIE, [CRL-1548] ATCC, Manassas [VA], USA) nach (Clemons et al. 1997) durchgeführt.

Die Zellen wurden mit 10.000 Zellen/well in 96-well-Platten in PKM ausgesät und für $72 \mathrm{~h}$ bei $37^{\circ} \mathrm{C}$ inkubiert. Anschließend wurde das Medium durch frisches Medium ersetzt, welchem die Testsubstanzen zugegeben wurden. Die Substanzen wurden als $10^{-2} \mathrm{M}$ Stammlösungen in DMSO angesetzt und entsprechend in Medium verdünnt.

Als Kontrollen wurden das Lösungsmittel in der niedrigsten Verdünnungsstufe und 3-Methylcholanthrene (3MC) $1 * 10^{-6} \mathrm{M}$ als Positivkontrolle für jede Platte mitgeführt.

Die Platten wurden für $48 \mathrm{~h}$ inkubiert. Im Anschluss wurde das Medium abgesaugt und es wurden $50 \mu 110 \mu \mathrm{M}$ Dicumarol und $50 \mu \mathrm{l} 4 \mu \mathrm{M}$ Ethoxyresorufin jeweils in PBS verdünnt zugegeben. Nach einer Inkubation von 30 Minuten bei $37^{\circ} \mathrm{C}$ wurde die Reaktion durch Zugabe von $200 \mu 1$ EtOH gestoppt. $200 \mu 1$ der Lösung wurden in schwarze Fluoreszenzplatten (FluoroNunc F96, Nunc) überführt und bei einer Exitationswellenlänge von $530 \mathrm{~nm}$ und einer Emissionswellenlänge von 590 nm (Synergy HT, Bio-Tek, Bad Friedrichshall mit Kineticalc4 Ver.3.4, Bio-Tek) gemessen. Als Standardkurve wurde eine 2,5 $\mu \mathrm{M}$ Resorufinlösung in $70 \%$ EtOH in PBS verwendet. Damit wurden durch 1:2-Verdünnungen 6 Standardpunkte erstellt.

- Dicumarol (3,3'-Methylenbis[4-hydroxycoumarin]), Sigma; $1 \mathrm{mM}$ in Ethanol gelöst

- Ethoxyresorufin (7-Ethoxy-3H-phenoxazin-3-on), Fluka; $400 \mu \mathrm{M}$ in Ethanol gelöst

- Resorufin (7-Hydroxy-3H-phenoxazin-3-on), Sigma; $10 \mathrm{mM}$ in Ethanol gelöst 


\subsubsection{Proteinbestimmung nach Bradford (1976)}

Die Zellen wurden trockengesaugt, mit $100 \mu \mathrm{l}$ RLB (Reporter-lysis-buffer, Promega, Mannheim) versetzt und 30 Minuten auf einem Schüttler inkubiert. $10 \mu 1$ der Lösung wurden in eine neue Platte überführt und mit $200 \mu \mathrm{l}$ Bradford-Reagenz (Protein Assay, Bio-Rad, München) versetzt. Als Standardkurve wurden sechs Verdünnungen einer bovinen IgG-Lösung (Standard I, Bio-Rad, München) zwischen 1,0 und 0,1 mg/ml eingesetzt. Nach weiteren 5 Minuten Inkubation auf dem Schüttler wurde die Absorption bei $595 \mathrm{~nm}$ (Spectra, Tecan) gemessen. Die Auswertung erfolgte mit dem Programm Magellan Ver. 3.11. (Tecan).

\subsubsection{Hypothalamuszellkultur}

Um den Einfluss von BP2 auf die hypothalamische Gonadotropin-Releasing-Hormon $(\mathrm{GnRH})$-Sekretion zu untersuchen, wurden eine murine Hypothalamuszelllinie (GT1-7, zur Verfügung gestellt von Richard Weiner, University of California, San Francisco, USA) verwendet. Die Zellen wurden in $1 \mathrm{ml}$ PKM mit $15 \%$ FCS mit 200.000 Zellen/well in 24-well-Platten ausgesät und 3 Tage inkubiert. Anschließend wurde das Medium abgesaugt und durch $1 \mathrm{ml}$ steroidfreies PKM mit $2 \%$ Aktivkohle-behandeltem FCS ersetzt. Die Platten wurden erneut für 16 Stunden inkubiert. Für die Belastung der Zellen mit den Substanzen wurde das Medium entfernt und durch $500 \mu$ f frisches Medium ersetzt, welchem die Testsubstanzen aus einer 10fach konzentrierten Stammlösung zugegeben wurden. Die Inkubation erfolgte für 6 Stunden. Anschließend wurde das Medium abgenommen und für die Bestimmung von $\mathrm{GnRH}$ mit einem Radioimmunoassay bei $-20^{\circ} \mathrm{C}$ gelagert.

\subsubsection{Bestimmung von GnRH im Zellkulturüberstand}

- Ansatz: $\quad 300 \mu 1$ Zellkulturüberstand oder Standard $100 \mu 1^{125} \mathrm{~J}$-markiertes GnRH $100 \mu 1$ Antikörperlösung (1:20.000 verdünnt in PBS, laboreigene Herstellung aus Kaninchen)

Die weitere Durchführung der Bestimmung erfolgte analog zu Punkt 2.3. Die Standardkurve umfasste 10 Punkte zwischen $1 \mathrm{pg} / \mathrm{ml}$ und $1 \mathrm{ng} / \mathrm{ml}$. 
- Aktivkohle-Lösung siehe Punkt 2.3

- Standardpräparat NIADDK GnRH-RP-2 (NIH, NHPP)

- Tracer

$\left[{ }^{125} \mathrm{I}\right] \mathrm{Tyr}^{5}$-Luteinizing Hormone-Releasing-Hormone

81,4 TBq/mmol (Kat.Nr.:NEX 163, Perkin Elmer)

\subsubsection{Hypophysenzellkultur}

Zur Gewinnung von Hypophysenzellen aus Ratten wurden die tief mit $\mathrm{CO}_{2}$ narkotisierten Tiere dekapitiert, die Adenohypophysen wurden präpariert und in eiskaltes Spinner-Medium überführt.

Unter der Sterilbank wurden die Hypophysen mit zwei Skalpellen zerkleinert. Dabei wurden Erythrozyten mit Spinner-Medium ausgewaschen. Die Fragmente wurden anschließend in $10 \mathrm{ml}$ Trypsinlösung ( $1 \mathrm{mg} / \mathrm{ml}$ Trypsin in Spinner-Medium) mit DNase (beides Sigma) bei $37^{\circ} \mathrm{C}$ inkubiert.

Nach 30 Minuten wurden die Fragmente mit einer abgeschnittenen Pipettenspitze trituriert. Die Lösung mit bereits vereinzelten Zellen wurde durch einen Cell-strainer (BD Biosciences, Erembodegem, Belgien) in $10 \mathrm{ml}$ Serum-Medium gegeben, um das Trypsin zu inaktivieren. Die restlichen Fragmente wurden mit neuer Trypsinlösung weitere 60 Minuten inkubiert, wobei die Fragmente alle 15 Minuten trituriert wurden.

Nachdem sich alle Fragmente aufgelöst hatten, wurde die Lösung ebenfalls durch den Cellstrainer zu dem Serum-Medium gegeben. Die Zellen wurden abzentrifugiert (300 g, 10 Minuten) und einmal mit Serum-Medium gewaschen. Anschließend wurden die Zellen in Serum-Medium resuspendiert und mit einer Neubauer-Zählkammer gezählt.

Die Zellsuspension wurde auf 250.000 Zellen/ml eingestellt und es wurden $250 \mu 1 /$ well in einer 96-well Platte ausplattiert. Die Zellen wurden $96 \mathrm{~h}$ bei $37^{\circ} \mathrm{C}$ inkubiert.

Im Anschluss wurde das Medium abgesaugt und gegen $250 \mu 1$ steroidfreies $\mathrm{PKM} /$ well ausgetauscht. Die Substanzen wurden aus $10^{-2} \mathrm{M}$ Stammlösungen (in Ethanol gelöst und in Medium verdünnt) zugegeben. Ein Teil der Platten wurde zusätzlich mit dem EstrogenRezeptor-Antagonisten ICI 182,780 (Tocris, Avonmouth, UK) in einer Konzentration von $1 * 10^{-6} \mathrm{M}$ koinkubiert. Nach einer 45 stündigen Inkubation wurde ein Stimulationsmix aus GnRH und TRH (Bachem) in einer Endkonzentration von jeweils $10^{-6} \mathrm{M}$ zugegeben. Nach weiteren $3 \mathrm{~h}$ Inkubation wurden $200 \mu \mathrm{l}$ des Überstandes abgenommen und für die Messung von LH und TSH (siehe 2.6.1) verwendet. 
- Spinner-Medium $500 \mathrm{ml}$ DMEM (Kat.Nr:21068-028), Gibco

$7 \mathrm{ml}$ BSA Fraction V Sol. 7,5\%, Gibco

$5 \mathrm{ml} 1 \mathrm{M}$ HEPES, Gibco

$5 \mathrm{ml}$ MEM Sodium Pyruvat $100 \mathrm{mM}$, Gibco

$5 \mathrm{ml}$ Glutamine (200 mM), Gibco

- Serum-Medium

500 ml DMEM (Kat.Nr:41965-039), Gibco

$40 \mathrm{ml}$ Horse Serum, (Kat.Nr:S9135), Biochrom

22,5 ml Fetal Bovine Serum, (Kat.Nr:S0115), Biochrom

$5 \mathrm{ml}$ MEM Sodium Pyruvat $100 \mathrm{mM}$, Gibco

\subsubsection{Vitalitättest (MTT-Test)}

$\mathrm{Zu}$ den restlichen $100 \mu \mathrm{l}$ Überstand wurden $10 \mu \mathrm{l}$ MTT-Lösung $(5 \mathrm{mg} / \mathrm{ml}$ in PBS) zugegeben. Die Platten wurden etwa 90 Minuten bei $37^{\circ} \mathrm{C}$ inkubiert, bis unter dem Mikroskop dunkle Kristalle erkennbar waren. Durch die Zugabe von $15 \mu 1$ 12,5 \%iger Glutaraldehydlösung in PBS und eine 15minütige Inkubation bei Raumtemperatur wurde die Reaktion abgestoppt. Der Überstand wurde abgesaugt und die Präzipitate wurden in $150 \mu 10,04 \mathrm{~N} \mathrm{HCl}$ in Isopropanol gelöst. Die Absorption wurde bei $590 \mathrm{~nm}$ und einer Referenzwellenlänge von $690 \mathrm{~nm}$ gemessen.

- MTT (3-[4,5-Dimethyl-2-thiazolyl]-2,5-diphenyl-2H-tetrazolium bromid), Sigma

- Glutaraldehyd, 25 \%ige Lösung in Wasser, Sigma 


\subsection{Tierversuche}

Für die durchgeführten Tierversuche lag die Genehmigung der Bezirksregierung Braunschweig mit dem Aktenkennzeichen 509.42502/01-36.03 (Steroidrezeptor-spezifische Wirkung von endokrinen Disruptoren) vor.

\subsubsection{Tierhaltung}

Weibliche Sprague-Dawley Ratten (Winkelmann, Borchen oder eigene Zucht) wurden zu fünft oder zu sechst in Makrolon®-Käfigen Typ IV gehalten.

Die Tiere wurden nach Erhalt oder ab dem 21. Tag nach der Geburt auf sojafreiem Futter (Spezialanfertigung, Ssniff, Soest) gehalten, welches ad libitum zur Verfügung stand. Die relative Luftfeuchtigkeit betrug durchschnittlich $55 \%$ bei $23^{\circ} \mathrm{C}$ Raumtemperatur. Das Licht wurde $12 \mathrm{~h} / \mathrm{d}$ eingeschaltet. Die Tiere für die subakute 5-Tage-Applikation stammten aus eigener Zucht von sojafrei gehaltenen Müttern, alle anderen Tiere wurden von der Firma Winkelmann (Borchen) bezogen.

\subsubsection{Ovariektomie}

Zur Entfernung der Ovarien wurden die Tiere mit Isofluran (Forene ${ }^{\circledR}$, Abbott, Wiesbaden) narkotisiert. Die Haut caudal der Rippenbögen wurde rasiert, desinfiziert und eröffnet. Nach dem Durchtrennen der Haut- und Muskelschichten wurde das Ovar freipräpariert, abgeklemmt, mit resorbierbarem Nahtmaterial (Vicryl, Ethicon, Norderstedt) abgebunden und entfernt. Anschließend wurden die Muskelschichten mit Vicryl verschlossen. Die Haut wurde mit nicht resorbierbarem Nahtmaterial (Supramid, Braun-Aesculap, Tuttlingen) verschlossen und zusätzlich mit Michel-Klammern (Martin Medizintechnik, Tuttlingen) gesichert. 


\subsubsection{Obduktion}

Die Tiere wurden am Ende des jeweiligen Versuches unter einer tiefen $\mathrm{CO}_{2}$-Narkose mit einer Guillotine dekapitiert. Das Blut wurde aufgefangen. Je nach Versuch wurden folgende Organe präpariert und sofort in flüssigem Stickstoff tiefgefroren und anschließend bei $-70^{\circ} \mathrm{C}$ bis zur weiteren Verwendung gelagert.

- Adenohypophyse

- Gehirn

- Schilddrüse

- Uterus (ein Uterushorn wurde in Formalin fixiert)

- Leber (ein Teil des mittleren Lappens)

Das Blut wurde abzentrifugiert (2000 g für 30 Minuten), das Serum wurde abgenommen und bis zur weiteren Analyse bei $-20^{\circ} \mathrm{C}$ gelagert.

\subsubsection{Subakute Applikation von BP2}

\subsubsection{Testsubstanzen und Dosierungen}

Benzophenon-2 (BP2) wurde in folgenden Konzentrationen in Olivenöl (DAB) suspendiert: $10 \mathrm{mg} / \mathrm{kg}$ Körpergewicht $\quad(\mathrm{Kg}), \quad 33 \mathrm{mg} / \mathrm{kg} \mathrm{Kg}, \quad 100 \mathrm{mg} / \mathrm{kg} \mathrm{Kg}, \quad 333 \mathrm{mg} / \mathrm{kg} \mathrm{Kg} \quad$ und $1000 \mathrm{mg} / \mathrm{kg} \mathrm{Kg}$.

$\beta$-Estradiol 17-valerat (E2V) wurde in einer Konzentration von $0,6 \mathrm{mg} / \mathrm{kg} \mathrm{Kg}$ ebenfalls in Olivenöl eingesetzt. Als Kontrolle wurde reines Olivenöl verwendet.

Die Ratten wurden kurz vor Beginn des Versuches gewogen, um die Lösungen entsprechend ansetzen zu können.

Die Ratten wurden im Alter von 3 Monaten ovariektomiert (siehe 2.5.2). Nach 3 Wochen wurden die Tiere zu Gruppen von je 12 Tieren zusammengefasst.

Den Tieren wurde 5 Tage morgens zwischen 6 und 8 Uhr jeweils $1 \mathrm{ml}$ der Testsubstanzen in Olivenöl beziehungsweise reines Olivenöl über eine Magensonde verabreicht. 


\subsubsection{Messparameter}

Die Tiere wurden täglich bei der Fütterung auf klinische Zeichen von Toxizität untersucht. Nach der Gavagierung wurde täglich das Körpergewicht bestimmt.

Am Ende des Versuches wurden das Serum, die Hypophyse, das Gehirn, die Schilddrüse der Uterus und ein Teil der Leber entnommen.

Folgende Parameter wurden bestimmt:

Tabelle 2-1: Messparameter in den einzelnen Organen

\begin{tabular}{|l|l|}
\cline { 2 - 2 } \multicolumn{1}{l|}{} & Messparameter \\
\hline Hypothalamus (MBH) & Genexpression: ER $\alpha$, ER $\beta$, Prä-Pro-TRH \\
\hline Hypophyse & Genexpression: ER $\alpha$, ER $\beta$, LH $\beta$, TSH $\beta, \alpha-$ Untereinheit, GH, TERP-1 \\
\hline Schilddrüse & $\begin{array}{l}\text { Genexpression: ER } \alpha, \text { ER } \beta, \\
\text { Natrium/Iodid-Symporter-Expression, Schilddrüsenperoxidase-Aktivität }\end{array}$ \\
\hline Uterus & $\begin{array}{l}\text { Gewicht, Histologie } \\
\text { Genexpression: IGF-1, Prä-Pro-C3, ER } \alpha, \text { ER } \beta\end{array}$ \\
\hline Leber & $\begin{array}{l}\text { Genexpression: Cyp1a1, IGF-1, ER } \alpha, \text { ER } \beta \\
\text { Typ I/II-5'Deiodase-Aktivität }\end{array}$ \\
\hline Serum & $\begin{array}{l}\text { Serumkonzentrationen von: den Testsubstanzen (E2 und BP2), GH, LH, TSH, } \\
\text { (f)T3/Trolaktin, HDL, LDL, Cholesterin, }\end{array}$ \\
\hline
\end{tabular}

\subsubsection{Kinetikversuch}

Zur Bestimmung der Metabolisierungsgeschwindigkeit von Benzophenon-2 wurde weiblichen, ovariektomierten Tieren ein Jugularvenenkatheter gelegt, durch den in einem Abstand von 30 Minuten Blutproben gewonnen werden konnten. Nach der Gewinnung der Null-Proben (vor Beginn der Behandlung) wurde den Tieren per gavage $1 \mathrm{ml}$ einer Benzophenon-2-Suspension (1000 mg/kg Kg) in Olivenöl verabreicht.

Wenn möglich, wurde den Tieren durch Druck auf die Blase eine Urinprobe entnommen.

Die Tiere blieben während der Behandlung unter Isofluran-Narkose.

Die gewonnenen Seren wurden anschließend mittels HPLC (siehe 2.6.3) analysiert. 


\subsubsection{Jugularvenen-Katheter}

An einen Silikonschlauch mit $20 \mathrm{~cm}$ Länge (InnenØ 0,5 mm, AussenØ: 0,9 mm, Dow Corning, Wiesbaden) wurde mit Silikonkleber (Elastosil ${ }^{\circledR}$, Wacker-Chemie, München) etwa $2 \mathrm{~cm}$ von einem Ende ein Teflonschild (ca. 0,5 x $1 \mathrm{~cm}$, Perthese ${ }^{\circledR}$ silicon sheeting, LPI, Frankreich) angeklebt. Anschließend wurde dieses Ende des Schlauches auf eine abgesägte Kanüle (Sterican Gr.1, Braun, Melsungen) geschoben, die in einer weiteren abgesägten Kanüle (Sterican Gr.17, Braun) steckte. Beide Kanülen wurden zur Fixierung etwa $30^{\circ}$ gebogen.

Die Kanülen mit dem Schlauch wurden in die freipräparierte Jugularvene des mit Isofluran narkotisierten Tieres eingeführt und durch den Brustmuskel wieder heraus gezogen. Die Kanülen wurden entfernt und der Schlauch wurde in die Vene zurückgezogen. In der Vene wurde der Schlauch vorwärts geschoben, bis mit einer aufgesteckten Spritze (1 ml, BD Plastipak $^{\mathrm{TM}}$, Becton Dickinson) Blut gezogen werden konnte. Der Katheter wurde mit Heparinlösung (Liquemin ${ }^{\circledR}$, Hoffmann-La Roche, Grenzach-Wyhlen; 50 I.E. in $1 \mathrm{ml}$ physiologischer NaCl-Lösung) gespült. Anschließend wurde der Katheter unter der Haut zum Nacken geführt.

Mit Hilfe einer $1 \mathrm{ml}$-Spritze wurden alle 30 Minuten $300 \mu 1$ Blut abgenommen, welche jeweils durch $300 \mu$ l physiologische Kochsalzlösung ersetzt wurden. Der Katheter wurde nach jeder Blutabnahme mit 50 I.E. Heparin/ml in physiologischer Kochsalzlösung gespült.

\subsubsection{Messparameter}

In den Seren wurden der Benzophenon-2-Spiegel sowie die Spiegel möglicher Metabolite mit HPLC (siehe 2.6.3) gemessen. 


\subsection{Serum Analyse}

\subsubsection{Radioimmunoassay}

Das Prinzip von Radioimmunoassays (RIA) beruht auf der Konkurrenz von in der Probe vorhandenem Hormon und radioaktiv markiertem Hormon (Tracer), welches in einer bekannten Aktivität zugegeben wird um Bindungsstellen eines primären Antikörpers. Der Primärantikörperkomplex wird anschließend gefällt, um ungebundenen Tracer zu entfernen. Die erhaltene Aktivität der Proben ist umgekehrt proportional zur Menge an Hormon in der Probe und kann über eine Standardkurve ausgewertet werden.

Folgende Hormone wurden mit kommerziell erhältlichen Kits nach Anweisung des Herstellers bestimmt:

- $\mathrm{T} 3$ (Active ${ }^{\circledR} \mathrm{T} 3$, DSL, Sinsheim)

- T4 (Active ${ }^{\circledR}$ Thyroxin, DSL)

- fT3 (RIAZENco FT3, ZenTech, Angleur, Belgien)

- $\mathrm{fT} 4$ (RIAZENco FT4, ZenTech)

Folgende Hormone wurden mit im Labor entwickelten Assays gemessen:

- $\mathrm{LH}$

- $\mathrm{TSH}$

- $\mathrm{GH}$

- Prolaktin

Die Tracer für die Bestimmung von LH, TSH, GH und Prolaktin wurden nach Hunter et al. (1962) mit ${ }^{125} \mathrm{~J}$ markiert.

Das entsprechende Probenvolumen (siehe Tabelle 2-2) wurde zunächst mit $1 \%$ BSA (Albumin bovine Fraction V, Serva) in PBS auf $500 \mu 1$ aufgefüllt. Anschließend wurden $200 \mu 1$ Primärantikörper (1:4.000 verdünnt mit Kaninchenserum [1:300 verdünnt in PBS]) zugegeben und für $24 \mathrm{~h}$ bei $4^{\circ} \mathrm{C}$ inkubiert.

Nach der Zugabe von $100 \mu$ iodiertem Tracer (etwa $20.000 \mathrm{cpm}$ ) und einer Inkubation von $24 \mathrm{~h}$ bei $4^{\circ} \mathrm{C}$ erfolgte die Zugabe des 1:30 in PBS verdünnten Zweitantikörpers (Antiserum gegen Kaninchen-IgG). Nach einer weiteren Inkubation von $48-72 \mathrm{~h}$ bei $4^{\circ} \mathrm{C}$ wurden alle 
Proben mit $2 \mathrm{ml}$ PBS versetzt und bei $2000 \mathrm{~g}$ für 60 Minuten zentrifugiert. Der Überstand wurde dekantiert und die Proben wurden mindestens 10 Minuten im Gamma-counter (Wizard 1470, Wallac [Perkin-Elmer]) gezählt. Die Auswertung erfolgte mit dem Programm RIACALC Ver.2.7 (Wallac).

In jedem Assay wurden die spezifische und unspezifische Bindung, die Totalaktivität und 10 Standardpunkte in Dreifachbestimmung gemessen.

Tabelle 2-2: Übersicht über verwendete Probenvolumina und Präparate

\begin{tabular}{|c|c|c|c|c|}
\hline & $\mathrm{GH}$ & LH & $\mathrm{TSH}$ & Prolaktin \\
\hline Probenvolumen & & & & \\
\hline Serum & $100 \mu \mathrm{l}$ & $10 \mu \mathrm{l}$ & $50 \mu 1$ & $25 \mu 1$ \\
\hline Zellkultur & - & $25 \mu \mathrm{l}$ & $50 \mu \mathrm{l}$ & - \\
\hline Referenz- & NIADDK & NIADDK & NIADDK & NIADDK \\
\hline Präparat & GH-RP-2 & Rat-LH RP-2 & TSH-RP-2 & Rat-Prol-RP-3 \\
\hline $\begin{array}{l}\text { Iodierungs- } \\
\text { Präparat }\end{array}$ & $\begin{array}{l}\text { NIADDK Rat- } \\
\text { GH-I-5 }\end{array}$ & $\begin{array}{l}\text { NIADDK Rat- } \\
\text { LH I-6 }\end{array}$ & $\begin{array}{l}\text { NIADDK Rat- } \\
\text { TSH-I-9 }\end{array}$ & $\begin{array}{l}\text { NIADDK Rat- } \\
\text { Prol-I-5 }\end{array}$ \\
\hline $\begin{array}{l}\text { prim. } \\
\text { Antiserum }\end{array}$ & $\begin{array}{l}\text { NIADDK } \\
\text { Anti-Rat-GH- } \\
\text { AK S } 5\end{array}$ & $\begin{array}{l}\text { NIADDK } \\
\text { Anti-Rat LH- } \\
\text { AK S } 10\end{array}$ & $\begin{array}{l}\text { NIADDK } \\
\text { Anti-Rat-TSH- } \\
\text { AK S } 5\end{array}$ & $\begin{array}{l}\text { laboreigenes } \\
\text { Kaninchen- } \\
\text { Antiserum (\#2) }\end{array}$ \\
\hline $\begin{array}{l}\text { Bereich der } \\
\text { Standardkurve }\end{array}$ & $\begin{array}{l}\text { 0,01-32 } \\
\text { ng/Röhrchen }\end{array}$ & $\begin{array}{l}0,005-5,12 \\
\text { ng/Röhrchen }\end{array}$ & $\begin{array}{l}\text { 0,01-10 } \\
\text { ng/Röhrchen }\end{array}$ & $\begin{array}{l}0,1-128 \\
\text { ng/Röhrchen }\end{array}$ \\
\hline
\end{tabular}

Das verwendete Probenvolumen hing von der Konzentration des Hormons im Serum, von der Art des Hormons sowie vom Alter des verwendeten Tracers ab. Die Referenzpräparate sowie die Iodierungspräparate und die primären Antiseren wurden vom National Hormone and Pituitary Program (NHPP) des NIH zur Verfügung gestellt.

Estradiol im Serum wurde nach einem leicht abgewandelten Testprinzip bestimmt. Der Tracer war in diesem Fall nicht radioaktiv, sondern mit einem Ruthenium-Komplex markiert, der nach Anlegen einer Spannung ein Lumineszenz-Signal abgibt, welches über einen Photomultiplier detektiert wurde (Elektrochemilumineszenz-Immunoassay, ECLIA). Die 
Bestimmung erfolgte mit einem kommerziell erhältlichen Kit (Estradiol II, Roche) nach Anleitung des Herstellers auf einem Elecsys 2010 (Roche)

\subsubsection{Metabolische Parameter}

Die Bestimmung der metabolischen Parameter erfolgte über optisch-enzymatische Tests auf einem Hitachi 902 Automatic analyzer (Roche, Mannheim). Folgende Parameter wurden mit kommerziell erhältlichen Kits nach Anleitung des Herstellers bestimmt:

- Cholesterin (Cholesterin CHOD-PAP, Roche)

- HDL (HDL-Cholesterin 2nd generation, Roche)

- LDL (LDL-Cholesterin 2nd generation, Roche)

\subsubsection{HPLC}

\subsubsection{Hydrolyse}

Für die Analyse von BP2 im Serum wurden $500 \mu 1$ (300 $\mu 1$ im Kinetikversuch) aufgearbeitet. Die Proben wurden mit dem gleichen Volumen $\mathrm{NH}_{4}$-Acetat Puffer $(0,1 \mathrm{M}, \mathrm{pH} 5,0)$ verdünnt. Um mögliche Metabolite (Sulfate und Glucuronide) mit $\mathrm{zu}$ bestimmen, wurde jeder Probe1 mg $\beta$-Glucuronidase aus Helix pomatia zugegeben und bei $37^{\circ} \mathrm{C}$ über Nacht inkubiert. Kontrollseren wurden analog behandelt.

Zur Bestimmung der Konzentration von freiem BP2 im Serum wurden jeweils $500 \mu 1$ Serum ohne Glucuronidase-Behandlung extrahiert.

- Helix pomatia $\beta$-Glucuronidase Typ H1 (Kat.Nr: G-0751, Sigma), Glucuronidase-Aktivität $>300.000 \mathrm{U} / \mathrm{g}$, Sulfatase-Aktivität $>10.000 \mathrm{U} / \mathrm{g}$

\subsubsection{Extraktion}

Die Proben wurden nach der Inkubation über Strata X-Säulen mit einer Bettmasse von $60 \mathrm{mg}$ und einem Säulenvolumen von $3 \mathrm{ml}$ (8B-S100-UBJ, Phenomenex, Aschaffenburg) extrahiert. Die Säulen wurden mit $3 \mathrm{ml}$ Methanol konditioniert und mit $3 \mathrm{ml} \mathrm{H} \mathrm{H}_{2} \mathrm{O}$ equilibriert. Nach dem Beladen mit den Proben wurde mit $3 \mathrm{ml} 5 \%$ Methanol gewaschen und mit $3 \mathrm{ml} 100 \%$ Methanol eluiert. 
Die Proben wurden anschließend lyophilisiert und mit $500 \mu 1(300 \mu 1$ im Kinetikversuch) $25 \%$ Acetonitril rekonstituiert. Vor dem Auftragen auf die HPLC wurde jede Probe durch einen Filter (Millex ${ }^{\circledR}-\mathrm{HV}$ Syringe driven filter unit, $0,45 \mu \mathrm{m} / 4 \mathrm{~mm}$, Millipore, Schwalbach) gegeben, um eventuell noch vorhandene Partikel zu entfernen.

\subsubsection{HPLC-Geräte und Laufbedingungen}

Säule

$\mathrm{NC} 250 \times 4,6 \mathrm{~mm}$

Bischoff, Leonberg

Hypersil-ODS 5,0 $\mu \mathrm{m}$

Part-Nr: 2546 1805, Ser.-Nr: 2711C30

Vorsäule

Guard 7,5 x 4,6 mm

Jasco, Groß-Umstadt

SS Jour-Guard RP/C18 5,0 $\mu \mathrm{m}$

Part-Nr: 69080, Ser.-Nr: 2110362.1

Autosampler

851-AS Intelligent Sampler

Jasco

Injektionsvolumen

$100 \mu \mathrm{l}(50 \mu \mathrm{lim}$ Kinetikversuch)

Pumpen

HPLC Pump K-501

Knauer, Berlin

Mischkammer

Dynamic mixing chamber

Knauer

Flussrate

$1 \mathrm{ml} /$ Minute

UV-Detektion

2158 UVICORD SD

LKB, Bromma, Schweden

$280 \mathrm{~nm}$

Laufmittel
A: $\mathrm{H}_{2} \mathrm{O}$ mit $0,085 \% \mathrm{H}_{3} \mathrm{PO}_{4}$
B: $100 \%$ Acetonitril

Gradient

Tabelle 2-3: Lösungsmittelgradient der HPLC

\begin{tabular}{|l|l|l|}
\hline Minuten & $\% \mathrm{~A}$ & \% B \\
\hline 0 & 75 & 25 \\
\hline 5 & 75 & 25 \\
\hline 10 & 20 & 80 \\
\hline 25 & 0 & 100 \\
\hline 30 & 0 & 100 \\
\hline 35 & 75 & 25 \\
\hline
\end{tabular}


Die Auswertung der UV-Signale erfolgte mit Chromgate Ver 2.8 (Knauer).

Die Auswertung der Peak-Flächen erfolgte über eine Standardkurve mit BP2 in einem Kontrollserum-Pool, welche analog zu den Proben behandelt wurde. Die Standardkurve umfasste 5 Punkte im Bereich zwischen 0,1 und $10 \mu \mathrm{g} / \mathrm{ml}$.

\subsubsection{Massenspektrometrie (HPLC-MS)}

Die bei der Analyse der Proben per HPLC gewonnenen Daten wurden mittels Massenspektrometrie genauer untersucht. Dazu wurden $5 \mu$ l einer nicht mit Glucuronidase behandelten, extrahierten Serumprobe mit einem Ion-Trap-Massenspektrometer analysiert. Die Probe wurde vorher durch eine HPLC mit UV-Detektion aufgetrennt.

\subsubsection{Geräte und Laufbedingungen}

Säule

Supersher 100, $100 \times 2 \mathrm{~mm}$

$$
\text { RP-C18 endcapped, } 4 \mu \mathrm{m}
$$

Autosampler

851-AS Intelligent Sampler

Jasco

Injektionsvolumen $5 \mu 1$

Pumpe

RHEOS 4000

Flux Instruments, Basel, Schweiz

Flussrate $0,3 \mathrm{ml} /$ Minute

UV-Detektion

Diodenarray-Detektor UV6000LP Thermo Electron, San Jose (CA),

Massenspektrometer Finnigan LCQ

Thermo Electron

Laufmittel

A: $\mathrm{H}_{2} \mathrm{O}$ mit $0,05 \% \mathrm{HCOOH}$

B: $90 \%$ Acetonitril + $10 \%$ Wasser mit $0,05 \% \mathrm{HCOOH}$

Gradient

Tabelle 2-4: Lösungsmittelgradient

\begin{tabular}{|l|l|l|}
\hline Minuten & $\% \mathrm{~A}$ & $\% \mathrm{~B}$ \\
\hline 0 & 90 & 10 \\
\hline 5 & 90 & 10 \\
\hline 20 & 0 & 100 \\
\hline 25 & 0 & 100 \\
\hline 27 & 90 & 10 \\
\hline 32 & 90 & 10 \\
\hline
\end{tabular}




\subsection{Molekularbiologische Arbeiten}

\subsubsection{Arbeiten mit Nukleinsäuren}

Zur Vermeidung von Kontaminationen mit Ribonukleasen (RNasen) wurden alle Arbeiten mit Ethanol-gewaschenen Handschuhen durchgeführt. Glaswaren wurden 12 Stunden bei $240^{\circ} \mathrm{C}$ sterilisiert und Plastikwaren wurden bei $120^{\circ} \mathrm{C}$ für 20 Minuten autoklaviert. Lösungen wurden entweder als sterile, RNase-freie Stammlösungen gekauft oder mit $1 \mathrm{ml}$ Velcorin ${ }^{\circledR}$ (Dimethylpyrocarbonat, Bayer, Leverkusen) je 11 Lösung für 4 Stunden inkubiert und anschließend autoklaviert $\left(\mathrm{H}_{2} \mathrm{O}_{\text {velc }}\right)$.

\subsubsection{RNA-Extraktion}

Die Extraktion der RNA aus den entnommenen Geweben erfolgte mit RNeasy® Kits (Qiagen, Hilden).

- Stücke des tiefgefrorenen Gewebes (Leber und Uterus) wurden dazu mit einem Gewebe-Homogenisator (Micro-dismembrator ${ }^{\mathrm{TM}}$, Braun) 15 Sekunden bei 2500 Upm zerkleinert. Etwa $50 \mathrm{mg}$ des Pulvers wurden in Lysispuffer aufgenommen.

- Die Adenohypophyse wurde mit einer Kanüle in einem Eppendorf-Cup in $350 \mu 1$ Lysispuffer zerkleinert.

- Ein Schilddrüsenlappen wurde in $400 \mu 1$ Lysispuffer mit einem Ultra-Turrax (TP18/10, IKA Labortechnik, Staufen) homogenisiert.

- Das Gehirn wurde auf ein Gefriermikrotom (Frigomobil 1206, Reichert-Jung, Bielefeld) mit Tissue-Tek ${ }^{\circledR}$ (Sakura Fintek, Zoeterwoude, Niederlande) aufgefroren. Es wurden frontale Serienschnitte von $600 \mu \mathrm{m}$ Dicke angefertigt. Der mediobasale Hypothalamus (MBH) wurde nach der Methode von Palkovits (1973) isoliert. Die entsprechenden Koordinaten wurden nach Paxinos et al. (1998) ermittelt. Die Gewebestückchen wurden in $500 \mu 1$ Lysispuffer homogenisiert.

Die lysierten Proben wurden 15 Sekunden in einem Ultraschallbad homogenisiert und anschließend über QIAShredderTM-Säulen (Qiagen) gegeben. Das Eluat wurde auf die Extraktionssäule gegeben und entsprechend der Anleitung des Herstellers aufgereinigt. Zur Entfernung der DNA wurde während der Aufreinigung ein 15minütiger DNase-Verdau nach Herstellerempfehlung (RNase-free DNase Set, Qiagen; 27,3 Kunitz units je Probe) durchgeführt. Die gereinigte RNA wurde mit $\mathrm{H}_{2} \mathrm{O}_{\text {velc }}$ eluiert. 
Tabelle 2-5: Verwendete Lysispuffer- und Elutionsvolumina bei den jeweiligen RNA-Aufreinigungen

\begin{tabular}{|l|l|l|}
\cline { 2 - 3 } \multicolumn{1}{c|}{} & $\begin{array}{l}\text { Lysispuffervolumen } \\
(\text { in } \mu \mathrm{l})\end{array}$ & $\begin{array}{l}\text { Elutionsvolumen } \\
\text { (in } \mu \mathrm{l})\end{array}$ \\
\hline Hypothalamus (MBH) & 500 & 50 \\
\hline Adenohypophyse & 350 & 50 \\
\hline Schilddrüse & 400 & 35 \\
\hline Leber & 600 & 50 \\
\hline Uterus & 500 & 50 \\
\hline
\end{tabular}

\subsubsection{Konzentrationsbestimmung der RNA}

Zur Bestimmung der Konzentration wurden $5 \mu \mathrm{l}$ der RNA-Lösung in $75 \mu \mathrm{H}_{2} \mathrm{O}_{\text {Velc }}$ verdünnt und in Quarzküvetten (Suprasil ${ }^{\circledR}$, Hellma, Müllheim) in einem Photometer (Biophotometer, Eppendorf, Hamburg) bei 260 und $280 \mathrm{~nm}$ gegen den Leerwert gemessen. Einer optischen Dichte (OD) von 1 bei $260 \mathrm{~nm}$ entspricht dabei näherungsweise eine Konzentration von $40 \mu \mathrm{g} / \mathrm{ml}$.

Aus dem Quotienten $\mathrm{OD}_{260} / \mathrm{OD}_{280}$ lässt sich die Reinheit der Lösung bestimmen, da aromatische Aminosäuren bei $280 \mathrm{~nm}$ absorbieren und so einen Hinweis auf Proteinverunreinigungen in der Lösung geben können. Der ideale Quotient liegt bei 1,8, niedrigere Werte weisen meist auf Proteinverunreinigungen hin.

\subsubsection{Reverse Transkription (RT)}

In der RT wird die gewonnene RNA in cDNA umgeschrieben, um als Vorlage für die sich anschließende real time detection-PCR dienen zu können. Dazu wurde eine murine retrovirale reverse Transkriptase ohne RNase-Aktivität eingesetzt.

Für die RT wurde die RNA-Lösung auf $20 \mathrm{ng} / \mu \mathrm{l}$ mit $\mathrm{H}_{2} \mathrm{O}_{\text {Velc }}$ eingestellt. In der Reaktion wurden jeweils $200 \mathrm{ng}$ eingesetzt.

Nach der Zugabe von $3 \mu \mathrm{H}_{2} \mathrm{O}_{\text {Velc }}$ und $1 \mu \mathrm{l}$ Random-Primer (Invitrogen, Karlsruhe; 1:30 verdünnt in $\mathrm{H}_{2} \mathrm{O}_{\text {Velc }}$ ) wurde der Ansatz zur Denaturierung von Sekundärstrukturen für 10 Minuten bei $70^{\circ} \mathrm{C}$ inkubiert. Anschließend wurde $\mathrm{zu}$ jeder Probe ein Mastermix aus folgenden Bestandteilen zupipettiert: 
- Mastermix: $1 \mu 1$ reverse Transkriptase (M-MLV Reverse Transcriptase RNase H Minus, Point Mutant, Promega)

$4 \mu 1$ Puffer (Bestandteil des RT-Sets)

$1 \mu 10 \mathrm{mM}$ dNTP-Mix (Invitrogen)

$0,1 \mu 1$ RNasin ${ }^{\circledR}$ (Recombinant RNasin ${ }^{\circledR}$ Ribonuclease Inhibitor, Promega)

Die Anlagerung der Primer erfolgte bei $22^{\circ} \mathrm{C}$ für 10 Minuten, die Gegenstrangsynthese anschließend bei $42^{\circ} \mathrm{C}$ für 50 Minuten. Abschließend folgte ein Denaturierungsschritt bei $95^{\circ} \mathrm{C}$ für 10 Minuten. Die Ansätze wurden anschließend kurz abzentrifugiert und bei $-20^{\circ} \mathrm{C}$ bis zur weiteren Verwendung gelagert.

\subsubsection{Real time detection-PCR (RTD-PCR)}

Bei der real time detection-PCR kamen in diesem Fall genspezifische Sonden zum Einsatz, an welche am 5'-Ende ein Reporterfluoreszenzfarbstoff (6-Carboxy-fluorescein, FAM) und am 3'-Ende ein Quencherfarbstoff (6-Carboxy-tetramethyl-rhodamin, TAMRA) gekoppelt wurde (TaqManTM_Prinzip)(Cardullo et al. 1988; Livak et al. 1995). Die Kombination dieser beiden Farbstoffe ermöglicht einen Fluoreszenz-Resonanz-Energie-Transfer. Wenn der Reporterfarbstoff durch Licht einer bestimmten Wellenlänge (hier $488 \mathrm{~nm}$ ) angeregt wird, strahlt er Licht einer anderen Wellenlänge (hier $518 \mathrm{~nm}$ ) ab, welches wiederum von einem räumlich benachbarten Quencherfarbstoff-Molekül aufgenommen werden kann. Während der Reaktion wird das vom Reporterfarbstoff abgegebene Licht registriert und ausgewertet. Durch die 5'-3'-Exonukleaseaktivität (Holland et al. 1991) der eingesetzten Taq-Polymerase (AmpliTaq DNA-Polymerase) wird die an die DNA gebundene Sonde im Verlauf der Elongation abgebaut. Die dabei auftretende räumliche Entfernung der beiden Farbstoffe führt zur Unterbrechung des Energietransfers und damit zur Erzeugung eines detektierbaren Fluoreszenzsignals des Reporterfarbstoffes. Die Signalstärke ist dabei proportional zur Produktkonzentration. 
In dieser Arbeit wurden bereits im Labor vorhandene und validierte Systeme benutzt (Sequenzen im Anhang, siehe Tabelle 7-1). Das System für Cyp1a1 wurde neu erstellt. Primer und Sonden wurden von Eurogentec (Seraing, Belgien) bezogen.

- Reaktionsansatz: $\quad$ 12,5 $\mu 1$ Puffer mit 3,5 mM MgCl 2 (qPCR ${ }^{\text {TM }}$ Core Kit, Eurogentec)

0,25 U Uracil-N-glycosylase (Eurogentec)

50 - $900 \mathrm{nM}$ jedes Primers (Konzentrationen siehe Tabelle 2-6)

$225 \mathrm{nM}$ Sonde

$2-4 \mu 1 \mathrm{cDNA}$

Das Volumen wurde mit $\mathrm{H}_{2} \mathrm{O}_{\text {Velc }}$ auf $25 \mu \mathrm{l}$ aufgefüllt.

Die Reaktionen für die einzelnen Gene wurden in 96-well Platten (96 well Multiply®-PCRPlate, Sarstedt) pipettiert und mit optischen Deckelketten $\left(0,2 \mathrm{ml}\right.$ Biosphere ${ }^{\circledR}$, Sarstedt $)$ verschlossen. Für jede Platte wurden mindestens 7 Standardpunkte in Doppelbestimmung und 6 Kontrollen ohne DNA zur Kontrolle auf Kontaminationen mitgeführt.

Die RTD-PCR wurde in einem ABI PRISM ${ }^{\mathrm{TM}} 7700$ Sequence detector (Perkin Elmer) für 40 Zyklen durchgeführt.

- Programm: $\quad$ 1. $94^{\circ} \mathrm{C}-180$ Sekunden

2. $94^{\circ} \mathrm{C}-30$ Sekunden

3. $60^{\circ} \mathrm{C}-90$ Sekunden

Schritte 2-3 39 mal wiederholt

4. $\quad 72^{\circ} \mathrm{C}-10$ Minuten

Die Auswertung der Daten erfolgte mit dem Programm Sequence Detection Systems (Ver. 1.9.1) von Applied Biosystems (Darmstadt) im exponentiellen Teil der Reaktion.

Tabelle 2-6: Primerkonzentrationen für die einzelnen RTD-PCR-Ansätze

\begin{tabular}{|l|l|l|l|}
\cline { 2 - 4 } \multicolumn{1}{c|}{} & ER $\alpha$ & C3 & alle anderen Gene \\
\hline forward $(n M)$ & 50 & 900 & 300 \\
\hline reverse $(\mathrm{nM})$ & 900 & 900 & 300 \\
\hline
\end{tabular}




\subsubsection{Herstellung der Standardkurven}

Zur Herstellung von Standardpunkten wurde zunächst in einer normalen PCR (Mullis et al. 1987) mit genspezifischen Primern (siehe Tabelle 7-1) die DNA amplifiziert.

- Reaktionsansatz: $45 \mu 1$ PCR SuperMix (Invitrogen)

$25 \mathrm{nM}$ jedes Primers

$0,5 \mu 1 \mathrm{H}_{2} \mathrm{O}_{\text {Velc }}$

$4 \mu 1 \mathrm{cDNA}$

- Programm: $\quad$ 1. $95^{\circ} \mathrm{C}-180$ Sekunden

2. $95^{\circ} \mathrm{C}-30$ Sekunden

3. $60^{\circ} \mathrm{C}-90$ Sekunden

Schritte 2-3 39 mal wiederholt

4. $\quad 72^{\circ} \mathrm{C}-30$ Minuten

5. $\quad 4^{\circ} \mathrm{C}-$ Pause

Nach einer Aufreinigung des Produktes (GFX PCR DNA and Gel Band Purification Kit, Amersham Biosciences, Freiburg) nach Herstellervorschrift und der Kontrolle der Amplifikation auf einem Agarosegel wurden $4 \mu 1$ des Produktes in eine zweite PCR eingesetzt (Ansatz siehe oben). Dabei wurde an die Gensequenz mit Hilfe eines Primers ein T7-Promoter angefügt.

- Programm: $1 . \quad 95^{\circ} \mathrm{C}-180$ Sekunden

2. $95^{\circ} \mathrm{C}-30$ Sekunden

3. $60^{\circ} \mathrm{C}-30$ Sekunden

4. $\quad 72^{\circ} \mathrm{C}-30$ Sekunden

Schritte 2-4 25 mal wiederholt

5. $95^{\circ} \mathrm{C}-30$ Sekunden

6. $72^{\circ} \mathrm{C}-60$ Sekunden

Schritte 5-6 35 mal wiederholt

5. $\quad 4^{\circ} \mathrm{C}-$ Pause 
Das aufgereinigte und durch Agarose-Gelelektrophorese kontrollierte Produkt wurde anschließend in eine in vitro-Transkription eingesetzt, welche bei $37^{\circ} \mathrm{C}$ über Nacht inkubiert wurde.

- Reaktionsansatz: $1 \mu 1$ Transkriptionspuffer

je $1 \mu 1$ ATP, GTP, CTP und UTP (75 nM)

$1 \mu 1$ T7-MEGAshortscript ${ }^{\mathrm{TM}}$ Enzym Mix (Ambion, Huntingdon, UK)

$4 \mu 1$ DNA

Im Anschluss an die Reaktion wurden 0,5 $\mu 1$ DNase zugegeben und für weitere 15 Minuten bei $37^{\circ} \mathrm{C}$ inkubiert. Zum Abstoppen der Reaktion wurden 57,5 $\mu 1$ Wasser und 7,5 $\mu 1$ Stopplösung (5 M Ammoniumacetat, $100 \mathrm{mM}$ EDTA) zu jedem Ansatz pipettiert und gemischt. Das Produkt wurde anschließend durch eine Phenol-Chloroform-Extraktion aufgereinigt. Dazu wurden $75 \mu \mathrm{l}$ puffergesättigtes Phenol/Chloroform (5:1) zugegeben und gut gemischt. Die Ansätze wurden 5 Minuten bei $10.000 \mathrm{~g}$ zentrifugiert, um die Phasen zu trennen. Die wässrige Phase wurde mit $75 \mu$ l Chloroform/Isoamylalkohol (24:1) versetzt und erneut gut gemischt. Nach einer Zentrifugation von 5 Minuten bei $10.000 \mathrm{~g}$ wurde die wässrige Phase mit $150 \mu \mathrm{l}$ Ethanol $(100 \%)$ versetzt und über Nacht bei $-20^{\circ} \mathrm{C}$ inkubiert. Anschließend wurden die Proben bei 10.000 g für 15 Minuten zentrifugiert. Das Pellet wurde zweimal mit $70 \%$ EtOH gewaschen, getrocknet und in 10-50 $\mu 1$ Wasser aufgenommen.

Die so gewonnene RNA wurde analog zu den Proben verdünnt und in eine RT-Reaktion (siehe 2.7.4) eingesetzt.

\subsubsection{Herstellung des Cyp1a1-TaqMan ${ }^{\mathrm{TM}}$-Systems}

Als Grundlage für die Auswahl von Primern und Sonde wurde die Sequenz von Cypla1 der Ratte (GenBank ${ }^{\circledR}$ Accession-Nummer: NM_012540, Cyp1a1-mRNA, Rattus norvegicus) verwendet. 
Um die Amplifikation genomischer DNA auszuschließen, wurden die beiden Primer auf unterschiedliche Exons gelegt. Die Sonde überspannte die Exongrenzen.

Bei der Auswahl der Sonde wurde auf einige Aspekte besonderer Wert gelegt:

- Länge 20-30 Basen, GC-Gehalt 40-60 \%

- Schmelzpunkt etwa $5^{\circ} \mathrm{C}$ unter dem der Primer

- Möglichst nicht mehr als 3 gleiche Basen hintereinander

- Am 5'-Ende kein G

- Keine Komplementarität zwischen der Sonde und den Primern

Die Ableitung von Primern und Sonde erfolgte mit dem Programm Primer Express, Ver. 1.5 (Applied Biosystems, Darmstadt).

Das erhaltene Amplifikat wurde kommerziel sequenziert (SEQLAB Sequence Laboratories, Göttingen), um die Sequenz verifizieren zu können.

\subsection{Proteinarbeiten}

\subsubsection{Analyse der Proteinexpression des Natrium/lodid-Symporters}

Unterschiede in der Expression des Natrium/Iodid-Symporters sollten in einem Western-Blot untersucht werden.

\subsubsection{Proteinextraktion aus Schilddrüsen}

Alle Arbeiten wurden auf Eis ausgeführt.

Zwei Schilddrüsenlappen wurden in $500 \mu 1$ Homogenisationspuffer mit einem Ultra-Turrax (TP18/10, IKA Labortechnik) homogenisiert und für 15 Sekunden mit Ultraschall (Sonifier B12, Branson Instruments, Danbury [CT], USA) behandelt. Anschließend wurden ungelöste Bestandteile für 10 Minuten bei $15.000 \mathrm{~g}$ und $4^{\circ} \mathrm{C}$ abzentrifugiert. Der Überstand wurde abgenommen und bei $-70^{\circ} \mathrm{C}$ gelagert. $10 \mu$ einer 1:10-Verdünnung in Homogenisationspuffer wurden für eine Proteinbestimmung (siehe 2.4.3.1) eingesetzt. 


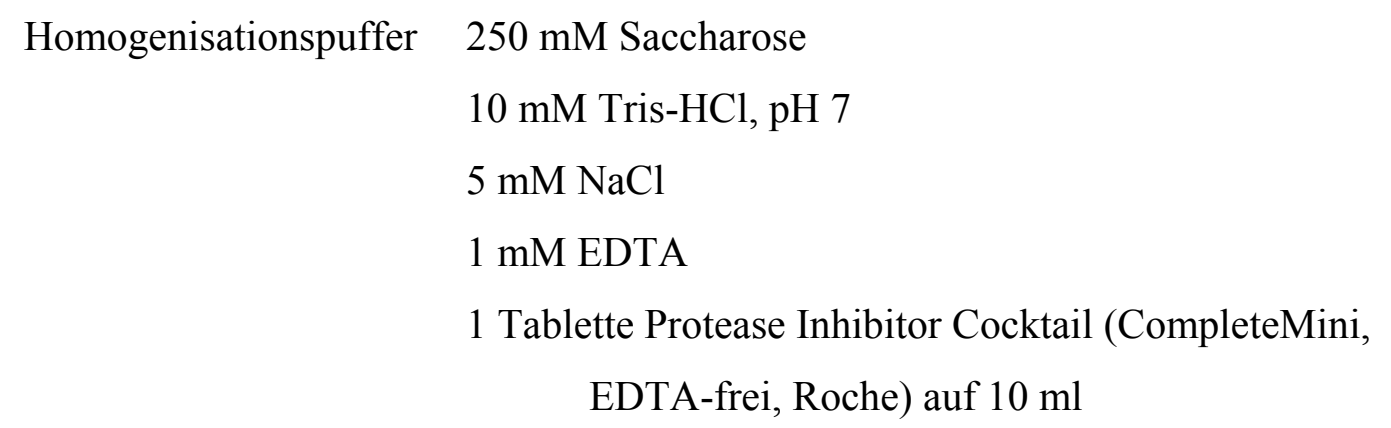

\subsubsection{SDS-Polyacrylamid-Gelelektrophorese (SDS-PAGE)}

Die Auftrennung der Proteine erfolgte nach Laemmli (1970) auf einem 7,5 \% PolyacrylamidGel $(80$ x 73 x 0,75 mm) mit einem 5 \%igen Sammelgel in einer Mini PROTEAN® 3 Cell (Bio-Rad). Die Proben wurden vor dem Auftragen mit Homogenisationspuffer auf eine Proteinkonzentration von 3,5 mg/ml verdünnt und mit 4x Probenpuffer (Roti ${ }^{\circledR}$-Load 1, Roth) versetzt. Anschließend wurden die Proben 5 Minuten auf $95^{\circ} \mathrm{C}$ erhitzt, bevor sie auf das Gel aufgetragen wurden.

- Trenngel $1,25 \mathrm{ml} \mathrm{30 \%} \mathrm{Acrylamid}$

$1,88 \mathrm{ml}$ Trenngelpuffer

$1,78 \mathrm{ml} \mathrm{H}_{2} \mathrm{O}$

$50 \mu 110 \%$ SDS in $\mathrm{H}_{2} \mathrm{O}$

$40 \mu 110 \%$ Ammoniumperoxodisulfat (APS) in $\mathrm{H}_{2} \mathrm{O}$

$4 \mu \mathrm{l}$,N,N',N'-Tetramethylethylendiamin (TEMED)

- Trenngelpuffer $1 \mathrm{M}$ Tris-HCl pH 8,8

- Sammelgel 0,333 ml 30\% Acrylamid

0,250 ml Sammelgelpuffer

$1,39 \mathrm{ml} \mathrm{H}_{2} \mathrm{O}$

$20 \mu 110 \%$ SDS in $\mathrm{H}_{2} \mathrm{O}$

$10 \mu 110 \%$ APS in $\mathrm{H}_{2} \mathrm{O}$

$2 \mu 1$ TEMED

- Sammelgelpuffer 1 M Tris-HCl pH 6,8

- Laufpuffer (10x) 144 g Glycin

$30 \mathrm{~g}$ Tris

$10 \mathrm{~g}$ SDS

auffüllen auf 11 mit $\mathrm{H}_{2} \mathrm{O}_{\text {dest }}$, pH 8,9 


\subsubsection{Semi-Dry-Blot}

Nach der Elektrophorese wurden die Proteine auf einer Nitrozellulose-Membran (Porengröße: 0,2 $\mu \mathrm{m}$, Sartorius, Göttingen) mit Hilfe einer Semi-Dry-Blot Kammer (FastBlot, Bio-Rad) immobilisiert. Die Membran wurde auf Gelgröße zugeschnitten und in Transferpuffer getränkt. Membran und Gel wurden zwischen 6 Lagen, mit Transferpuffer getränktem, Gel Blotting-Papier (GB003, Schleicher \& Schuell, Dassel) in die Kammer gelegt. Der Blot erfolgte unter Wasserkühlung für 30 Minuten bei etwa $3 \mathrm{~mA} / \mathrm{cm}^{2}$ Gelfläche.

- Transferpuffer 5,8 g Tris-Base

$$
\begin{aligned}
& 2,9 \mathrm{~g} \text { Glycin } \\
& 0,375 \mathrm{~g} \text { SDS } \\
& 200 \mathrm{ml} \text { Methanol } \\
& \text { auffüllen auf } 11 \text { mit } \mathrm{H}_{2} \mathrm{O}_{\text {dest }}
\end{aligned}
$$

Die Membran wurde anschließend mit Ponceau S-Lösung $(0,1 \%$ Ponceau $\mathrm{S}$ in $5 \%$ Essigsäure, Sigma) 15 Minuten auf einem Schüttler inkubiert. Die Membran wurde anschließend kurz in Wasser entfärbt und gescannt. Mit Hilfe einer geeigneten Software (ds 1D, Kodak, New Haven (CT), USA) wurden die Banden im Bereich zwischen 30 und $100 \mathrm{kDa}$ densitometrisch ausgewertet, um die gleichmäßige Beladung aller Spuren zu überprüfen.

\subsubsection{Natrium/Iodid-Symporter (NIS)-Proteinexpression}

Die Membran wurde anschließend in PBS mit $1 \%$ Tween-20 (TPBS) und $7 \%$ Trockenmilchpulver (Amersham) für eine Stunde bei Raumtemperatur inkubiert, um überschüssige Proteinbindestellen der Membran abzusättigen. Die Membran wurde 3-mal 5 Minuten in TPBS gewaschen und anschließend über Nacht bei $4^{\circ} \mathrm{C}$ mit dem Primärantikörper (1:2500 in TPBS verdünnt) inkubiert. Nach drei Waschschritten in TPBS wurde der Sekundärantikörper für $1 \mathrm{~h}$ zugegeben. Vor der Inkubation in DiaminobenzidinLösung (1:50 in Substratpuffer, [Envision, Dako Cytomation, Hamburg]) für 1 Minute erfolgten drei weitere Waschschritte in TPBS.

Die Membran wurde anschließend eingescannt und analog zu 2.8.1.3 ausgewertet. 
Tabelle 2-7: Details der verwendeten Antikörper

\begin{tabular}{|l|l|l|l|l|l|}
\cline { 2 - 6 } \multicolumn{1}{c|}{} & Hersteller & Kat.Nr. & erzeugt in & Gegen & Typ \\
\hline $\begin{array}{l}\text { Primär- } \\
\text { antikörper }\end{array}$ & $\begin{array}{l}\text { Acris Antibodies, } \\
\text { Hiddenhausen }\end{array}$ & EUD4101 & Kaninchen & Ratte & $\begin{array}{l}\text { Ig-Fraktion, } \\
\text { polyclonal }\end{array}$ \\
\hline $\begin{array}{l}\text { Sekundär- } \\
\text { antikörper }\end{array}$ & Dianova, Hamburg & $111-035-144$ & Ziege & Kaninchen & $\begin{array}{l}\text { polyklonal, } \\
\text { HRP-gekoppelt }\end{array}$ \\
\hline
\end{tabular}

\subsubsection{Typ I/II 5'-Deiodase (5'DI/II)-Assay}

In diesem Assay wurden die Aktivitäten von zwei Isoformen der 5'-Deiodase (Typ I und II) bestimmt. Deiodasen werden gewebe- und entwicklungspezifisch exprimiert und sind für die Bereitstellung und auch in geringerem Masse für den Abbau von T3 verantwortlich. In diesem Assay wurde die Aktivität der Typ I- und II-Deiodase durch die Abspaltung eines Jodatoms von ${ }^{125}$ Jod-markiertem reversen T3 gemessen. Durch die Zugabe von 6-n-Propyl-2-thiouracil (PTU) wird spezifisch die Typ I-5'Deiodase gehemmt. Dadurch kann die Aktivität der Typ II5'Deiodase bestimmt werden.

\subsubsection{Proteinextraktion}

Stücke des tiefgefrorenen Lebergewebes wurden mit einem Gewebe-Homogenisator (Microdismembrator ${ }^{\mathrm{TM}}$, Braun) 15 Sekunden bei 2500 Upm homogenisiert. Eine Spatelspitze des Gewebepulvers wurde in $500 \mu$ l Homogenisationspuffer auf Eis resuspendiert. Anschließend wurden die Proben auf Eis mit Ultraschall behandelt und sofort für 10 Minuten bei $10.000 \mathrm{~g}$ und $4^{\circ} \mathrm{C}$ abzentrifugiert. Das Pellet wurde erneut in Homogenisationspuffer resuspendiert.

Die Proteinkonzentration wurde analog zu 2.4.3.1 bestimmt. Für die Bestimmung der Aktivitäten wurden $20 \mu \mathrm{g}$ Protein in $40 \mu \mathrm{l}$ Homogenisationspuffer eingesetzt. Für die Bestimmung der 5'Deiodase-Gesamtaktivität (Typ I + II) wurden $10 \mu \mathrm{H}_{2} \mathrm{O}_{\text {dest }}$ zugegeben beziehungsweise $10 \mu 110$ mM PTU für die Bestimmung der Typ II-5'Deiodase-Aktivität.

- Homogenisationspuffer $250 \mathrm{mM}$ Saccharose

$$
\begin{aligned}
& 20 \text { mM HEPES } \\
& 1 \text { mM EDTA } \\
& \text { pH 7,4 einstellen } \\
& \text { vor Gebrauch } 1 \mathrm{mM} \text { Dithiothreitol zugeben }
\end{aligned}
$$


- 10 mM PTU-Lösung 1,7 g PTU (MP Biomedicals, Irvine [CA], USA)

$80 \mathrm{ml} 40 \mathrm{mM} \mathrm{NaOH}$

unter Zugabe von 0,1 M NaOH lösen

anschließend 1:10 mit $40 \mathrm{mM} \mathrm{NaOH}$ verdünnen

\subsubsection{Assay}

Zunächst wurde der Tracer zur Entfernung von Abbauprodukten über Sephadex LH20-Säulen aufgereinigt. Die Säulen wurden mit $3 \mathrm{ml} \mathrm{0,1} \mathrm{N} \mathrm{HCl}$ gespült, bevor der Tracer auf die Säule aufgetragen wurde. Anschließend wurde mit $3 \mathrm{ml} \mathrm{0,1} \mathrm{N} \mathrm{HCl}$ und $3 \mathrm{ml}$ Wasser gespült. Der Tracer wurde mit $1 \mathrm{ml} \mathrm{EtOH} / \mathrm{NH}_{4} \mathrm{OH}$ (49:1) eluiert. Das Eluat wurde 5 Minuten bei $2.000 \mathrm{~g}$ zentrifugiert und anschließend unter leichtem Stickstoffstrom in einem handwarmen Wasserbad eingedampft. Der Tracer wurde in Substratmix resuspendiert. Im Assay wurden je Probe $50 \mu 1$ Tracer-Substratmix mit etwa $5000 \mathrm{cpm}$ eingesetzt.

Um die Reaktion zu starten, wurden $50 \mu 1$ Tracer-Substratmix zu den $50 \mu 1$ Proteinextrakt pipettiert. Nach einer Inkubation von 60 Minuten bei $37^{\circ} \mathrm{C}$ wurden $50 \mu$ Stopp-Lösung zupipettiert und gemischt. Die Proben wurden mit $400 \mu 1 \quad 10 \%$ iger Trichloressigsäure versetzt, 5 Minuten bei $14.000 \mathrm{~g}$ zentrifugiert und der Überstand anschließend auf AG 50W-X2-Säulen (Bio-Rad) gegeben, welche zuvor 2 mal mit $2 \mathrm{ml} 10$ \%iger Essigsäure gespült wurden. Durch Zugabe von $2 \mathrm{ml} 10$ \%iger Essigsäure erfolgte die Elution des freien ${ }^{125} \mathrm{~J}^{-}$in Zählröhrchen, welche anschließend im Gamma-Counter (Wizard 1470, Wallac (Perkin-Elmer) 10 Minuten gemessen wurden.

- Substrat-Mix

$10 \mu 11 \mathrm{M} \mathrm{KPO}_{4}$-Puffer

$2 \mu 11$ M Dithiothreitol

$0,41 \mu 140 \mathrm{mM} \mathrm{NaOH}$

$1 \mu 10,1 \mathrm{M}$ reverses $\mathrm{T} 3$

$36,59 \mu \mathrm{l} \mathrm{H}_{2} \mathrm{O}_{\text {dest }}$

- Stopp-Lösung $10 \mathrm{~g} \mathrm{BSA}$

$0 \mathrm{ml}$ 0,1 M PTU-Lösung

auffüllen auf $100 \mathrm{ml} \mathrm{mit} \mathrm{H}_{2} \mathrm{O}_{\text {dest }}$

- Tracer L-3,3`, $5^{`}-\left[{ }^{125} \mathrm{I}\right]$-Triiodothyronine $\left(\left[{ }^{125} \mathrm{I}\right]\right.$-Reverse $\left.\mathrm{T}_{3}\right)$,

11.9 MBq/ml (Kat.Nr.:NEX 109250UC, Perkin Elmer) 
- $\mathrm{KPO}_{4}$-Puffer

A: $\quad 43,55 \mathrm{~g} \mathrm{~K}_{2} \mathrm{HPO}_{4}$

0,93 g EDTA-Na-Dihydrat

auffüllen auf $250 \mathrm{ml} \mathrm{mit} \mathrm{H}_{2} \mathrm{O}_{\text {dest }}$

B: $\quad 34,03 \mathrm{~g} \mathrm{KH}_{2} \mathrm{PO}_{4}$

0,93 g EDTA-Na-Dihydrat

auffüllen auf $250 \mathrm{ml} \mathrm{mit} \mathrm{H}_{2} \mathrm{O}_{\text {dest }}$

Lösung A mit Lösung B titrieren auf pH 6,8

\subsubsection{Schilddrüsenperoxidase-Assay}

Die Schilddrüsenperoxidase (TPO) ist ein Enzym in der apikalen Membran der Schilddrüse, welches die Oxidation von Iodid sowie den Einbau des Jods in Tyrosinreste des Thyreoglobulins katalysiert. Die TPO ist durch TSH stimulierbar und durch PTU hemmbar.

\subsubsection{Proteinextraktion}

Ein Lappen der Schilddrüse wurde in $1 \mathrm{ml}$ Extraktionspuffer mit dem Ultra-Turrax zerkleinert. Die Suspension wurde 10 Minuten bei $1000 \mathrm{~g}$ und $4^{\circ} \mathrm{C}$ abzentrifugiert. Der Überstand wurde bei $100.000 \mathrm{~g}$ und $4^{\circ} \mathrm{C}$ für 60 Minuten zentrifugiert. Das Pellet wurde in $100 \mu 1200$ mM Kaliumphosphat-Puffer aufgenommen und mittels Ultraschall homogenisiert. Die Proteinkonzentration wurde nach Bradford bestimmt (siehe 2.4.3.1).

- Extraktionspuffer $5 \mathrm{mM}$ Kaliumphosphat-Puffer $200 \mathrm{mM}$ Saccharose 1 mM EDTA $500 \mathrm{U} / \mathrm{ml}$ Katalase auf $\mathrm{pH}$ 7,4 einstellen

\subsubsection{Assay}

- Reaktionsansatz: $\quad 250 \mu 1100 \mu \mathrm{M}$ Kaliumphosphat-Puffer $(\mathrm{pH} 7,4)$

$200 \mu 100$ mM Guaiacol (Sigma; in $\mathrm{H}_{2} \mathrm{O}$ )

$50 \mu \mathrm{g}$ Membranprotein auf 487,5 $\mu 1$ mit $\mathrm{H}_{2} \mathrm{O}$ auffüllen

Start der Reaktion mit 12,5 $\mu 130 \% \mathrm{H}_{2} \mathrm{O}_{2}$

Die Reduktion von $\mathrm{H}_{2} \mathrm{O}_{2}$ wurde photometrisch bei $470 \mathrm{~nm}$ für 90 Sekunden verfolgt. 


\subsection{Histologie}

\subsubsection{Probenvorbereitung}

Das linke Uterushorn wurde in $2 \mathrm{ml}$ Formalin (4\% Paraformaldehyd in 0,01 M PBS) für $2 \mathrm{~d}$ fixiert. Anschließend wurde es quer in 3 Stücke geschnitten und in Einbettkassetten (Sarstedt) gegeben. Die Proben wurden $1 \mathrm{~h}$ in Leitungswasser gewässert und anschließend mit einem Einbett-Automaten (TP1020, Leica, Wetzlar) entwässert und mit flüssigem Paraffin durchtränkt.

Tabelle 2-8: Programm des Einbett-Automaten

\begin{tabular}{|l|l|}
\hline Lösung & Zeit \\
\hline $50 \%$ Ethanol & $60 \mathrm{~min}$ \\
\hline $75 \%$ Ethanol & $80 \mathrm{~min}$ \\
\hline $75 \%$ Ethanol & $80 \mathrm{~min}$ \\
\hline $96 \%$ Ethanol & $80 \mathrm{~min}$ \\
\hline $96 \%$ Ethanol & $80 \mathrm{~min}$ \\
\hline $99 \%$ Ethanol & $80 \mathrm{~min}$ \\
\hline $99 \%$ Ethanol & $80 \mathrm{~min}$ \\
\hline $99 \%$ Ethanol & $80 \mathrm{~min}$ \\
\hline Xylol & $80 \mathrm{~min}$ \\
\hline Xylol & $80 \mathrm{~min}$ \\
\hline Paraffin & $60 \mathrm{~min}$ \\
\hline Paraffin & $60 \mathrm{~min}$ \\
\hline
\end{tabular}

Die Proben wurden anschließend mit Hilfe einer Paraffin-Ausgießstation (EG 1140C, Leica) so in Blöcken eingebettet, dass die Schnittflächen des Uterushorns parallel zur Schnittfläche der Blöcke lag. Alle 3 Proben eines Uterus wurden in einem Block eingebettet.

Nach dem Aushärten des Paraffins wurden von den Uteri mit einem Mikrotom (RM 2135, Leica) Dünnschnitte $(3 \mu \mathrm{m})$ angefertigt, welche in warmem Wasser gestreckt und auf beschichtete Objektträger (Superfrost plus, Menzel, Braunschweig) aufgezogen wurden. Die Objektträger wurden anschließend bei $37^{\circ} \mathrm{C}$ getrocknet. 


\subsubsection{HE-Färbung}

Die Schnitte wurden nach folgendem Protokoll entwässert und mit Hämatoxylin (Haematoxylin Mayer, Merck) und Eosin (0,25 \% Eosin gelb [Merck] in $80 \%$ Ethanol) (HE) gefärbt.

Tabelle 2-9: Protokoll der HE-Färbung

\begin{tabular}{|l|l|}
\hline Lösung & Zeit \\
\hline Xylol & $3 \times 10 \mathrm{~min}$ \\
\hline $99 \%$ Ethanol & $3 \times 2 \mathrm{~min}$ \\
\hline $96 \%$ Ethanol & $2 \times 2 \mathrm{~min}$ \\
\hline $75 \%$ Ethanol & $2 \mathrm{~min}$ \\
\hline $\mathrm{H}_{2} \mathrm{O}_{\text {dest }}$ & 2 min \\
\hline $\mathrm{Hämatoxylin}^{\text {Leitungswasser }}$ & $2 \mathrm{~min}$ \\
\hline Eosin & $5-10 \mathrm{~min}$ \\
\hline $75 \%$ Ethanol & $2 \mathrm{~min}$ \\
\hline $96 \%$ Ethanol & $2 \times 2 \mathrm{~min}$ \\
\hline $99 \%$ Ethanol & $3 \times 2 \mathrm{~min}$ \\
\hline Xylol & $3 \times 5 \mathrm{~min}$ \\
\hline
\end{tabular}

\subsubsection{Auswertungskriterien}

Die Schnitte wurden anschließend mikroskopisch ausgewertet. Dazu wurden die Morphologie der Zellen, die Dicke und das Erscheinungsbild bestimmter Zellschichten bestimmt. Die einzelnen Parameter waren:

- Zelldicke des Epithels des Endometriums

- Lage der Zellkerne des Epithels und Verhältnis der Flächen von Cytoplasma/Kern

- Form der Zellkerne der Zellen der Lamina propria 


\subsection{Statistische Auswertung}

Alle Daten wurden vor der Auswertung auf ihre Plausibilität überprüft.

Die Daten wurden anschließend mit dem Grubbs-Test (Burke 2001) auf Ausreißer untersucht. Verwendet wurde dazu folgende Formel:

$$
G=\frac{\left|\bar{x}-x_{i}\right|}{s}
$$

wobei $\bar{x}$ den Mittelwert der Gruppe, $x_{i}$ den Einzelwert und $s$ die Standardabweichung darstellen.

Die erhaltenen Werte wurden mit den kritischen Werten für das 95\%-Konfidenzintervall verglichen. Lagen die erhaltenen Werte höher, wurde der Wert als Ausreißer betrachtet.

Bei den Genexpressionsdaten wurde der Mittelwert der Kontrollgruppen $=100 \%$ gesetzt. Alle anderen Behandlungsgruppen wurden dazu in Bezug gesetzt.

Alle Messwerte wurden mit Prism ${ }^{\circledR}$, Ver.4 (GraphPad, San Diego [CA], USA) ausgewertet. Die Daten wurden mit einem Kruskal-Wallis-Test (One-Way analysis of variance [ ANOVA], nicht-parametrisch) und einem Dunn's multiple comparison Post-Test ausgewertet. Ein p-Wert von $\leq 0,05$ wurde als signifikant betrachtet (mit * oder \# in Abbildungen markiert).

In den Graphen sind jeweils die Mittelwerte sowie der Standardfehler des Mittelwertes (Mean $\pm S E M)$ angegeben. Sofern an den Graphen keine andere Einheit angegeben ist, wurden die Werte der einzelnen Gruppen auf den Mittelwert der Kontrollgruppe (=100\%) prozentrelativiert $(\% \mathrm{rel})$.

Dosis-Wirkungsbeziehungen wurden mit der PROAST-Software, Ver.02.R (Slob 2002) erstellt. Dieses Programm verwendet ineinander verschachtelte Gleichungen (1.-5.), um eine Kurve an die Daten zu modellieren

1. $y=a$

2. $y=a^{*} \exp \left(b^{*} x\right)$

3. $y=a^{*} \exp \left(b^{*} x^{d}\right)$

4. $y=a^{*}\left(c-(c-1) * \exp \left(b^{*} x\right)\right.$

5. $y=a^{*}\left(c-(c-1) * \exp \left(b^{*} x^{d}\right)\right.$ 
Die einzelnen Funktionen werden auf ihre Wahrscheinlichkeit mit einem likelihood-ratio-Test überprüft. Es wird das Modell ausgewählt, welches mit möglichst wenigen Variablen signifikant besser die Daten beschreibt als die vorhergehende Gleichung. Mit Hilfe dieser Funktion kann aus einer festgelegten Effekt-Größe (CES) die entsprechende Effekt-Dosis (CED) ermittelt werden. Die CES ist mathematisch definiert als $C E S=f(C E D) / f(0)-1$.

In diesem Fall betrug die CES die einfache Standardabweichung der Kontrollgruppe. Die Schritte der Auswertung sind ausführlich in Woutersen et al. (2001) dargestellt. 


\section{Ergebnisse}

\subsection{Rezeptorbindungsassay}

In Abbildung 3-1 ist die Verdrängung von radioaktiv markiertem E2 durch nicht markiertes E2 und durch BP2 von cytosolischen Komponenten gezeigt. Der EC $_{50}$ für E2 liegt bei einer Konzentration von $0,47 \mathrm{nM}$ der $\mathrm{EC}_{50}$ von $\mathrm{BP} 2$ bei einer Konzentration von $495 \mathrm{nM}$. E2 bindet etwa 1000-mal stärker an die Komponenten des Cytosols als BP2.

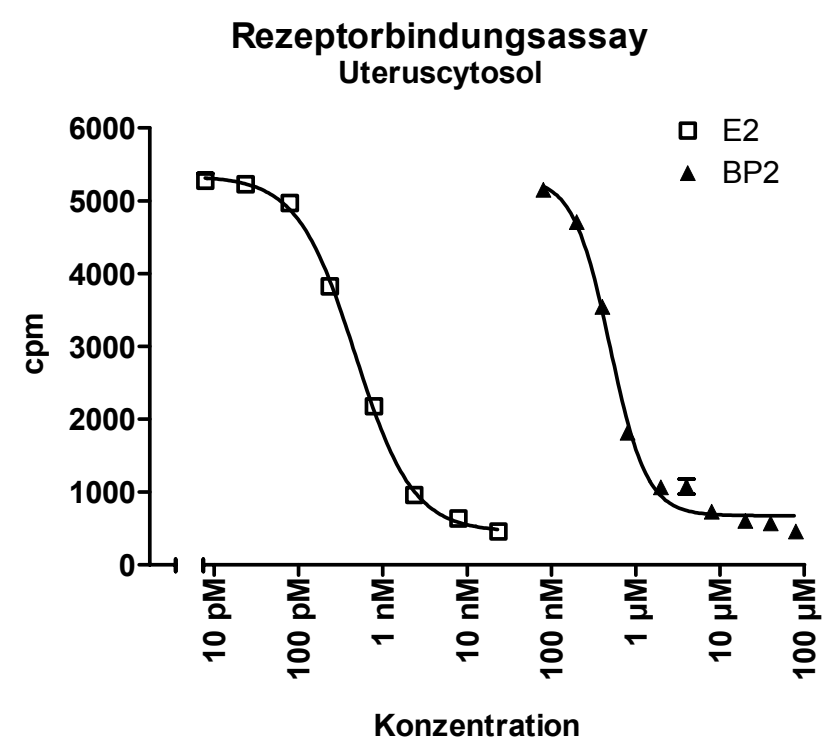

Abbildung 3-1: Rezeptorbindungsassay mit porcinem Uteruscytosol. Gemessen wurde die Verdrängung von radioaktivem E2 durch die Substanzen in den angegebenen Konzentrationen. 


\subsection{Zellkultur}

\subsubsection{Proliferationstest mit MCF-7-Zellen (E-Screen)}

Die Proliferation von MCF-7-Zellen wurde durch die Behandlung mit BP2 in den Konzentrationen $1 * 10^{-6}$ und $1 * 10^{-5} \mathrm{M}$ signifikant gesteigert. Von $1 * 10^{-9} \mathrm{M}$ bis $1 * 10^{-7} \mathrm{M} \mathrm{BP} 2$ konnte kein Einfluss auf die Proliferation festgestellt werden. Eine Behandlung mit E2 in einer Konzentration von $1 * 10^{-8} \mathrm{M}$ hatte einen ähnlichen Einfluss auf die Proliferation wie die höchste Dosis BP2.

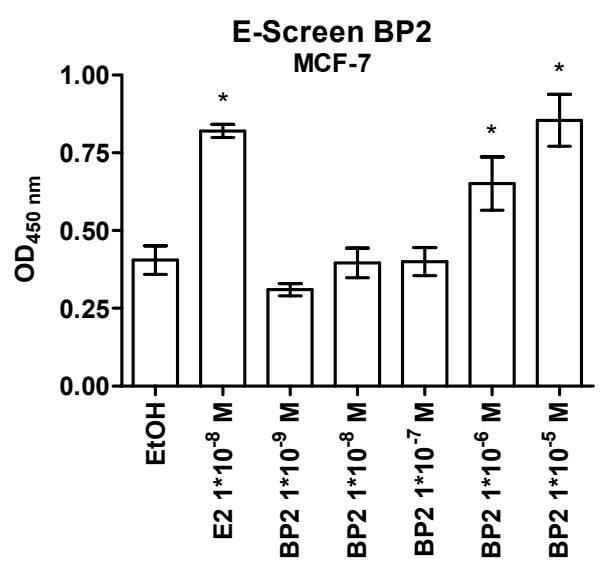

Abbildung 3-2: Einfluss von E2 und BP2 auf die Proliferation von MCF-7 Zellen. Die Umsetzung des Substrats wurde nach 5 Minuten abgestoppt und die OD bei $450 \mathrm{~nm}$ gemessen. $*=$ signifikant gegenüber der Lösungsmittelkontrolle (EtOH)

\subsubsection{Transaktivierungsassays}

Wie in Abbildung 3-3 zu erkennen, zeigte BP2 im Transaktivierungsassay bereits in einer Konzentration von $3 * 10^{-8} \mathrm{M}$ eine aktivierende Wirkung in MELN-ER $\beta-Z e l l e n$. In MELNER $\alpha$-Zellen zeigte sich die Aktivierung der Luciferase-Aktivität erst ab einer Konzentration von $3 * 10^{-7} \mathrm{M}$ und in MELN-Zellen, welche keinen der beiden Rezeptoren überexprimieren, wurde ab $3 * 10^{-6}$ M BP2 eine Aktivierung beobachtet. Die ermittelten $\mathrm{EC}_{50}$-Werte liegen für MELN-ER $\alpha$ bei $320 \mathrm{nM}$ und für MELN-ER $\beta$ bei $120 \mathrm{nM}$. 


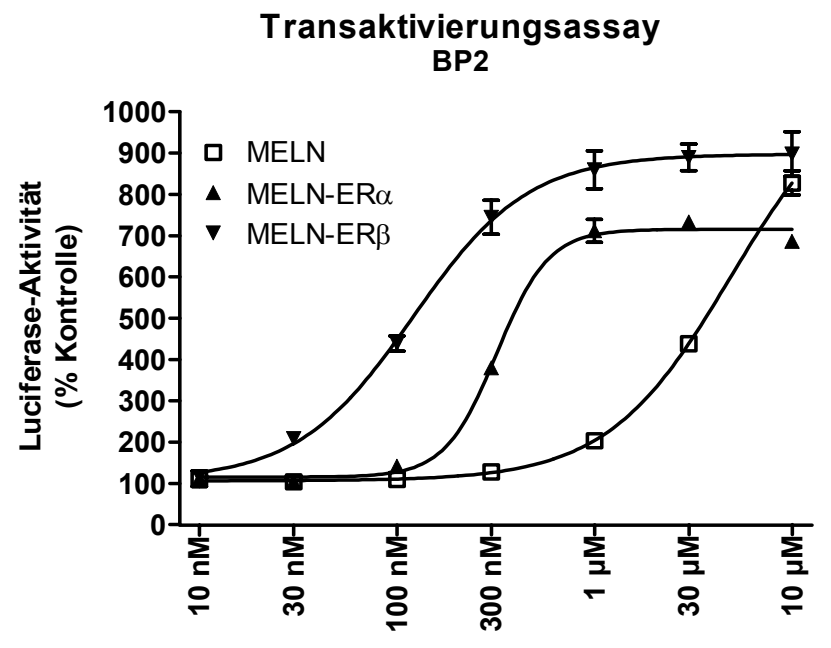

Konzentration BP2

Abbildung 3-3: Luciferase-Aktivität nach Belastung der verschiedenen Zellen mit den angegebenen Konzentrationen BP2. Alle Werte wurden auf die Kontrollgruppe $(\mathrm{EtOH})=100 \%$ bezogen.

\subsubsection{EROD-Assay}

Im EROD-Assay (Abbildung 3-4) wurde neben der Stimulation durch 3MC nur bei einer BP2-Konzentration von $1 * 10^{-4} \mathrm{M}$ eine signifikante Stimulation der EROD-Aktivität beobachtet. Bei dieser Konzentration wurde auch bei der Koinkubation mit $1 * 10^{-6} \mathrm{M} 3 \mathrm{MC}$ ein stimulierender Effekt beobachtet, welcher die Stimulation durch 3MC noch weiter verstärkte.
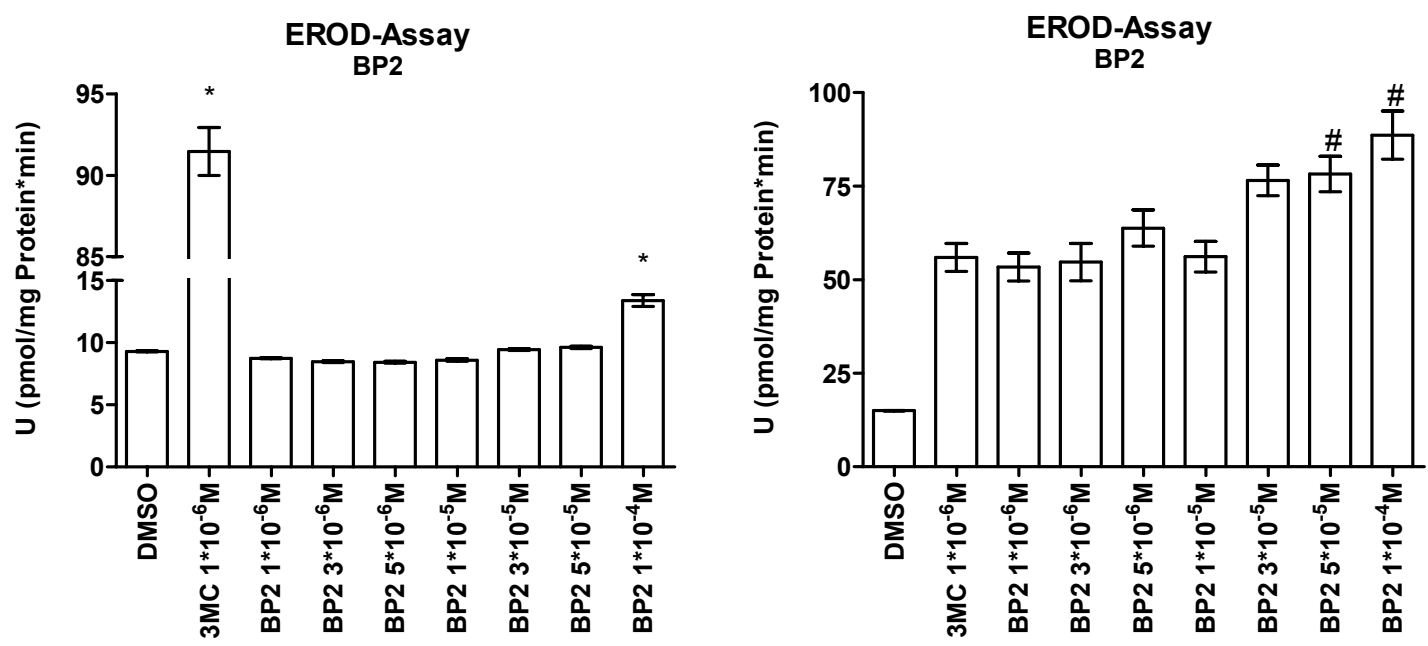

Abbildung 3-4: Ergebnisse der EROD-Assays für BP2. Der erste Graph zeigt die Stimulation durch BP2, der zweite Graph zeigt die Ergebnisse der Koinkubation mit $1 * 10^{-6} \mathrm{M} 3 \mathrm{MC}$. * = signifikant gegenüber Lösungsmittel (DMSO), \# = signifikant gegenüber 3MC 


\subsubsection{Hypothalamuszellkultur}

Bei murinen Hypothalamuszellen zeigte sich eine Hemmung der GnRH-Sekretion bei einer Belastung mit E2 in einer Konzentration von $1 * 10^{-9} \mathrm{M}$ (Abbildung 3-5). Eine ähnliche Hemmung der Sekretion konnte auch bei Belastung der Zellen mit $1 * 10^{-5} \mathrm{M}$ BP2 gezeigt werden. Bei beiden Substanzen konnte die Hemmung durch eine Koinkubation mit ICI 182,780, einem Estrogen-Rezeptor-Antagonisten, in einer Konzentration von $1 * 10^{-6} \mathrm{M}$ aufgehoben werden.

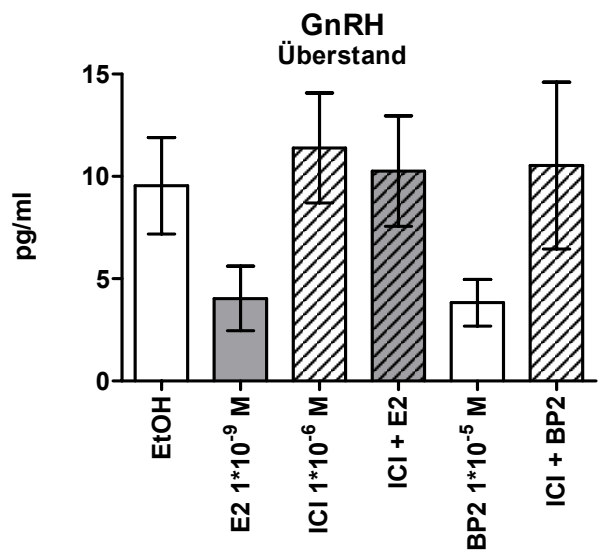

Abbildung 3-5: Messung der GnRH-Konzentration im Zellüberstand von GT1-7-Zellen. Die Belastung der Zellen erfolgte für 6 Stunden. ICI = ICI 182,780

\subsubsection{Hypophysenzellkultur}

Mit isolierten Ratten-Hypophysenzellen konnte nachgewiesen werden, dass die LH-Sekretion durch BP2 in Konzentrationen von $1 * 10^{-5} \mathrm{M}$ und $1 * 10^{-6} \mathrm{M}$ signifikant gegenüber der Lösungsmittelkontrolle gesteigert wurde (Abbildung 3-6). Dieser Effekt konnte durch eine Koinkubation mit ICI 182,780 in einer Konzentration von $10^{-6} \mathrm{M}$ inhibiert werden. Auch die signifikante Stimulation der LH-Sekretion durch E2 konnte mit ICI inhibiert werden.

Die TSH-Sekretion der Hypophysenzellen wurde durch E2 und BP2 in den Konzentrationen $1 * 10^{-5}$ und $1 * 10^{-6} \mathrm{M}$ signifikant gesteigert. Die Inkubation mit $1 * 10^{-7} \mathrm{M}$ BP2 zeigte eine leichte, jedoch nicht signifikante Stimulation der TSH-Sekretion. Diese stimulierenden Effekte konnten ebenfalls durch die Koinkubation mit ICI aufgehoben werden. 

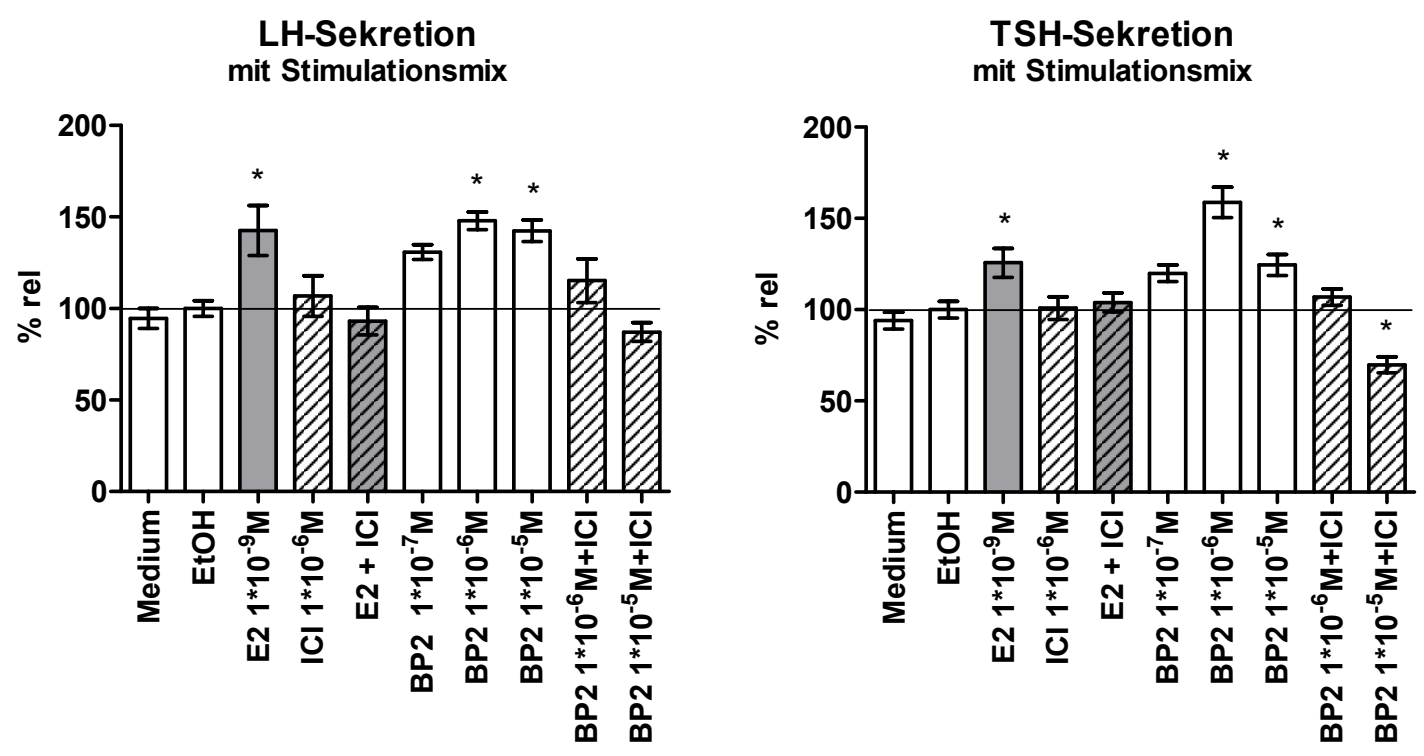

Abbildung 3-6: LH- und TSH-Sekretion in primären Rattenhypophysenzellen. Die Zellen wurden mit TRH und GnRH (jeweils $1 * 10^{-6} \mathrm{M}$ ) für 3 Stunden inkubiert. Die Werte wurden prozentrelativiert auf die Kontrollgruppe $(\mathrm{EtOH}+\mathrm{Mix}){ }^{*}=$ signifikant gegenüber der Lösungsmittelkontrolle $(\mathrm{EtOH}+\mathrm{Mix})$, Stimulationsmix $=\mathrm{GnRH}+\mathrm{TRH}\left(\right.$ beides $\left.1 * 10^{-6} \mathrm{M}\right), \mathrm{E} 2=17 \beta$-Estradiol, ICI $=$ ICI 182,780

\subsubsection{Viabilitätsbestimmung mittels MTT-Test}

Im MTT-Test konnte keine signifikante Beeinträchtigung der Zellviabilität durch die Testsubstanzen in den eingesetzten Konzentrationen beobachtet werden (Abbildung 3-7).

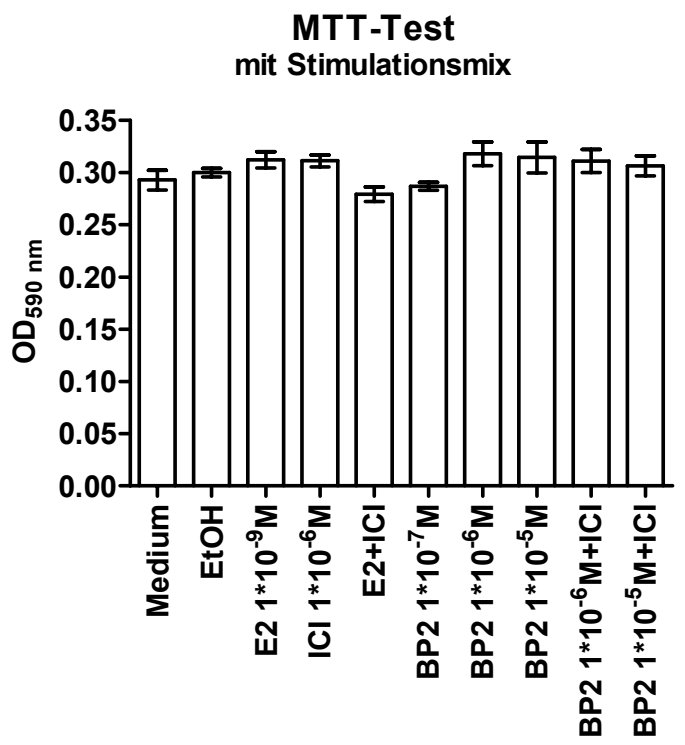

Abbildung 3-7: Auswirkungen der Testsubstanzen auf die Viabilität der Hypophysenzellen. Alle Gruppen wurden mit GnRH und TRH (jeweils $10^{-6} \mathrm{M}$ ) für 3 Stunden inkubiert. 


\subsection{Subakute Applikation von BP2}

\subsubsection{Körpergewicht}

Alle Gruppen lagen bei Beginn der Behandlung bei einem durchschnittlichen Gewicht von $292,86 \pm 5,5 \mathrm{~g}$. Trotz einer leichten Gewichtsreduktion in der E2V-Gruppe auf durchschnittlich $278 \mathrm{~g}$ konnten keine signifikanten Unterschiede im Körpergewicht der Tiere nach fünf Tagen Behandlung beobachtet werden.
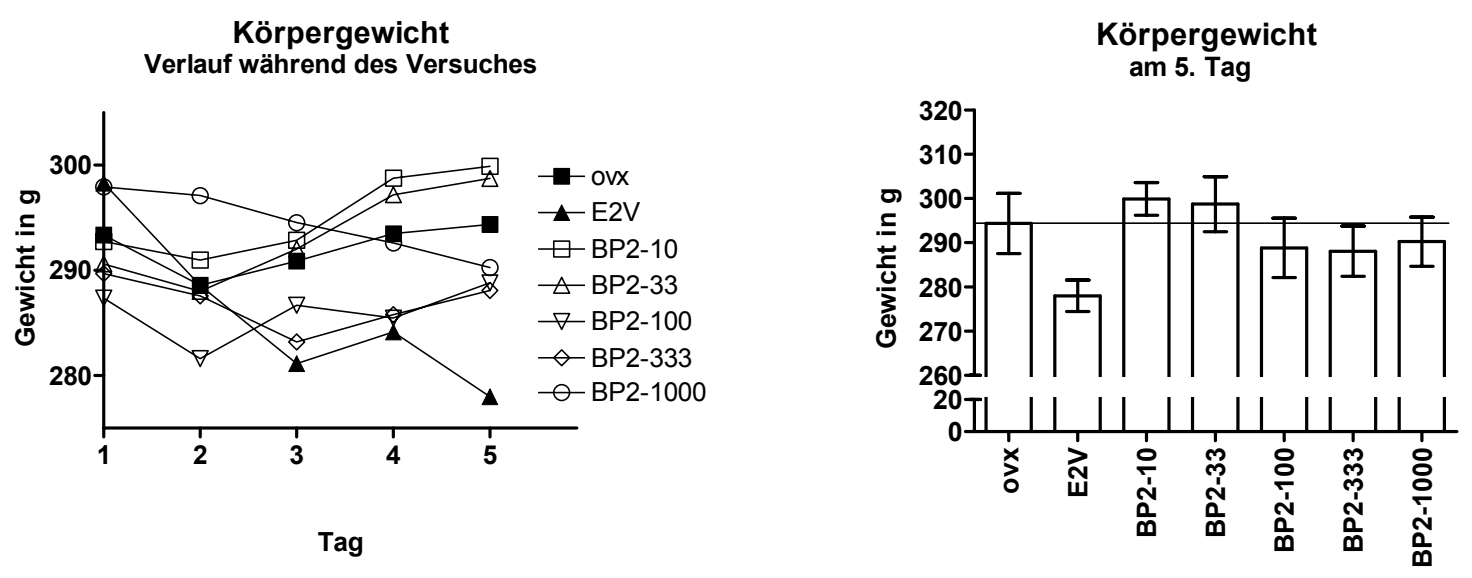

Abbildung 3-8: Entwicklung der Körpergewichte während der Behandlung und am letzten Tag. In der ersten Abbildung sind der Übersichtlichkeit wegen nur die Mittelwerte der Gruppen dargestellt.

\subsubsection{Uterus}

\subsubsection{Uterusgewicht}

Das Uterusgewicht in den Behandlungsgruppen zeigte deutliche Veränderungen gegenüber der ovx-Gruppe (Abbildung 3-9). Durch die E2V-Behandlung wurde fast eine Verdreifachung des Uterusgewichtes beobachtet. Auch in der BP2-1000-Gruppe wurde das Uterusgewicht verdreifacht. In den niedrigeren BP2-Gruppen 100 und 333 wurde eine leichte Erhöhung beziehungsweise eine Verdopplung des Uterusgewichtes gegenüber der ovx-Gruppe beobachtet. 


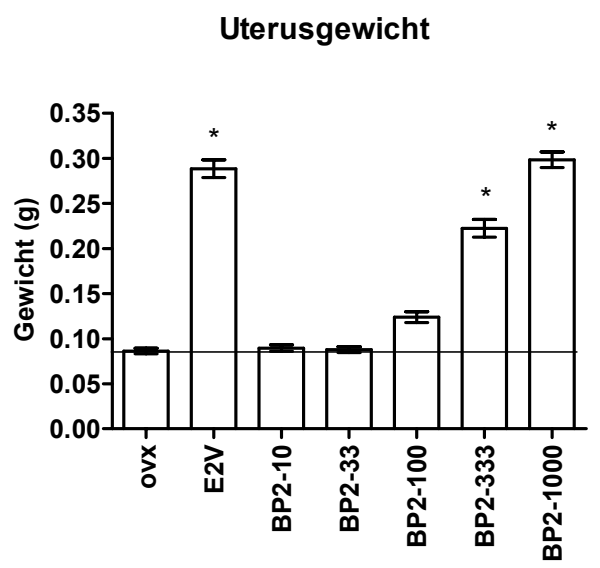

Abbildung 3-9: Absolute Uterusgewichte in den Behandlungsgruppen nach 5tägiger Behandlung. * signifikant gegenüber ovx.

\subsubsection{Histologie}

Wie in Abbildung 3-10 $\mathrm{zu}$ erkennen, ist das Epithel des Endometriums bei allen Behandlungsgruppen meist einschichtig. Die Epithelzellen sind in der Kontrollgruppe klein und säulenförmig, die Zellkerne befinden sich in der Mitte der Zellen. Das Verhältnis Zytoplasma/Kern ist in diesen Zellen sehr klein. Bei den Gruppen E2V und BP2-1000 ist eine deutliche Streckung der Zellen in Richtung des Lumens zu beobachten. Das Ausmaß der Streckung ist in den beiden Gruppen etwa gleich. Der Zellkerne liegen in unterschiedlichen Positionen in den Zellen. Das Verhältnis von Zytoplasma zu Kern ist in diesen Zellen viel höher als in den Zellen der Kontrollgruppe.

Die Zellkerne der Lamina propria-Zellen sind in der Kontrollgruppe rund bis oval. In den beiden Behandlungsgruppen (E2V und BP2-1000) besitzen die Zellkerne dieser Zellen ein spindelförmiges Erscheinungsbild. 


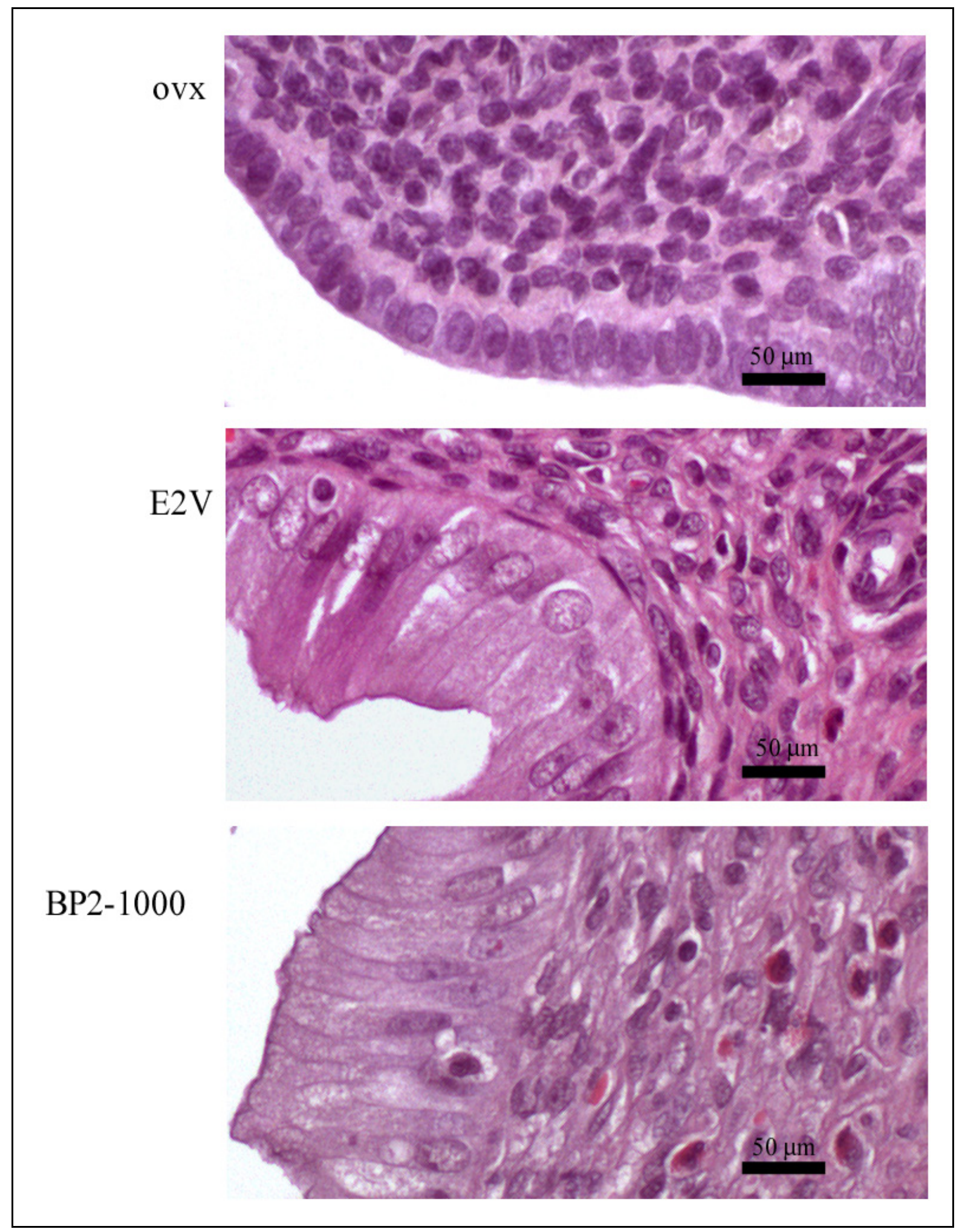

Abbildung 3-10: Histologisches Erscheinungsbild der Uteri nach 5 Tagen Behandlung mit Olivenöl (ovx), E2V oder BP2-1000. HE-Färbung der transversalen Uterus-Schnitte. 


\subsubsection{Serumanalyse}

\subsubsection{Serumkonzentration von Estradiol}

Durch die Gabe von $600 \mu \mathrm{g} / \mathrm{kg} \mathrm{Kg}$ E2V pro Tag wurden Estradiol-Serumspiegel von etwa $85 \mathrm{pg} / \mathrm{ml}$ erreicht (Abbildung 3-11). Damit liegen die erreichten Serumkonzentrationen etwas höher als die physiologischen Level, welche durch den Estradiolpeak während des Proestrus erreicht werden (etwa $50 \mathrm{pg} / \mathrm{ml}$ ). Bei den ovariektomierten Tieren wurde eine durchschnittliche Serumkonzentration von 9 pg E2/ml gemessen.

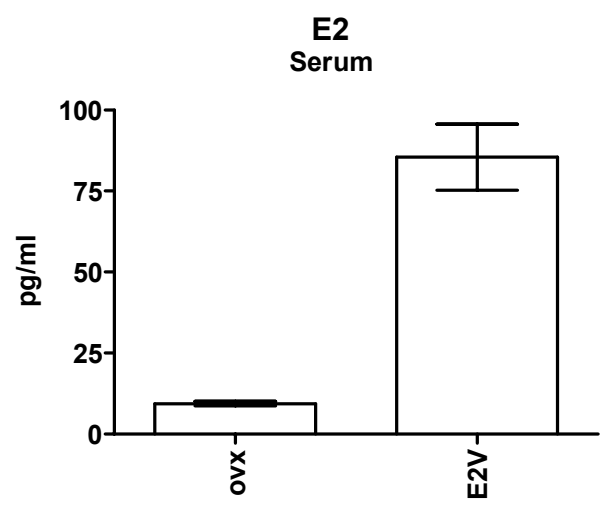

Abbildung 3-11: Serumkonzentration von Estradiol in der Kontrollgruppe (ovx) und in der E2V-Gruppe. Die Werte wurden mit einem ECLIA gemessen.

\subsubsection{Serumkonzentration von Benzophenon-2}

Zunächst wurden die Seren ohne Glucuronidase-Behandlung gemessen. Ein beispielhaftes Chromatogramm ist in Abbildung 3-12 gezeigt. Anhand der Standardkurve mit BP2 in Rattenserum konnte der Peak bei einer Retentionszeit von 11,9 Minuten (Peak 3 in der Abbildung) BP2 zugeordnet werden. Dosisabhängig wurden zwei weitere Peaks bei Retentionszeiten von 5,6 und 5,9 Minuten (Peaks 1 und 2) gefunden. 


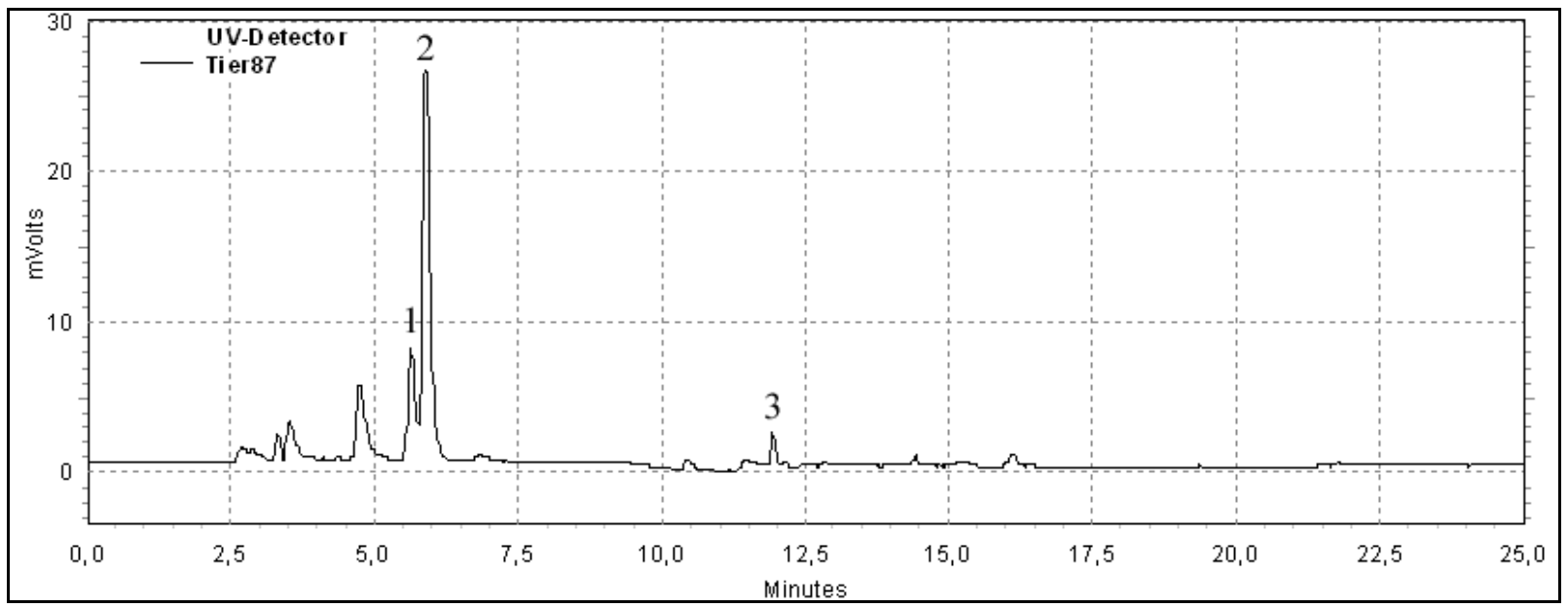

Abbildung 3-12: Beispiel eines Chromatogramms. Peak 3 entspricht dem freien BP2 mit einer Retentionszeit von 11,9 Minuten.

Anhand der Standardkurve wurden die Konzentrationen des freien BP2 im Serum der Versuchstiere bestimmt (Abbildung 3-13). Die niedrigen Gruppen bewegen sich im Bereich um $0,1 \mu \mathrm{g} / \mathrm{ml}$, wobei in der BP2-33-Gruppe eine Konzentration von 0,2 $\mu \mathrm{g} / \mathrm{ml}$ gemessen wurde. Ein deutlicher Anstieg der Serumkonzentration von BP2 ist erst in der BP2-333Gruppe sichtbar. In der höchsten Dosierung, BP2-1000, wurden Serumkonzentrationen von durchschnittlich 1,1 $\mu \mathrm{g} / \mathrm{ml}$ gemessen. Diese Konzentration entspricht 4,6 $\mu \mathrm{M}$ BP2.

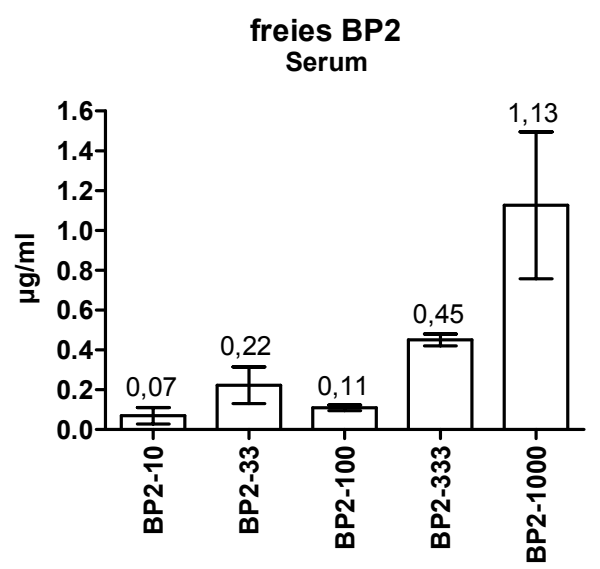

Abbildung 3-13: Serumkonzentrationen von freiem BP2 in den Behandlungsgruppen. Im Diagramm sind über den Balken die Mittelwerte angegeben. 
Nach der Inkubation mit Glucuronidase aus Helix pomatia konnten die beiden zusätzlichen Peaks (1 und 2 in Abbildung 3-12) nicht mehr detektiert werden. Die Peakfläche der Reinsubstanz war dafür im Vergleich zu den unbehandelten Seren der gleichen Tiere entsprechend größer (Abbildung 3-14).

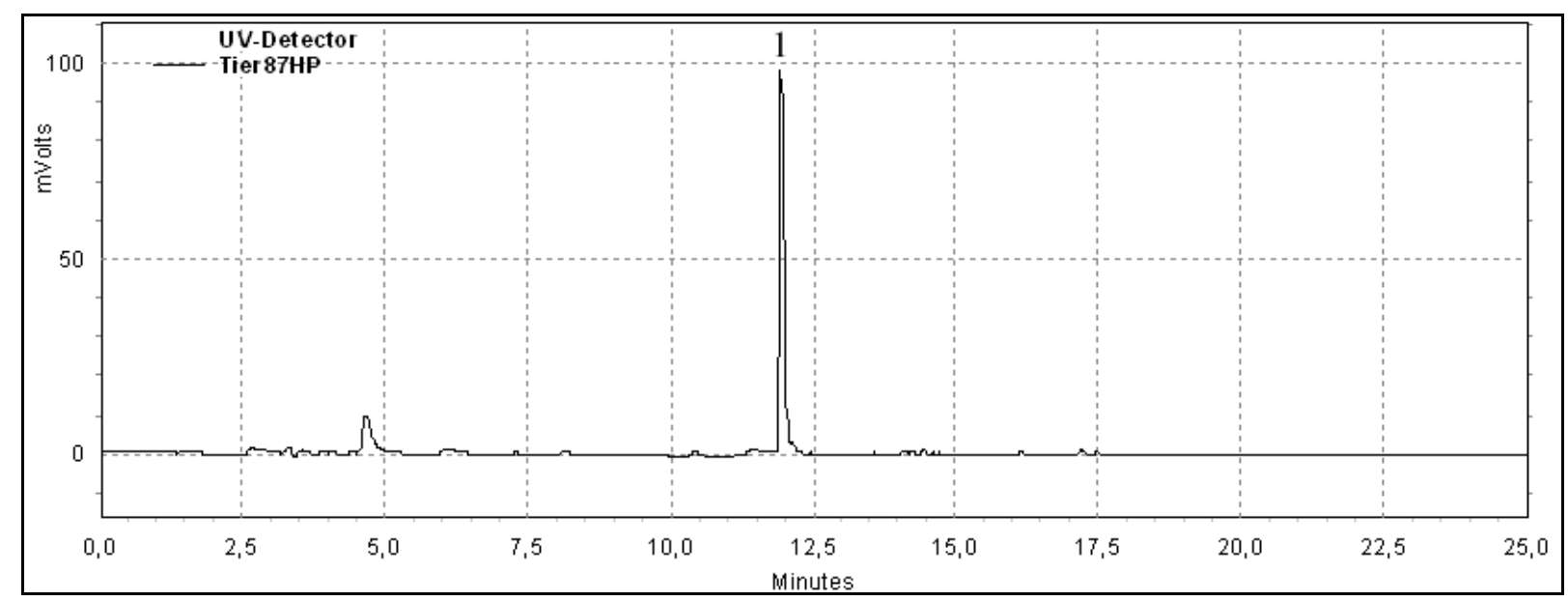

Abbildung 3-14: UV-Chromatogramm einer mit Glucuronidase behandelten Serumprobe. Die Probe entspricht, außer der Glucuronidasebehandlung der in Abbildung 3-12 verwendeten Probe. Es ist nur ein Peak (1) bei einer Retentionszeit von 11,9 Minuten erkennbar.

In Abbildung 3-15 sind die Serumkonzentrationen von BP2 aufgetragen, die nach der Behandlung des Serums mit Glucuronidase messbar waren. Hier zeigte sich im Gegensatz zum freien BP2 bereits in den niedrigen Gruppen, BP2-33 und BP2-100, ein Anstieg auf 2,3 beziehungsweise $6,4 \mu \mathrm{g} / \mathrm{ml}$ ausgehend von einer Konzentration von $0,97 \mu \mathrm{g} / \mathrm{ml}$ bei der BP210-Gruppe. Diese Werte liegen deutlich höher als die gemessenen Konzentrationen in den Seren ohne Glucuronidasebehandlung. In der BP2-333-Gruppe wurde eine Konzentration von $16,1 \mu \mathrm{g} / \mathrm{ml}$ und in der BP2-1000-Gruppe eine Konzentration von 62,5 $\mu \mathrm{g} / \mathrm{ml}$ gemessen. Diese Konzentration entspricht $0,25 \mathrm{mM}$ BP2. 


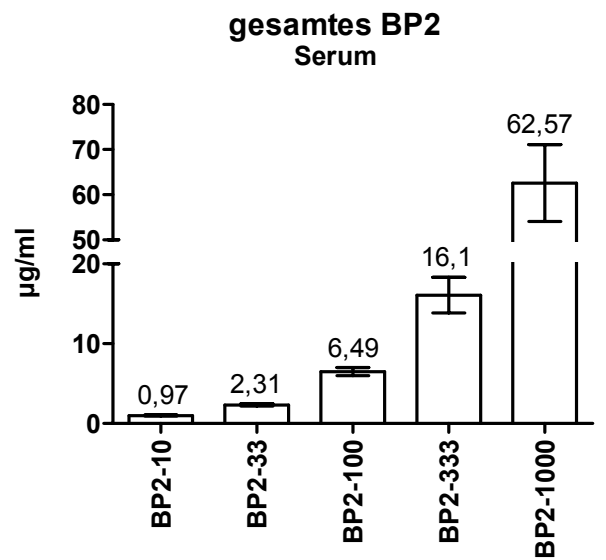

Abbildung 3-15: Serumkonzentrationen von BP2 nach der Behandlung des Serums mit Glucuronidase aus Helix pomatia. Die BP2-Konzentration wurde durch UV-Detektion bei $280 \mathrm{~nm}$ nach der Trennung durch HPLC bestimmt. In der Kontrollgruppe (ovx) war kein BP2 nachweisbar. In der Abbildung sind über den Balken die Mittelwerte der Gruppen angegeben.

Die Massenspektren der drei Substanzen sind Abbildung 3-16 gezeigt.

Die Massenbestimmung per HPLC-MS ergab für die beiden nicht identifizierten Peaks eine molare Masse von $326 \mathrm{~g} / \mathrm{mol}$ (Peak 1 in Abbildung 3-12; A in Abbildung 3-16) beziehungsweise $422 \mathrm{~g} / \mathrm{mol}$ (Peak 2 in Abbildung 3-12; B in Abbildung 3-16). Für den letzten Peak (Peak 3 in Abbildung 3-12; $\mathrm{C}$ in Abbildung 3-16) ergab sich eine molare Masse von $246 \mathrm{~g} / \mathrm{mol}$, welche der Masse von BP2 entspricht. 
A
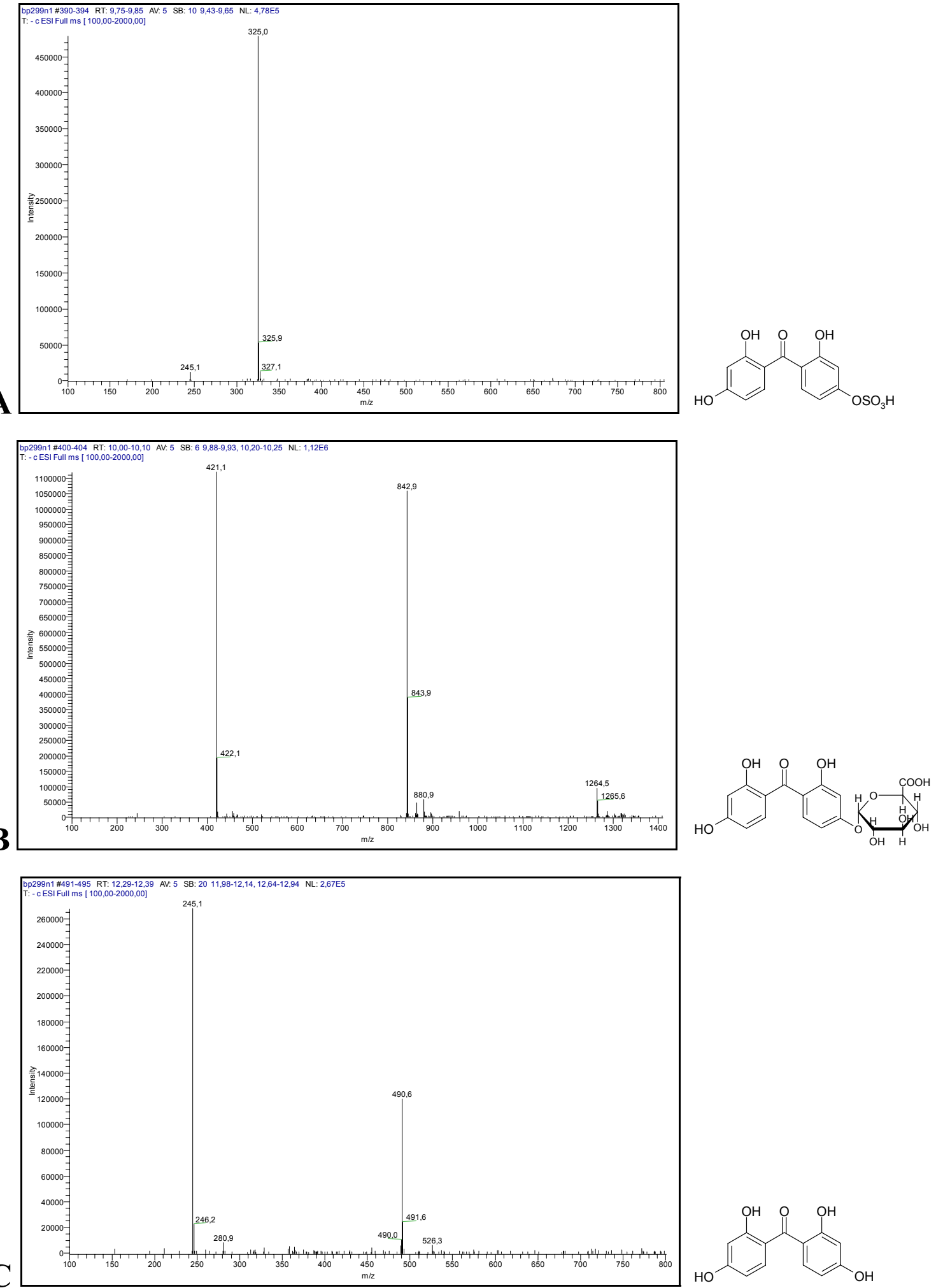

Abbildung 3-16: ESI(-)-Massenspektren der drei detektierbaren Substanzen. Die Substanzen wurden durch Abspaltung eines $\mathrm{H}^{+}$-Ions ionisiert, die im Spektrum angezeigten Massen sind deshalb $1 \mathrm{~g} / \mathrm{mol}$ kleiner. Die Retentionszeiten $(A=9,80, B=10,03$ und $C=12,34$ Minuten) sind aufgrund anderer Laufbedingungen etwas verschoben. Neben den Spektren wurde jeweils eine mögliche molekulare Struktur gezeigt, die mit dem ermittelten Molekulargewicht übereinstimmen würde. 


\subsubsection{Hypophysenhormone}

Auf die Serumkonzentrationen von TSH hatte keine der Behandlungen einen signifikanten Einfluss, obwohl die TSH-Werte durch BP2-333 und -1000 leicht erhöht waren (Abbildung 3-17).

Auf die Serumkonzentrationen von LH hatte BP2 in den höchsten beiden Dosen einen signifikanten Einfluss. Auch bei den anderen BP2-Gruppen ist eine leichte dosisabhängige, jedoch nicht signifikante Erhöhung zu beobachten.

Die Bestimmung von GH im Serum ergab eine dosisabhängige Erhöhung der Werte durch die beiden höchsten Dosen von BP2. Die E2V-Behandlung hatte keinen Einfluss auf die GHSerumspiegel.

Die Serumkonzentrationen von Prolaktin wurden durch die E2V- und die BP2-Behandlung in den beiden höchsten Konzentrationen signifikant erhöht.
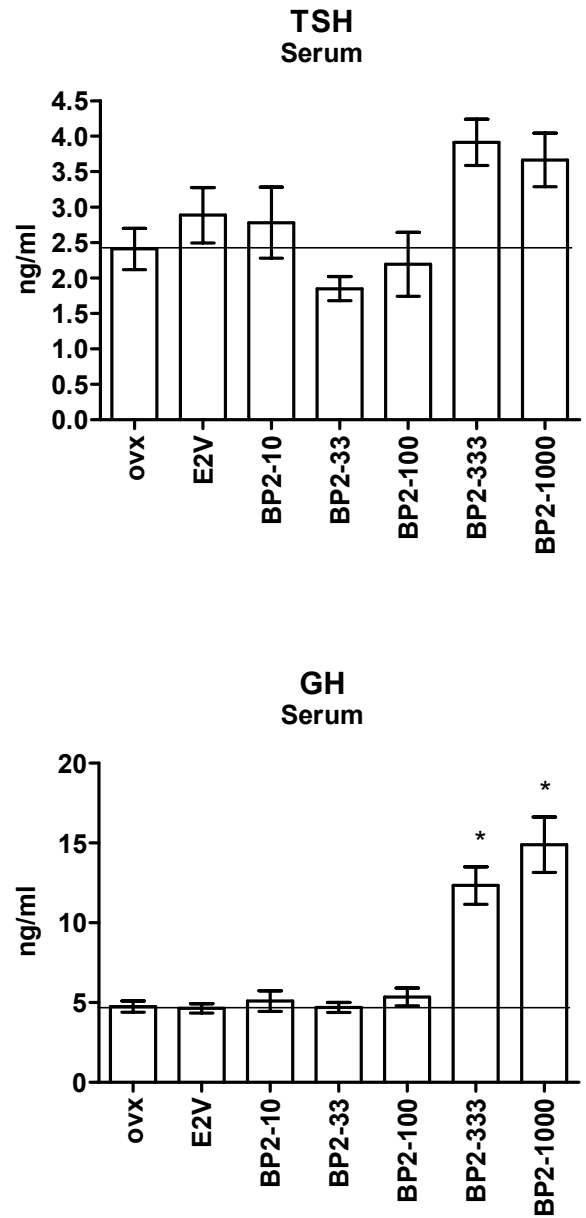
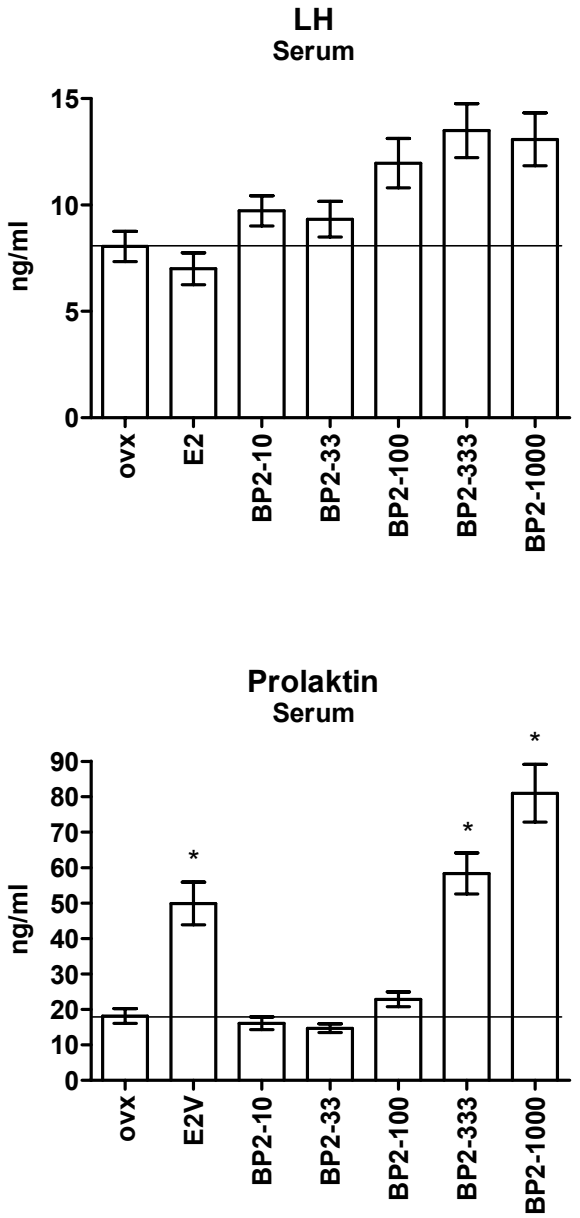

Abbildung 3-17: Serumkonzentrationen der Hypophysenhormone TSH, LH, GH und Prolaktin. * = signifikant gegenüber ovx. 


\subsubsection{Schilddrüsenhormone}

Im Serum wurden die Konzentrationen von freiem T3 und T4 sowie von gesamt-T3 und -T4 bestimmt. Abbildung 3-18 zeigt einen leichten senkenden, aber nicht signifikanten Einfluss von E2V auf den Serumspiegel von T3 und freiem T3. Durch die Behandlung mit BP2 wurden die freien T3-Werte der Gruppen BP2-100 und BP2-333 signifikant gesenkt.

Auf den T4-Spiegel hatte die Behandlung mit E2V keinen Einfluss, auf die Konzentration von freiem T4 einen leicht stimulierenden Einfluss. Der gesamt-T4-Spiegel wurde deutlich dosisabhängig durch die Behandlung mit BP2 gesenkt. Die Serumkonzentration von freiem T4 wurde nur durch die höchste BP2-Dosis signifikant gesenkt.
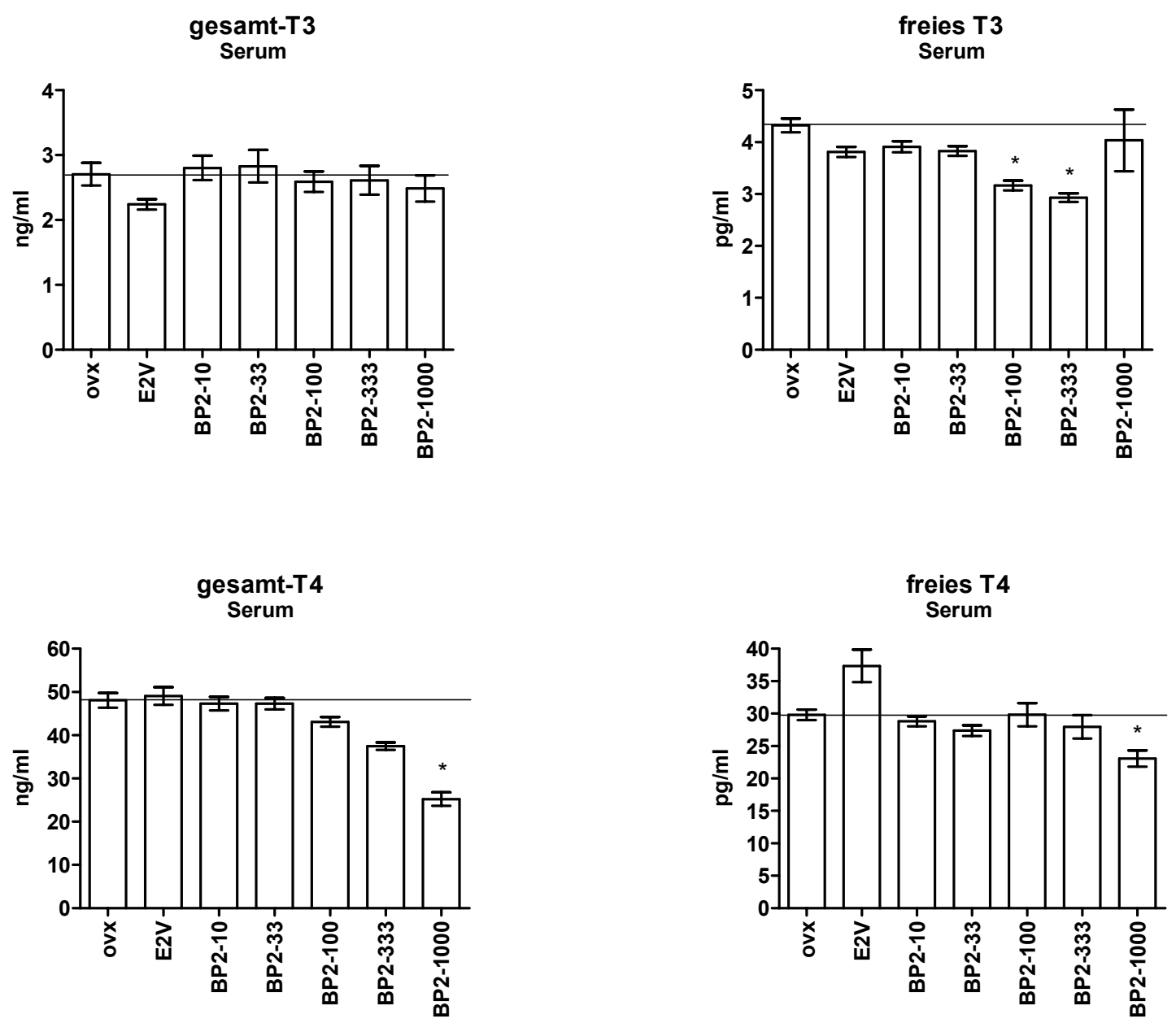

Abbildung 3-18: Serumkonzentrationen der Schilddrüsenhormone. * = signifikant gegenüber ovx. 


\subsubsection{Metabolische Parameter}

Bei allen gemessenen Parametern wurde durch die Behandlung mit E2V eine signifikante Senkung beobacht (Abbildung 3-19). Auch die Applikation von BP2 führte dosisabhängig zu einer E2V-ähnlichen Senkung der Serumspiegel von Cholesterin, HDL und LDL. Die Stärke der Effekte von BP2 in der höchsten Dosis ist mit der Stärke der E2V-Effekte vergleichbar (Cholesterin und LDL) beziehungsweise übersteigt diese im Fall von HDL noch.
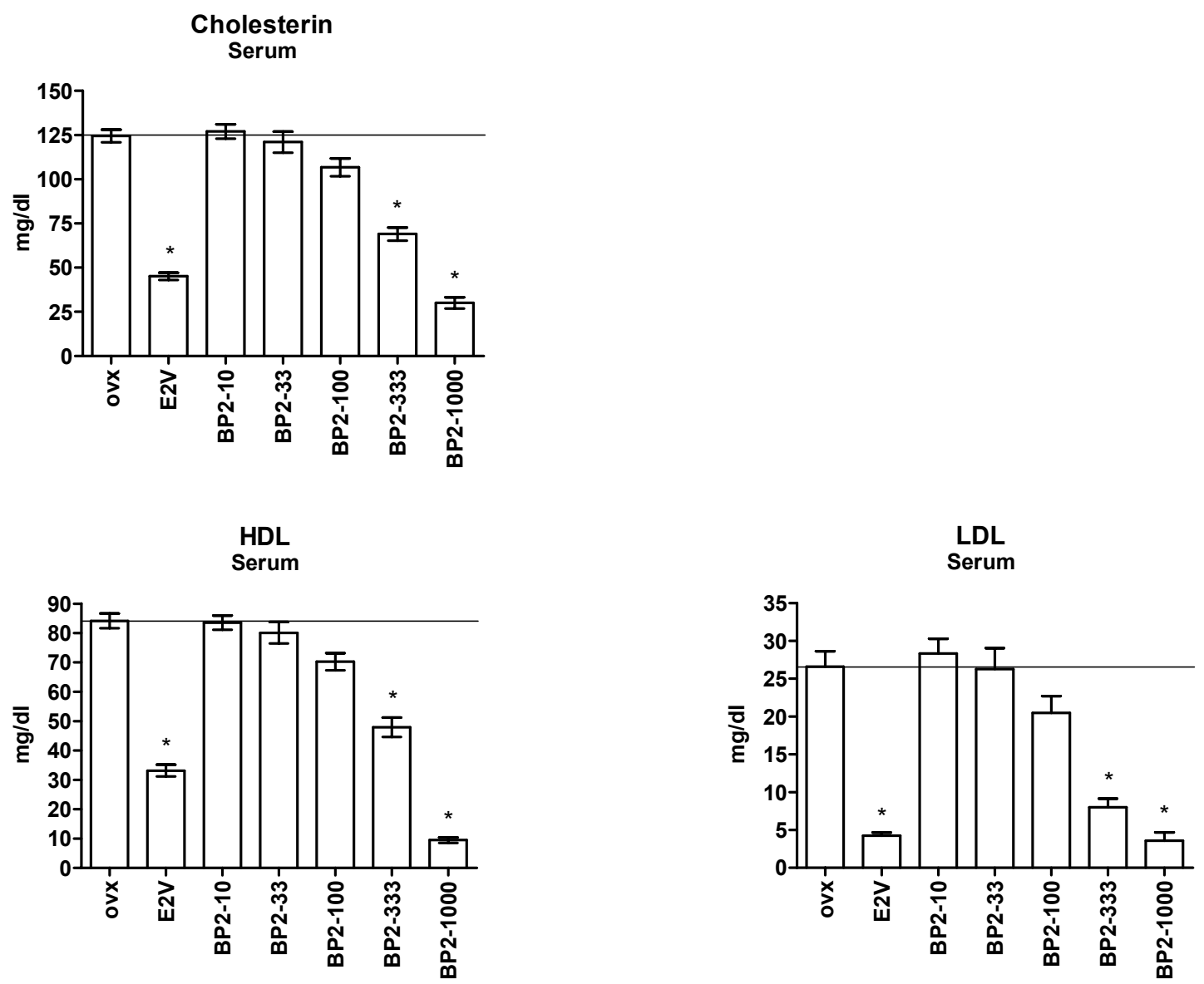

Abbildung 3-19: Cholesterin-, HDL- und LDL-Serumkonzentrationen. * = signifikant gegenüber ovx. 


\subsubsection{Genexpressionsdaten}

\subsubsection{Hypothalamus}

Im mediobasalen Hypothalamus (MBH) wurde die Genexpression der beiden EstrogenRezeptoren (ER) $\alpha$ und $\beta$ untersucht (Abbildung 3-20). Bei beiden Rezeptoren konnte keine signifikante Änderung der Genexpression durch die Behandlung mit E2V oder mit BP2 beobachtet werden. Bei der E2V-Gruppe wurde jedoch ein leichter Anstieg der Expression beider Rezeptoren gemessen.
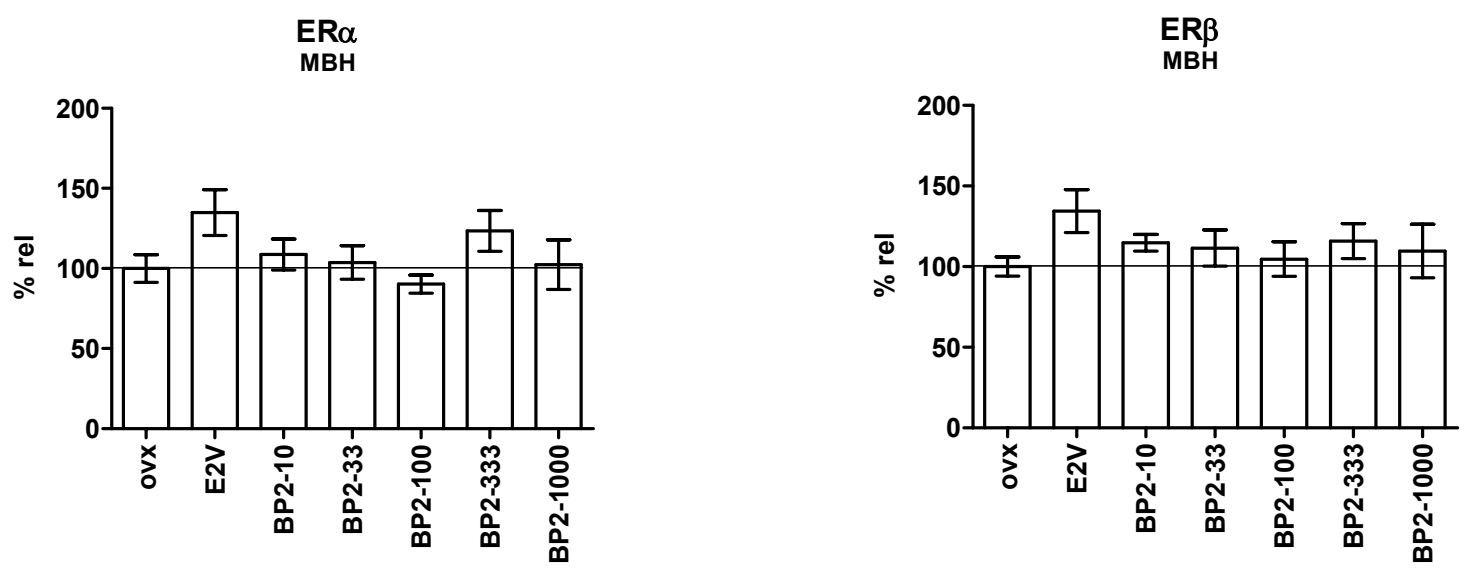

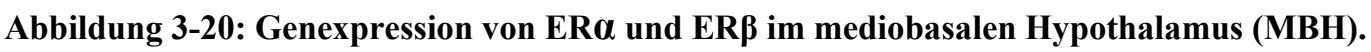

Auch die Genexpression von Prä-Pro-TRH wurde in keiner Behandlungsgruppe signifikant verändert (Abbildung 3-21).

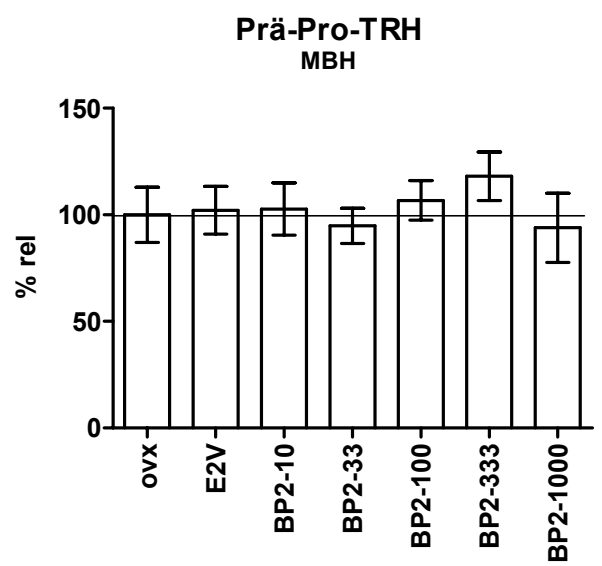

Abbildung 3-21: Genexpression von Prä-Pro-TRH im mediobasalen Hypothalamus. 


\subsubsection{Hypophyse}

In der Hypophyse wurden die Genexpression der Untereinheiten von LH und TSH bestimmt (Abbildung 3-22). Die Expression der $\beta$-Untereinheit von LH zeigte keine signifikanten Veränderungen gegenüber der Kontrolle (ovx). In den höchsten beiden Konzentrationen von BP2 wurde jedoch eine ähnliche Absenkung wie in der E2V-Gruppe beobachtet.

Die Genexpression der $\beta$-Untereinheit von TSH wurde signifikant in den Gruppen BP2-333 und BP2-1000 gesenkt. Auch in den restlichen Behandlungsgruppen wurde die Genexpression gesenkt.

Bei der Genexpression der $\alpha$-Untereinheit zeigten sich keine signifikanten Veränderungen. Ähnlich wie bei LH $\beta$ wurde jedoch eine leichte Senkung in den Gruppen E2V, BP2-333 und BP2-1000 beobachtet.
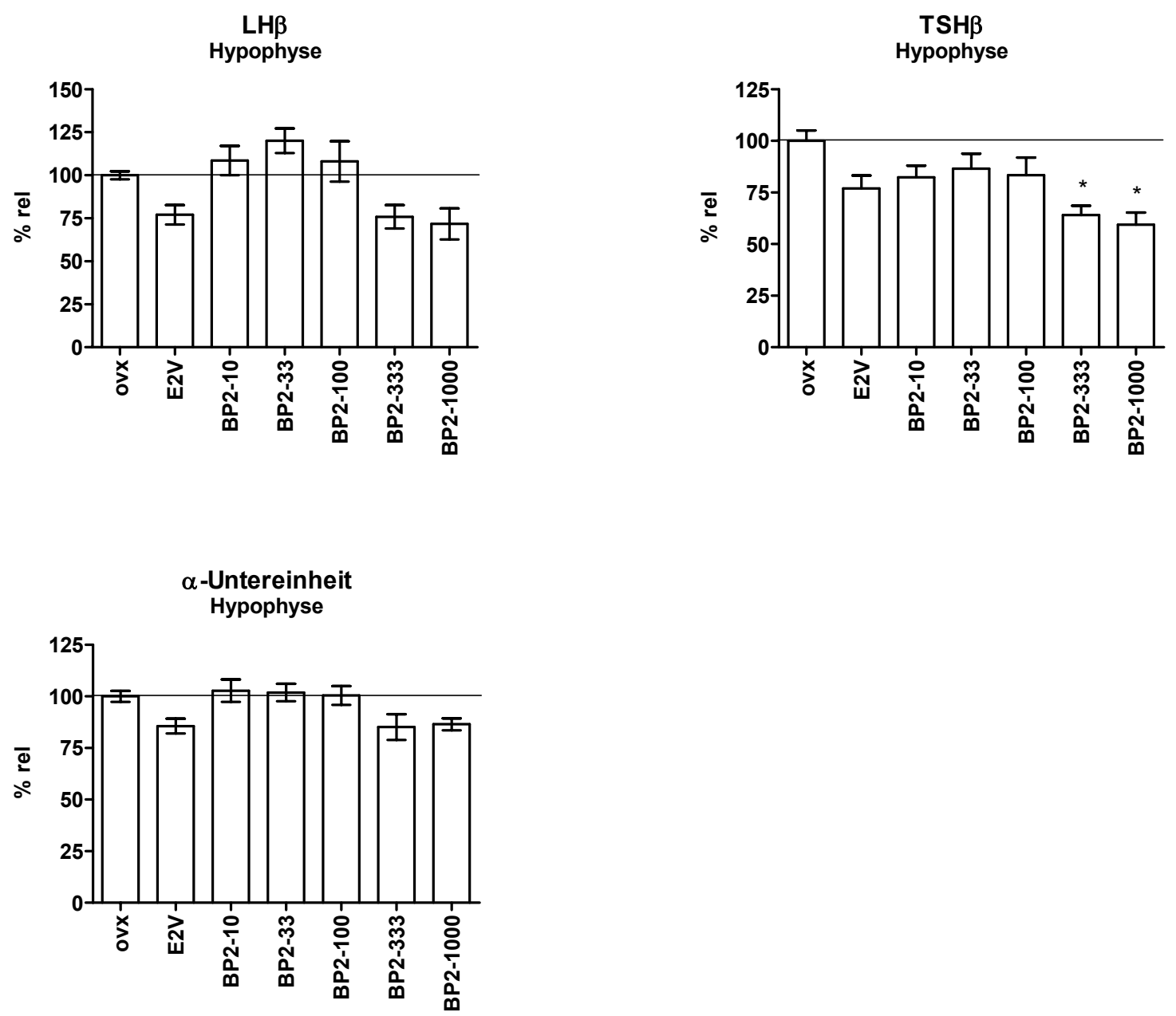

Abbildung 3-22: Genexpression der Untereinheiten von LH und TSH in der Hypophyse. * = signifikant gegenüber ovx. 
Als Marker für eine Estrogen-ähnliche Wirkung wurde die Genexpression von TERP-1 in der Hypophyse bestimmt. In Abbildung 3-23 ist eine signifikante Steigerung der Expression durch die Behandlung mit E2V zu erkennen. Durch die Behandlung mit BP2 wurde schon bei der geringsten Dosierung eine leichte Stimulation der TERP-1-Genexpression beobachtet. Dieser Effekt setzte sich dosisabhängig bei den höheren Dosierungen fort. In den Gruppen BP2-333 und BP2-1000 wurde eine deutlich stärkere Stimulation als in der E2V-Gruppe gemessen. Die Effekte in der BP2-1000-Gruppe liegen etwa 4,3-mal höher, in der BP2-333-Gruppe etwa 2,2-mal höher als in der E2V-Gruppe.

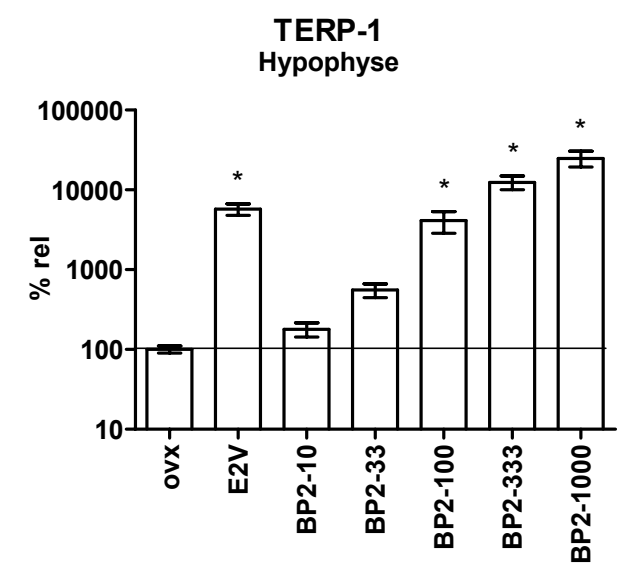

Abbildung 3-23: Genexpression von TERP-1 in der Hypophyse. * = signifikant gegenüber ovx.

Die Genexpression von ER $\alpha$ wurde in der Hypophyse durch keine Behandlung signifikant beeinflusst. Die Genexpression von ER $\beta$ wurde durch E2V und BP2-1000 signifikant vermindert (Abbildung 3-24). 

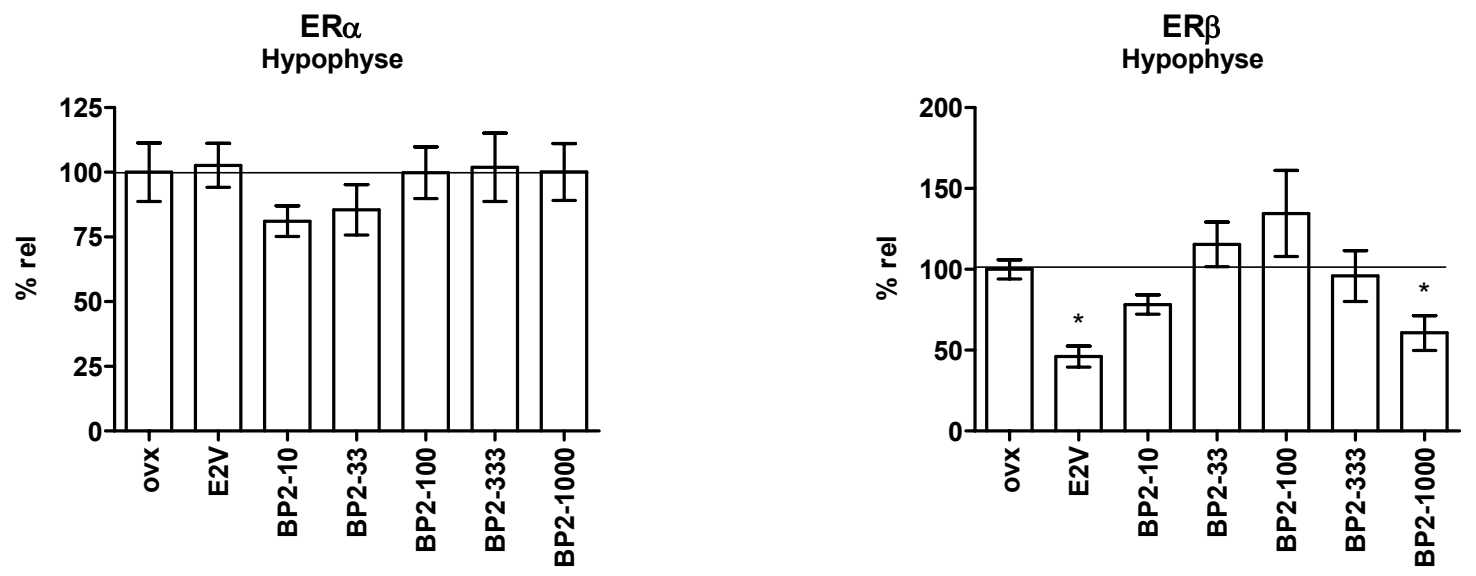

Abbildung 3-24: Genexpression der Estrogen-Rezeptor-Subtypen in der Hypophyse. * $=$ signifikant gegenüber ovx.

\subsubsection{Schilddrüse}

In der Schilddrüse wurde nur die Genexpression von ER $\alpha$ durch die Behandlung mit BP2 in der höchsten Konzentration signifikant gesenkt. Durch E2V wurde jedoch ein ähnlicher Effekt beobachtet. Die Genexpression von ER $\beta$ wurde in keiner Behandlungsgruppe signifikant verändert, obwohl durch BP2 in der höchsten Konzentration eine Steigerung der Expression beobachtet werden konnte.
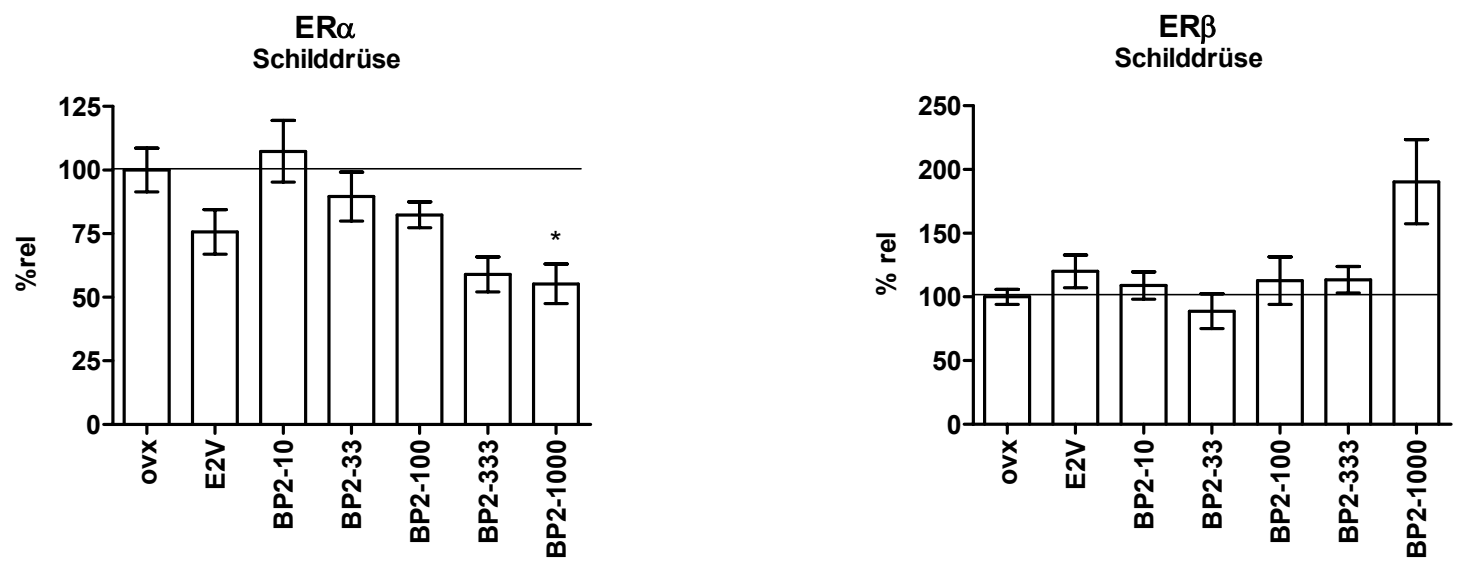

Abbildung 3-25: Genexpression von ER $\alpha$ und ERß in der Schilddrüse. * = signifikant gegenüber ovx. 


\subsubsection{Uterus}

Als Marker für estrogene Wirkung im Uterus wurden die Genexpressionen von IGF-1 und Prä-Pro-C3 gemessen. Bei beiden zeigte sich eine signifikante Steigerung der Genexpression durch BP2 in den Gruppen BP2-333 und -1000. Die Steigerung war in beiden Systemen deutlich dosisabhängig. Auch die Behandlung mit E2V führte zu einer Steigerung der Genexpression in beiden Systemen.
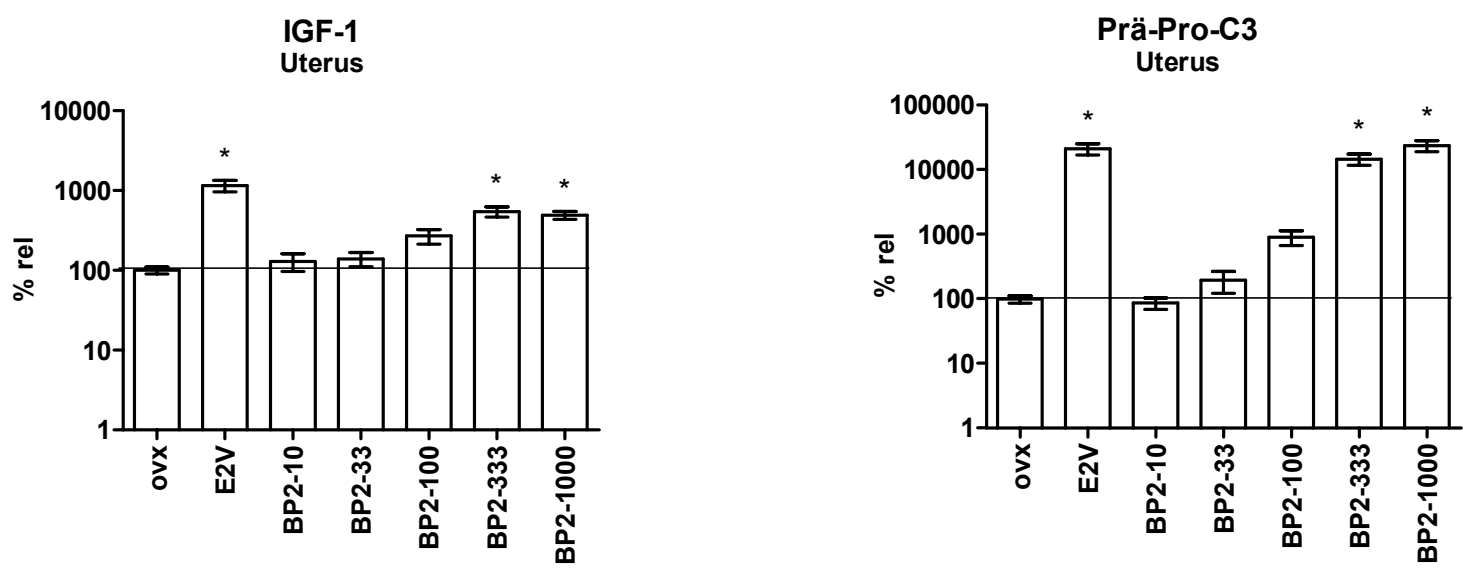

Abbildung 3-26: Genexpression von IGF-1 und Prä-Pro-C3 im Uterus. * = signifikant gegenüber ovx.

Auf die Genexpression von ER $\alpha$ hatte weder die Behandlung mit E2V noch die Behandlung mit BP2 einen Einfluss. Die Genexpression von ER $\beta$ wurde jedoch durch die Gabe von E2V und BP2-333 und BP2-1000 signifikant gesenkt. In den Gruppen BP2-33 und BP2-100 wurde eine leichte Senkung der ER $\beta$-Expression gemessen.
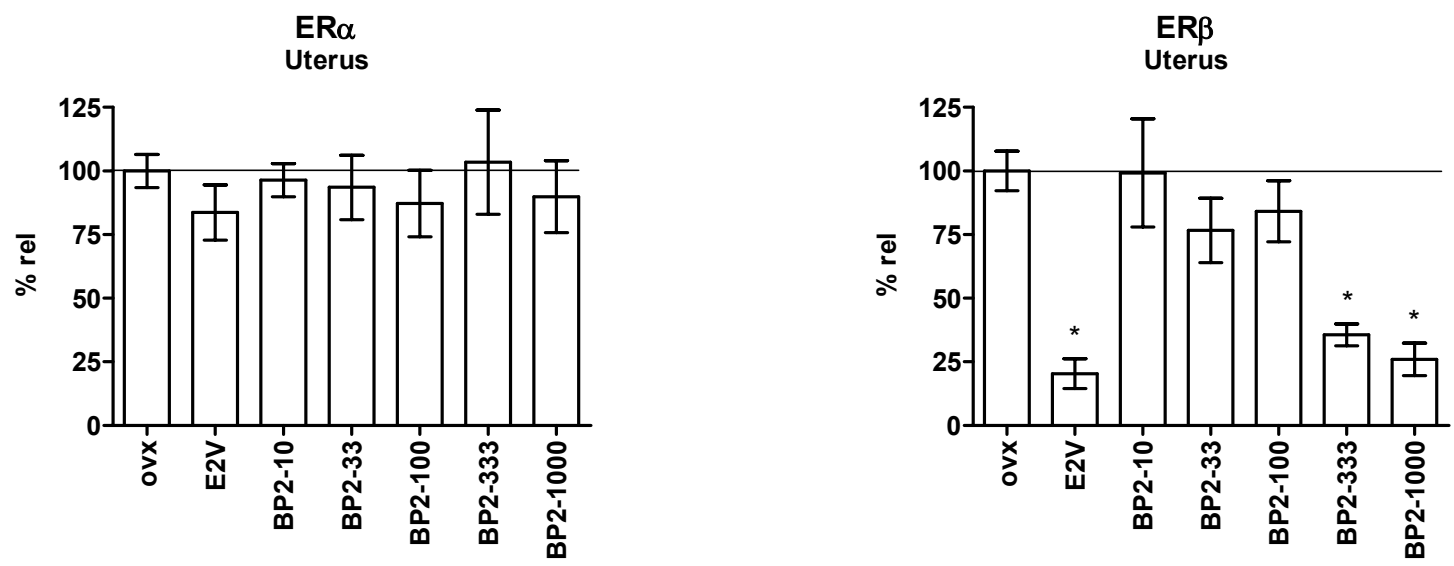

Abbildung 3-27: Genexpression von ER $\alpha$ und ERß im Uterus. * = signifikant gegenüber ovx. 


\subsubsection{Leber}

In der Leber wurde die Genexpression von IGF-1 und ER $\alpha$ untersucht (Abbildung 3-28). Bei beiden Systemen wurde eine signifikante Verringerung der Expression durch E2V und BP2-1000 beobachtet. Die niedrigeren Konzentrationen von BP2 führten ebenfalls in beiden Fällen, zu einer leichten, nicht signifikanten Senkung der Genexpression. Die Expression von ER $\beta$ konnte aufgrund zu geringer Mengen in allen Gruppen nicht mit dem beschriebenen System gemessen werden.
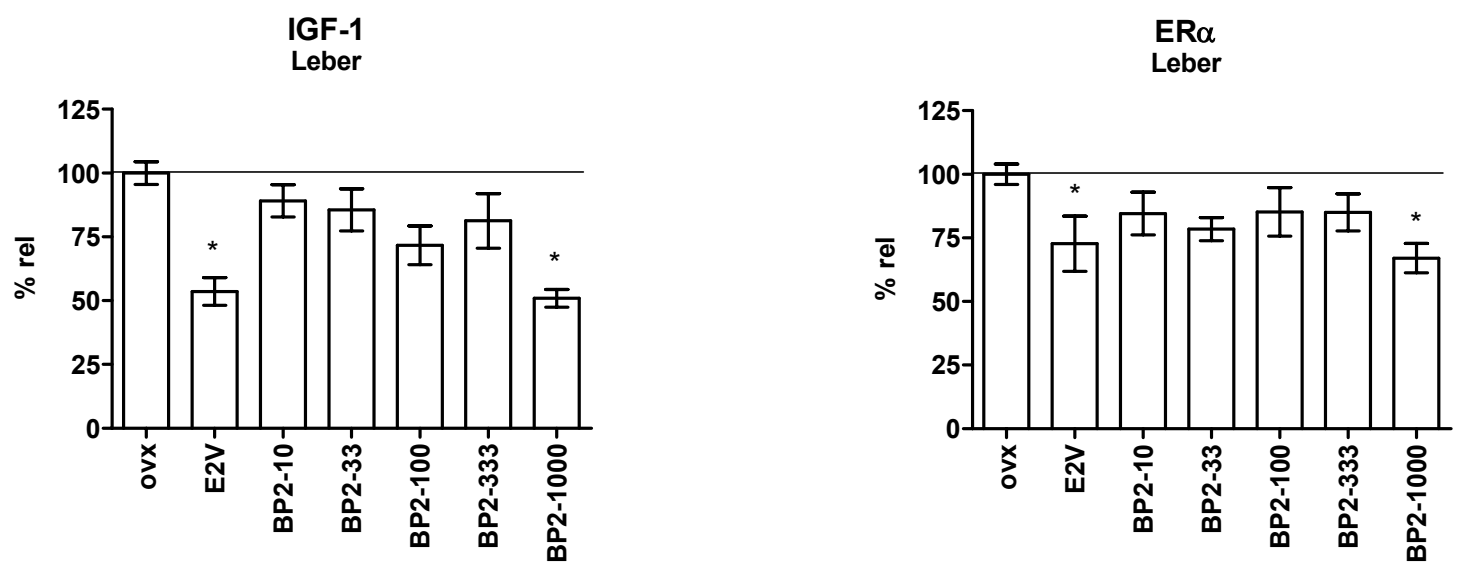

Abbildung 3-28: Genexpression von IGF-1 und ERa in der Leber. * = signifikant gegenüber ovx.

Die Genexpression von Cyp1a1 in der Leber wurde durch BP2 nur minimal in der höchsten Dosierung erhöht (Abbildung 3-29). Diese Erhöhung war jedoch etwa 10.000fach geringer als die Induktion der Genexpression durch 3-Methylcholanthren (3MC), einem Induktor des Cypla1-Systems, der ebenfalls 5 Tage an ovariektomierte Ratten verfüttert wurde. E2V hatte auf die Expression von Cypla1 einen leicht senkenden Einfluss, ebenso wie die niedrigen Dosierungen von BP2. 


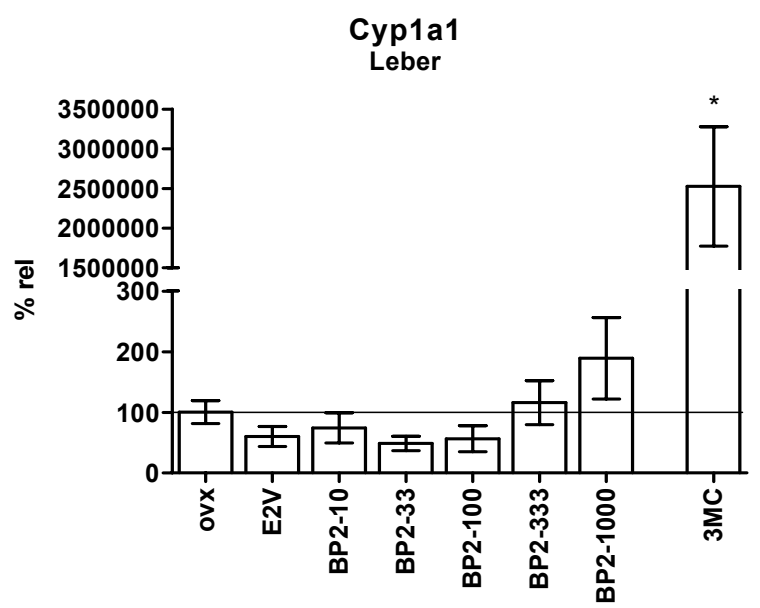

Abbildung 3-29: Genexpression von Cyp1a1 in der Leber. 3MC (= 3-Methylcholanthren) wurde unter gleichen Versuchsbedingungen in einer Dosis von $40 \mathrm{mg} / \mathrm{kg} \mathrm{Kg}$ pro Tag verabreicht. * = signifikant gegenüber ovx.

\subsubsection{Proteinarbeiten}

\subsubsection{5'-Deiodase-Aktivität}

In Abbildung 3-30 ist die Aktivität der Typ I 5'-Deiodase gezeigt. Durch die Behandlung mit E2V und BP2-10 wurde die Aktivität nicht verändert. Durch die Gabe von BP2 in einer Konzentration von $33 \mathrm{mg} / \mathrm{kg} \mathrm{Kg}$ wurde die Aktivität erhöht. Durch die höheren Dosen wurde jedoch eine Erniedrigung der Aktivität beobachtet. Die Aktivität bei der höchsten Dosierung lag unter der Aktivität der Kontrollgruppe. Die Aktivität der Typ II-5'-Deiodase war für eine Auswertung zu gering.

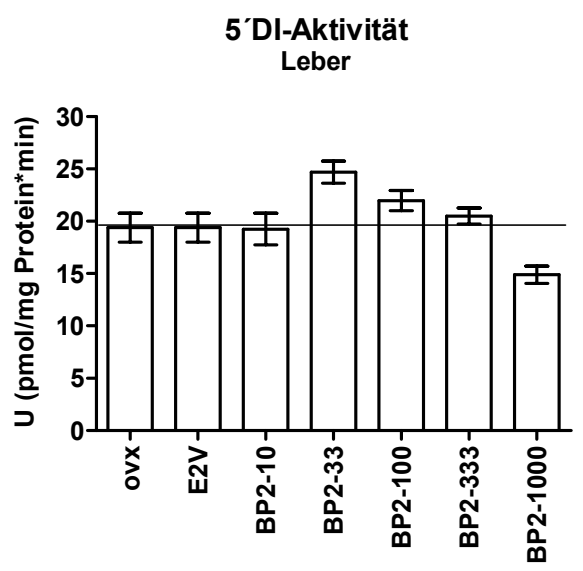

Abbildung 3-30: Typ I 5'-Deiodase-Aktivität in der Leber. 


\subsubsection{Schilddrüsenperoxidase (TPO)-Aktivität}

Die TPO-Aktivität in der Schilddrüse wurde am stärksten, jedoch nicht signifikant in der BP2-100-Gruppe erhöht. In allen anderen BP2-Gruppen, außer der BP2-10-Gruppe, wurde nur eine leichte Erhöhung der TPO-Aktivität beobachtet.

In der E2V-Gruppe konnte keine Veränderung der TPO-Aktivität beobachtet werden.

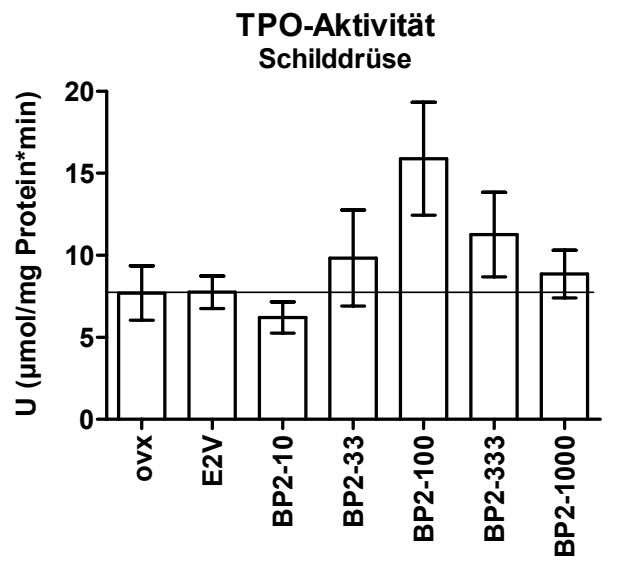

Abbildung 3-31: TPO-Aktivität in der Schilddrüse.

\subsubsection{Natrium/Iodid-Symporter (NIS)-Expression}

Eine Beeinflussung der NIS-Expression durch BP2 konnte im Western-Blot nicht festgestellt werden.

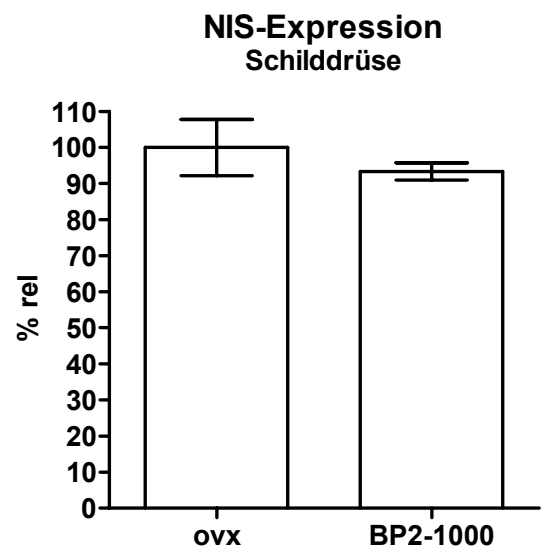

Abbildung 3-32: Proteinexpression des Natrium/Iodid-Syporters in der Schilddrüse. 


\subsubsection{Dosis-Wirkungsbeziehungen}

Für die Parameter mit den stärksten Änderungen wurden Dosis-Wirkungsbeziehungen mit Hilfe der PROAST-Software (Slob 2002) aufgestellt. Diese Parameter waren:

- TERP-1-Genexpression in der Hypophyse

- Prä-Pro-C3-Genexpression im Uterus

- LDL-Konzentration im Serum

Nachfolgend sind die Graphen der Regressionskurven für die einzelnen Parameter dargestellt (Abbildung 3-33).
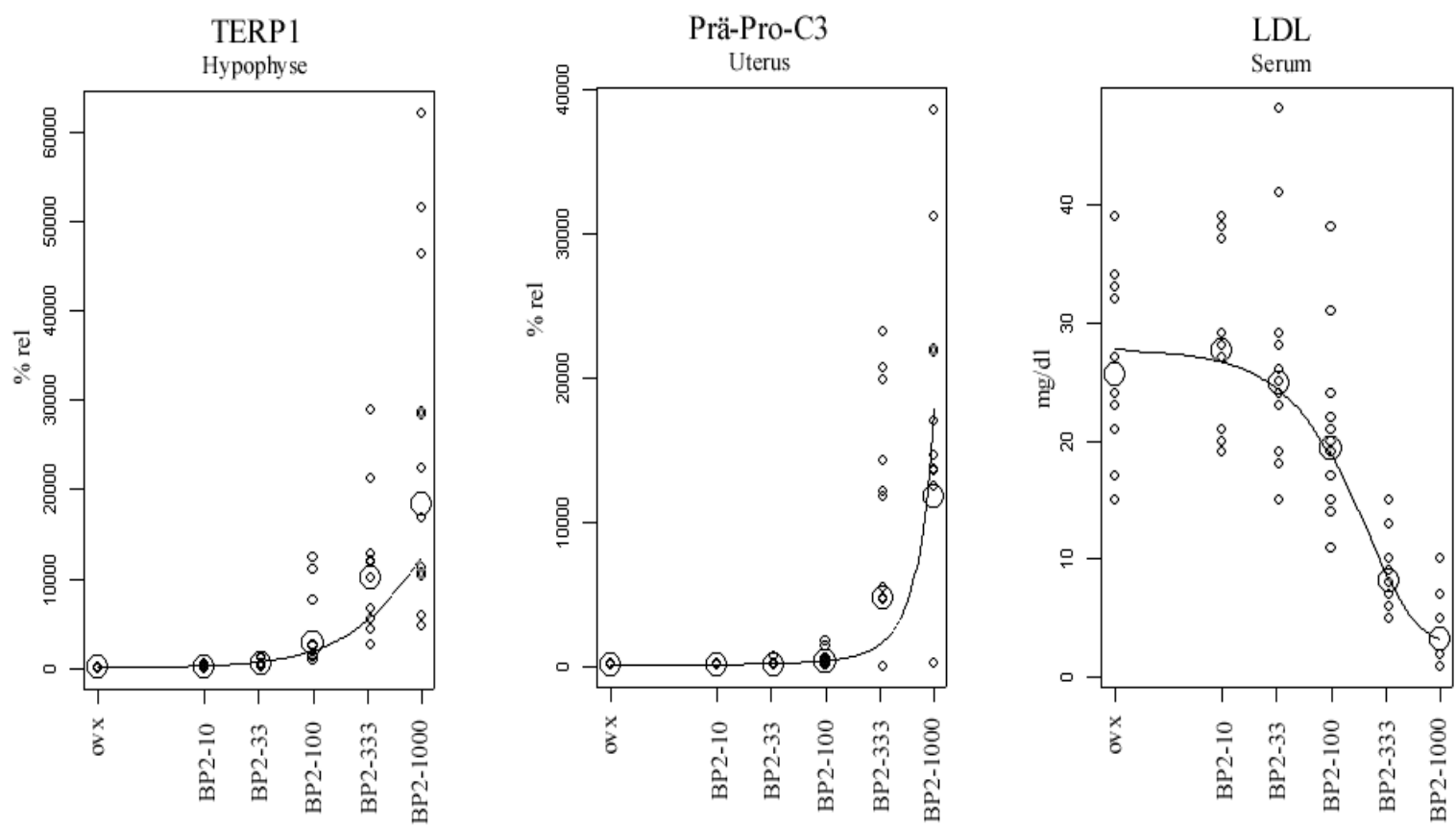

Abbildung 3-33: Graphische Darstellung der nichtlinearen Regression zur Ermittlung der DosisWirkungsbeziehungen. Dargestellt sind die Einzelwerte (kleine Kreise) und der Mittelwert der einzelnen Gruppen (große Kreise). 
Die entsprechenden Dosen (= kritische Effekt-Dosis; CED), bei denen eine Wirkung von mehr als der einfachen Standardabweichung der Kontrollgruppe (= kritische Effekt-Größe; CES) erreicht wurde, sind in der nachfolgenden Tabelle 3-1 angegeben.

Tabelle 3-1: Relevante Werte der Dosis-Wirkungsbeziehungen.

\begin{tabular}{|c|c|c|c|}
\hline Parameter & $\begin{array}{l}\text { CES } \\
(\%)\end{array}$ & $\begin{array}{l}\text { CED } \\
(\mathrm{mg} / \mathrm{kg} \mathrm{Kg})\end{array}$ & vereinfachte Gleichung der Regressionskurve \\
\hline $\begin{array}{l}\text { TERP-1 } \\
\text { (Hypophyse) }\end{array}$ & $+32,95$ & 1,59 & $\begin{array}{l}y=a *\left[c-(c-1) * \exp \left(-b^{*} x\right)\right] \\
a=96,16856 ; b=0,00104 ; c=200,03339\end{array}$ \\
\hline Prä-Pro-C3 (Uterus) & $+44,26$ & 3,24 & $\begin{array}{l}y=a^{*} \exp \left(b^{*} x^{\wedge} d\right) \\
a=55,18802 ; b=0,208 ; d=0,48118\end{array}$ \\
\hline LDL (Serum & $\begin{array}{l}-26,78 \\
(=-7,115 \mathrm{mg} / \mathrm{dl})\end{array}$ & 78,2 & $\begin{array}{l}y=a *[c-(c-1) * \exp (-b * x)] \\
a=27,74055 ; b=0,00457 ; c=0,10819\end{array}$ \\
\hline
\end{tabular}

Für Erklärung der Begriffe siehe Text. $C E S=f(C E D) / f(0)-1$ 


\subsection{Kinetikversuch}

Bei der Bestimmung von P2 und den Metaboliten im Serum zeigte sich, dass die höchste Serumkonzentration bei allen Substanzen bereits nach 30 Minuten erreicht wurde (Abbildung 3-34). Die Menge an BP2 und BP2-Sulfat war zu diesem Zeitpunkt deutlich geringer als die Menge an BP2-Glucuronid. Die Kurve von BP2-Glucuronid fiel jedoch im Gegensatz zu den beiden anderen Substanzen schnell ab und erreichte nach 180 Minuten etwa das Niveau von BP2 und BP2-Sulfat.

Im Urin wurde ein Maximum aller Substanzen erst nach 120 Minuten festgestellt. Bis zu diesem Zeitpunkt stiegen die Messwerte kontinuierlich an. Auch bei diesen Messungen lagen die Anteile an BP2-Glucuronid deutlich über den Anteilen von BP2 und BP2-Sulfat. Im Vergleich zum Serum waren die gemessenen Werte insgesamt deutlich höher.
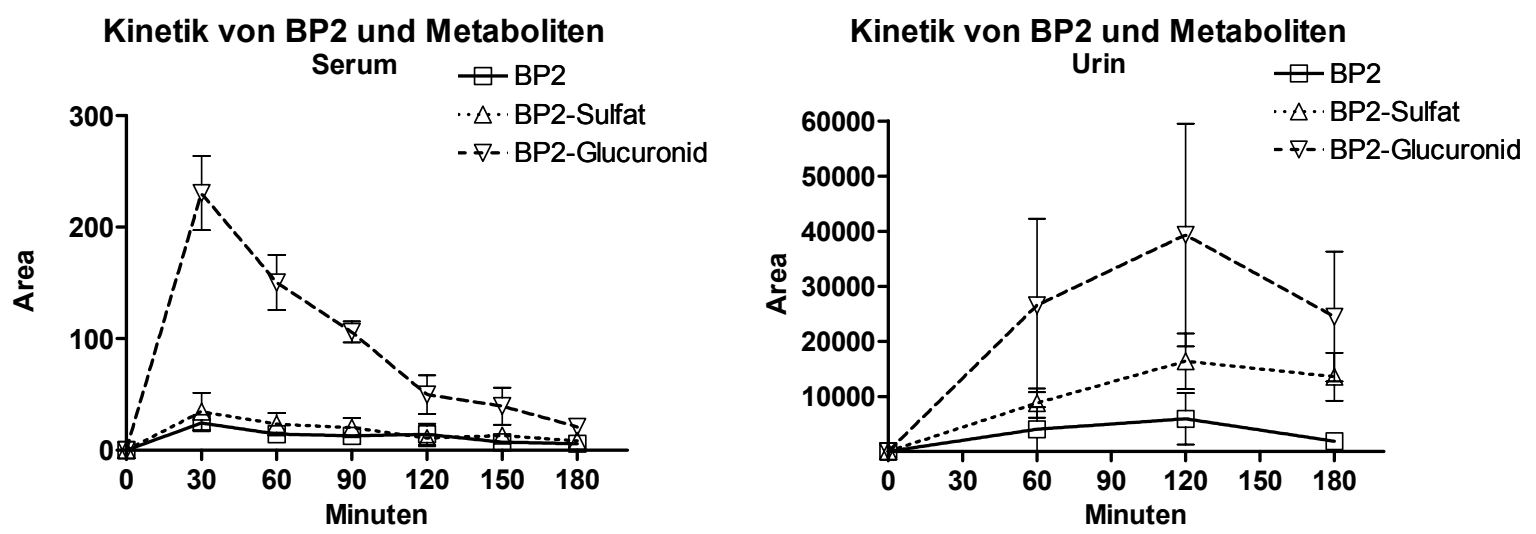

Abbildung 3-34: Messung von BP2 und den Metaboliten im Serum und im Urin. Die Bestimmung erfolgte per UV-Detektion bei $280 \mathrm{~nm}$ nach einer Trennung durch HPLC. Angegeben sind die Flächen der Peaks, da für die Metabolite keine Standardkurve erstellt werden konnte. 


\section{Diskussion}

Aus den in dieser Arbeit erhaltenen Ergebnissen ist ersichtlich, dass BP2 in den meisten der beobachteten Parameter eine Estrogen-ähnliche Aktivität besitzt und somit als ein Xenoestrogen bzw. eine EAC anzusehen ist.

Darüber hinaus wurden nicht Effekte von BP2 auf die GH- und LH-Sekretion gefunden, die, falls sie auch in männlichen Tieren zu beobachten sind, durch eine antiandrogene Aktivität von BP2 erklärt werden könnten.

In der HPT-Achse wurde eine nicht Estrogen-ähnliche Wirkung von BP2 auf die Schilddrüse identifiziert. Die Ergebnisse zeigen, dass in diesem Fall ein uterotropher Assay nicht ausreichend gewesen wäre, um das gesamte endokrine Potential von BP2 aufzudecken.

Es wurde gezeigt, dass BP2 in vivo metabolisiert wurde. Die Metabolite konnten identifiziert werden und die Kinetik der Exkretion wurde untersucht.

Aus den erhaltenen Daten wurden Dosis-Wirkungsbeziehungen aufgestellt, die als Grundlage für eine Risiko-Bewertung herangezogen werden können.

\subsection{Bestätigung der estrogenen Aktivität von BP2 durch screening-Methoden}

Die Testsubstanz BP2 entfaltet in den in dieser Arbeit benutzten in vitro-Testsystemen eine estrogene Wirkung.

Im RBA verdrängte BP2 das radioaktiv markierte E2 ab einer Konzentration von etwa $100 \mathrm{nM}$. Der $\mathrm{EC}_{50}$-Wert von BP2 liegt bei einer Konzentration von $495 \mathrm{nM}$, während der $\mathrm{EC}_{50}$-Wert von „kaltem“ E2 bei einer Konzentration von 0,47 nM liegt. Damit hat BP2 nur ein 1000stel der Potenz von E2.

In Untersuchungen von funktionellen Gruppen wurde ein mit Hydroxylgruppen in ortho- und para-Position substituierter Phenolring als essentiell für die Bindung an das aktive Zentrum des ER identifiziert. Deshalb war eine Bindung von BP2 an den ER wahrscheinlich. Bei eigenen Untersuchungen von anderen Benzophenon-Derivaten (BP1, BP3) sowie der chemischen Grundstruktur Benzophenon im RBA (Daten nicht gezeigt) stellte sich BP2 als der stärkste Ligand heraus. Wodurch die Hypothese von Nishihara et al. (2000) experimentell bestätigt wurde, nach der Hydroxylgruppen in ortho- und para-Stellung am Phenylring strukturelle Hinweise auf eine estrogene Aktivität geben. 
2,4 Dihydroxybenzophenon (BP1) wurde im RBA mit einem $\mathrm{EC}_{50}$ von $3,65^{*} 10^{-5} \mathrm{M}$ getestet (Blair et al. 2000). Im Vergleich zu anderen Arbeitsgruppen liegen die eigenen Ergebnisse für BP1 bei einem $\mathrm{EC}_{50}$ von $1,67 * 10^{-5} \mathrm{M}$. Damit sind die Messwerte des RBA mit den Ergebnissen anderer Arbeitsgruppen vergleichbar. Mit diesen Ergebnissen wurde BP2 verlässlich und reproduzierbar als Ligand für E2-Bindestellen identifiziert.

Obwohl der Rezeptorbindungsassay ein weltweit angewandter Assay für die Identifikation von Rezeptor-Liganden ist, erlaubt er keine Aussage über die Art der Wirkung am Rezeptor. Es wurde nur die Bindung von BP2 an den Rezeptor festgestellt; ob die Substanz jedoch in der Lage ist, die Rezeptorkonformation für eine agonistische oder antagonistische Funktion zu verändern, ist aus diesem Test nicht abzuleiten.

Der Endpunkt des Proliferationsassays ist die biologische Antwort auf das estrogene Signal. Das Wachstum der MCF-7-Zellen wurde ab einer Konzentration von $1 * 10^{-6}$ M BP2 stimuliert und erreichte bei einer Konzentration von $1 * 10^{-5} \mathrm{M}$ das gleiche Niveau wie in der Positivkontrolle mit E2 $1 * 10^{-8} \mathrm{M}$. BP2 entfaltete hier also eine eindeutige Estrogenagonistische Wirkung. Bislang sind noch keine Vergleichsdaten zu BP2 veröffentlicht. Die wirksame Konzentration von BP2 liegt hier allerdings im gleichen Bereich wie die des RBAs. Für ER $\alpha$-negative MCF-7-Zellen konnte gezeigt werden, dass diese Zellen nicht mit Proliferation auf Estrogen reagieren (Zhang et al. 2005). Erst eine Re-Expression von ER $\alpha$ führte zur Proliferation bei Estrogengabe (Oesterreich et al. 2001). Die E2-induzierte Proliferation wird in MCF-7-Zellen also über den ER $\alpha$ vermittelt. Die Ergebnisse des in dieser Arbeit vorgestellten Proliferationsassays lassen demnach darauf schließen, dass BP2 den agonistischen Effekt über den ER $\alpha$ ausübt.

Im Transaktivierungsassay in MCF-7-Zellen wurde gezeigt, dass die Testsubstanz BP2 über die Fähigkeit verfügt, über beide Subtypen des ER die Expression des Reporters zu induzieren. Bei der Testsubstanz BP2 zeigte sich die Aktivierung der Luciferase-Aktivität ab einer Konzentration von $3 * 10^{-8} \mathrm{M}$ in MELN-ER $\beta$-Zellen und ab einer Konzentration von $3 * 10^{-7} \mathrm{M}$ in MELN-ER $\alpha-Z e l l e n$. Die ermittelten $\mathrm{EC}_{50}$-Werte liegen für MELN-ER $\alpha$ bei $320 \mathrm{nM}$ und für MELN-ER $\beta$ bei $120 \mathrm{nM}$. Hier zeigt sich, dass BP2 eine 2,7fach geringere Affinität zum ER $\alpha$ aufweist. Trotz der in diesem Assay ermittelten Präferenz für ER $\beta$ ist die Bindung an ER $\alpha$ ausreichend, um die ER $\alpha$-abhängige Proliferation der MCF-7-Zellen zu 
induzieren. Das endogene Estradiol hingegen hat eine vergleichbare Affinität zu beiden Rezeptorsubtypen (Kuiper et al. 1998). Somit könnte in vivo ein von E2 abweichender Effekt $\mathrm{zu}$ erwarten sein, möglicherweise hat BP2 SERM-Eigenschaften. In einer aktuellen Veröffentlichung wurde BP2 in einem ähnlichen Transaktivierungssystem in MCF-7-Zellen auf die Fähigkeit der Induktion eines Estrogen-regulierten Reporters getestet (Suzuki et al. 2005). Der ermittelte $\mathrm{EC}_{50}$-Wert lag in dieser Studie bei $300 \mathrm{nM}$. Dieses System verfügte allerdings nicht über die Möglichkeit, spezifisch die beiden ER-Subtypen zu überprüfen, da die Rezeptoren nicht einzeln überexprimiert wurden. Das Ergebnis entspricht dem $\mathrm{EC}_{50}$-Wert der Transaktivierung über den ER $\beta$.

Auch zeigte sich hier eine deutlich bessere Sensitivität des Transaktivierungsassays im Vergleich zum RBA und zum Proliferationsassay, da der durchschnittliche $\mathrm{EC}_{50}$-Wert für BP2 zwei Potenzen geringer ausfällt. Die deutlich bessere Sensitivität von Transaktivierungsassays wurde auch schon von Korach beschrieben (Korach et al. 1995).

Im EROD-Assay konnte eine minimale Induktion der EROD-Aktivität bei einer Konzentration von $1 * 10^{-4}$ M BP2 gezeigt werden. Die Induktion betrug jedoch nur 9,5\% der maximalen Induktion durch die Positivkontrolle 3MC. Bei der Koinkubation konnte ebenfalls nur eine leichte Induktion festgestellt werden. Diese Beobachtungen werden durch die ebenfalls geringe Induktion der Cypla1-mRNA-Expression in der Leber gestützt. Die Induktion beträgt hier jedoch nur ein 25.000stel der Positivkontrolle mit 3MC. Eine Wirkung von BP2 als AhR-Ligand auf estrogene Signalwege kann aufgrund der geringen Induktion durch BP2 ausgeschlossen werden.

\subsection{Auswirkungen von BP2 in vivo}

\subsubsection{Auswirkungen von BP2 auf metabolische Parameter}

Die Tiere der E2V-Behandlungsgruppe verloren während der 5tägigen Behandlung an Körpergewicht. Dies resultierte in einem geringfügig niedrigeren Körpergewicht am letzten Tag des Versuches im Vergleich $\mathrm{zu}$ den anderen Behandlungsgruppen. Die BP2-Behandlungsgruppen zeigten einen leichten Anstieg während des Versuches mit Ausnahme der BP2-1000-Gruppe, in der das Tiergewicht im Verlaufe des Versuches 
ebenfalls leicht absank. Obwohl die Tendenz erkennbar war, blieb das Tiergewicht am fünften Tag der Behandlung nahezu unverändert.

Die Serum-Konzentrationen von Cholesterin, HDL und LDL waren sehr deutlich durch E2V beeinflusst. E2V senkte die Konzentration aller drei Parameter signifikant. In den BP2Behandlungsgruppen war der gleiche Effekt ab der BP2-100-Gruppe zu erkennen. In der BP21000-Gruppe wurde die maximale Wirkung von E2V noch übertroffen. Damit konnte der in der Literatur beschriebene estrogene Effekt auf die Serumlipidparameter (Lundeen et al. 1997) in der vorliegenden Arbeit auch für BP2 nachgewiesen werden.

Die Leber unterliegt als zentrales Organ des Metabolismus einer Regulation durch E2. Als Estrogen-regulierter Parameter der Leber wurde die Genexpression von IGF-1 bestimmt. In der Literatur wurde eine Senkung des IGF-1-Serumspiegels und der-Genexpression in der Leber nach E2-Administration beschrieben (Krattenmacher et al. 1994). In der vorliegenden Arbeit konnte dies für E2V bestätigt werden. Auch in der BP2-1000-Gruppe zeigte sich ein Estrogen-ähnlicher Effekt auf die IGF-1-Genexpression.

GH ist ein wichtiges Hormon in der Regulation des Metabolismus und der Entwicklung. Die Behandlung der Versuchstiere mit BP2 verursacht eine starke Induktion in der GH Sekretion in der Hypophyse, wie an den Serumspiegeln zu erkennen ist. Dieser Effekt konnte durch E2V nicht hervorgerufen werden. Bei der Untersuchung der Aktivität von UV-Filtern in einem Reportergenassay für Estrogene und Androgene wurde BP2 als potentes Antiandrogen identifiziert (Suzuki et al. 2005). Für andere Antiandrogene ist gezeigt worden, dass diese den GH-Serumspiegel in Männchen erhöhen können (Metzger et al. 1993). Es könnte sich hier demnach um einen nicht-estrogenen sondern einen ,antiandrogenen“ Effekt der Testsubstanz handeln (siehe auch LH-Sekretion).

\subsubsection{Beeinflussung des ERa /ER $\beta$-Status durch BP2}

Nach der Yin/Yang-Theorie bzw. der Erweiterung der Funktion in der Aufteilung nach Proliferation und Differenzierung wird postuliert, wie wichtig das Verhältnis der Expression der beiden Subtypen in Organen ist, in denen sie koexprimiert werden.

Im Hypothalamus wurde die Genexpression beider ERs durch die Behandlung mit E2V leicht hochreguliert. Das Verhältnis der Expression von ER $\alpha$ und ER $\beta$ änderte sich dadurch allerdings nicht. Es konnte gezeigt werden, dass die Genexpression beider ERs während des Zyklus in Abhängigkeit der E2-Serumkonzentration reguliert wird (Hatoya et al. 2003). 
Damit wird das System in seiner Sensitivität an die verfügbare Menge des Induktors angepasst.

BP2 hat auf die Genexpression der beiden ERs im MBH keinen erkennbaren Einfluss, wodurch sich auch das Verhältnis der beiden Rezeptoren zueinander nicht ändert. Das System wird somit nicht sensitiver, wird aber auch in seiner Funktion nicht beeinträchtigt.

In der Hypophyse wurde der ER $\alpha$ durch E2V auf der Ebene der mRNA nicht reguliert, während die Expression des ER $\beta$ deutlich auf unter $50 \%$ im Vergleich zur Kontrollgruppe sank. Dies deckt sich mit der Arbeit von Schreihofer et al., die allerdings auf der Proteinebene ein Absinken der ER $\alpha$-Konzentration zeigen konnten (Schreihofer et al. 2000). Tena-Sempere et al. zeigten eine Stimulation der hypophysären ER $\beta$-Expression nach Ovariektomie, welche durch Gabe von E2-benzoat auf das Niveau intakter Tiere gesenkt werden konnte (TenaSempere et al. 2004). Dieser Effekt wird über ER $\alpha$ vermittelt, da der ER $\beta$-Agonist Diarylpropionitril (DPN) keine senkende Auswirkung auf die ER $\beta$-Expression hat.

Es wird vermutet, dass die Regulation der ERs in der Hypophyse eine wichtige Rolle bei der Hemmung der Induktion des prä-ovulatorischen LH-, FSH- und Prolaktin-Anstieges spielt (Schreihofer et al. 2000). Ein Ansteigen des E2-Serumspiegels führt direkt in der Hypophyse sowie indirekt über GnRH zu einem Ansteigen der Sekretion von LH, FSH und Prolaktin. Die Hemmung der ER-Expression unterbricht diesen positiven feedback-Mechanismus durch eine Desensibilisierung der estrogenen Signalwege. Zusätzlich wird die TERP-1-Genexpression induziert. TERP-1 agiert als Repressor der ER-vermittelten Wirkung, da die ERs durch die Bildung von inaktiven Heterodimeren gebunden werden (Resnick et al. 2000).

In den Behandlungsgruppen zeigte sich erst in der BP2-1000-Gruppe eine signifikante Hemmung der Genexpression des ER $\beta$. Die maximale Hemmung erreichte nicht das Niveau der E2V-Behandlungsgruppe, allerdings wurde die Funktion des Systems, das sich aus dem Verhältnis der beiden ERs definiert, in der gleichen Weise moduliert wie unter E2-Behandlung. Obwohl in den in vitro-Untersuchungen eine Präferenz für ER $\beta$ gezeigt wurde, ist BP2 in der Lage, in vivo ER $\alpha$-regulierte Systeme als Agonist zu beeinflussen. Die Funktion des Systems wird in der Hypophyse in der gleichen Weise wie durch E2 moduliert. BP2 wirkt auf die Regulation des ,Zyklus“ als reines Estrogen.

Die Expression des ER $\alpha$ im Uterus wurde durch die E2V-Behandlung nicht beeinflusst, während die Genexpression des ER $\beta$ noch stärker reprimiert wurde, als bereits in der Hypophyse beobachtet. Hier wird eine Veränderung der Signalwirkung des E2 durch die 
Modulation des ER-Expressionssystems noch deutlicher. Ähnlich wie in der Hypophyse wurde von Murata et al. eine verstärkte ER $\beta$-Expression nach Ovariektomie beschrieben, die nach E2-Gabe auf das Niveau der intakten Kontrolle zurückfiel (Murata et al. 2003).

Die E2-Administration führt zu gravierenden Veränderungen im Uterus. Im Zuge dieser Veränderungen wird die ER $\beta$-Expression drastisch reduziert. Eine mögliche Interpretation ist, dass die Entfernung des ER $\beta$ als Antagonist der ER $\alpha$-Wirkung dafür sorgt, dass das estrogene Signal von E2 über ER $\alpha$ diese Veränderungen einleiten kann. Unter der Annahme, dass die ER-Subtypen eine unterschiedliche Funktion in der Regulation der Reproduktion einnehmen, bedeutet eine annähernde Elimination des ER $\beta$ eine Stärkung des ER $\alpha$-vermittelten Signals.

In den BP2-Behandlungsgruppen wurde eine deutliche Tendenz beobachtet. Die Repression der ER $\beta$-Genexpression erreicht in den Gruppen BP2-333 und BP2-1000 das Niveau der E2V-Gruppe. Das Expressionssystem der ER erfährt dieselbe Modulation wie unter E2V-Behandlung. Damit zeigt BP2 im Uterus eine klare estrogene Wirkung in Bezug auf die Remodulierung der estrogenen Signalwege.

In der Schilddrüse wurde die Expression des ER $\alpha$ unter E2V-Einfluss leicht reprimiert. Die Expression des ER $\beta$ hingegen blieb unverändert. Damit sinkt das Verhältnis von ER $\alpha$ zu ER $\beta$. Die Behandlung mit BP2 senkte die ER $\alpha$-Expression signifikant auf ein mit der E2V-Gruppe vergleichbares Niveau. Die ER $\beta$-Expression hingegen wurde bei der hohen Dosierung von BP2 (BP2-1000) auf über $150 \%$ erhöht. Die Tendenz der Verschiebung des ER $\alpha / E R \beta-$ Verhältnisses bleibt dabei gleich, wird aber durch die Hochregulation von ER $\beta$ noch verstärkt. Die genauen Funktionen der beiden ER-Subtypen in der Schilddrüse sind bislang unbekannt. Allerdings wurde die Regulation der Schilddrüsenfunktion durch Estrogene beschrieben (Cidlowski et al. 1975; Bray et al. 1976). Anhand dieser Daten wird deutlich, dass BP2 in der Schilddrüse einen von E2 abweichenden Effekt auf die Expression von ER $\alpha$ und ER $\beta$ ausübt. Inwieweit diese Effekte eine biologische Relevanz haben, muss in weiteren Versuchen geklärt werden.

In der Leber konnte nur die Genexpression von ER $\alpha$ bestimmt werden, da Hepatozyten nur $\mathrm{ER} \alpha$ exprimieren (Alvaro et al. 2000). ER $\beta$ wird nur von einigen speziellen Zelltypen wie zum Beispiel den Kupffer'schen Sternzellen und Cholangiozyten exprimiert und ist daher kaum nachweisbar. In diesem Experiment wurde die ER $\alpha$-Expression sowohl durch E2V als auch durch BP2 gesenkt. Die Genexpression von ER $\alpha$ in der Leber wird direkt durch 
Estrogene reguliert. Durch Ovariektomie sinkt die mRNA-Konzentration, während eine Behandlung mit E2 diese wieder das Niveau von intakten Tieren anhebt (Xu et al. 2004).

Die Tendenz der Veränderung der Expression des ER $\alpha$ stimmt somit hier nicht mit der Literatur überein, dennoch zeigt BP2 in diesem Versuch ein rein estrogenes Verhalten. Eine mögliche Ursache könnten Splice-Varianten sein, die mit dem beschriebenen Messsystem nicht erfasst werden konnten. Da das Taqman ${ }^{\mathrm{TM}}$-Prinzip nur für die Amplifikation kurzer Sequenzen konzipiert wurde, können nicht alle alternativen Transkripte, wie sie auch für ER $\alpha$ beschrieben wurden (Herynk et al. 2004), erfasst werden.

\subsubsection{Auswirkungen von BP2 auf die HPG-Achse}

- Hypothalamus: Mit der Hypothalamuszellkultur wurde ein biologischer Endpunkt überprüft. Die Testsubstanz BP2 erreichte eine maximale, mit E2 vergleichbare Hemmung der GnRH-Sekretion bei einer Konzentration von $1 * 10^{-5} \mathrm{M}$.

In vivo wurde für E2 sowohl eine Induktion der GnRH-Sekretion als auch eine Repression abhängig vom Zeitpunkt der Tötung der Versuchstiere, der Behandlungsdauer, der Kastrationsdauer, der E2-Dosis und der Position der Neurone im Hypothalamus beschrieben (Herbison 1998). In vitro konnte dagegen die Repression der GnRH-mRNA-Expression in GT1-7 und JEG-3-Zellen durch E2 in Abhängigkeit von der ER $\alpha$-Konzentration in der Zelle gezeigt werden (Roy et al. 1999; Chen et al. 2001). Damit konnte ein Einfluss von BP2 auf ein biologisches System über ER $\alpha$ gezeigt werden. Andere Arbeitsgruppen postulieren einen anderen Mechanismus für das negative feedback der Estrogene auf die GnRH-Sekretion. Ein konstitutiver ER $\beta$ ist in der Lage, über zwei bislang unbekannte EREs im Promotor des GnRH-Gens dessen Expression konstitutiv zu induzieren. Erst die Bindung durch einen Liganden verändert die Konformation des Rezeptors und inaktiviert ihn (Pak et al. 2005). Das erklärt auch die erhöhten LH-Serumspiegel nach der Kastration von Versuchstieren, die durch eine E2-Gabe gesenkt werden können (Smith et al. 1974; Blake 1977). Der feedback-Mechanismus funktioniert nicht in ER $\beta$-knockout-Mäusen (Dorling et al. 2003). Diese Annahme wird auch dadurch gestützt, dass in in vitro-Studien eine konstitutive Aktivität des ER $\beta$ auf einen minimalen Promotor festgestellt werden konnte (Pak et al. 2006). Da BP2 wie auch E2 über ER $\alpha$ und ER $\beta$ transaktivierend wirkt, ist auch der Befund aus der Hypothalamuszellkultur mit dieser Hypothese vereinbar. 
- Hypophyse: Bei der Messung der hypophysären Hormone LH und Prolaktin im Serum zeigten sich unterschiedliche Auswirkungen von E2V und BP2 auf die Hormonkonzentrationen. Die Serumkonzentration von Prolaktin wurde durch beide Substanzen erhöht. In der BP2-333-Gruppe zeigte sich ein ähnlich starker Anstieg der Serumkonzentration wie in der E2V-Gruppe. Die Serumkonzentrationen in der BP2-1000-Gruppe lagen noch höher als in der E2V-Gruppe.

Die LH-Serumkonzentration wurde leicht durch E2V-Gabe gesenkt, während sie durch BP2, besonders in den hohen Dosierungen, signifikant gesteigert wurde. Dieses Ergebnis ist im Hinblick auf die in der Hypothalamuszellkultur erhaltenen Ergebnisse unerwartet, da BP2 wie E2 auch dort einen negativen Einfluss auf die GnRH-Sekretion zeigte. Die Suppression der LH-Sekretion durch E2V fiel weniger stark als erwartet aus. Das im Versuch verwendete E2V, welches speziell für die orale Applikation entwickelt wurde, zeigte im Gegensatz zu anderen Präparaten wie E2-benzoat, welches für subkutane Applikation verwendet wird, einen schwächeren Effekt auf die LH-Suppression, obwohl die E2-Serumspiegel ausreichend hoch waren (SeidlovaWuttke et al. 2005). Möglicherweise ist dieser Effekt auf die unterschiedliche Struktur und damit verbunden einer langsameren Freisetzung von E2 zurückzuführen (Hubertus Jarry, unveröffentlichte Daten).

Die Genexpression der beiden LH-Untereinheiten ( $\alpha$ und $\beta$ ) hingegen wurde in der Hypophyse durch E2V und BP2 leicht, aber nicht signifikant, gesenkt. Die Senkung der Genexpression der Untereinheiten von LH nach E2-Gabe wurde von Shupnik und Mitarbeitern beschrieben (Shupnik et al. 1988). Diese Ergebnisse stützen die Beobachtungen der Hypothalamuszellkultur. Die Diskrepanz des erhöhten Serumspiegels ist ein Kurzzeiteffekt, der bei einer Behandlungsdauer von 5 Tagen auftritt. Nach einer Behandlung von 3 Monaten sind die LH-Serumspiegel in der BP2-Behandlungsgruppe wie in der E2-Gruppe gesenkt (Seidlova-Wuttke et al. 2005). Da die erhöhten Serumspiegel nicht mit der Genexpression des Hormons korrelieren, ist es durchaus möglich, dass BP2 die Sekretion von LH moduliert und LH aus zellulären Speichern freigesetzt wird. 
Die LH-Sekretion wird auch auf der Ebene der Hypophyse beeinflusst. So reagieren Hypophysenzellen in der Primärzellkultur auf die Belastung mit E2 durch eine erhöhte LH-Sekretion (Tang et al. 1975; Emons et al. 1986). Dies konnte auch für BP2 in der Hypophysenzellkultur gezeigt werden. Dieser Effekt ist ER-vermittelt und kann durch den ER-Antagonisten ICI 182,780 gehemmt werden. Die Aktivität von BP2 unterscheidet sich auch darin nicht von der der Positivkontrolle E2 und entfaltet somit eine rein estrogene Aktivität. Dieser in vitro-Versuch liefert keine Erklärung für den Kurzzeiteffekt von BP2 auf die Serumkonzentration von LH. Es kann sich dennoch um einen BP2 spezifischen SERM-Effekt auf die Hypophyse handeln, der mit diesem Assay nicht erfasst werden konnte.

Eine neuere Untersuchung konnte zeigen, dass BP2 die Effekte von Testosteron hemmt, also ein potentes Antiandrogen ist (Suzuki et al. 2005). Für andere Antiandrogene wie Flutamide, Procymidon oder Equol wurde gezeigt, dass diese Substanzen die LH-Sekretion induzieren können (Kerrigan et al. 1994; Lund et al. 2004; Svechnikov et al. 2005). Diese Versuche wurden in männlichen Ratten durchgeführt, so dass eine Übertragung dieser Ergebnisse nicht ohne weiteres möglich ist. Doch stellt es einen weiteren Wirkmechanismus von BP2 dar, der anhand eines anderen Tiermodells untersucht werden müsste.

Die Genexpression von TERP-1 in der Hypophyse wird durch E2V auf etwa $6000 \%$ der basalen Expression in der Kontrollgruppe gesteigert. Die Behandlung mit BP2 hat ebenfalls in allen Dosen einen deutlich stimulierenden Effekt auf die TERP-1-Genexpression. In der BP2-100-Gruppe erreicht die Expression das Niveau der Positivkontrolle mit E2V, in den höheren Konzentrationen wird die Genexpression noch stärker als bei E2V stimuliert. In Zellkulturexperimenten wurde gezeigt, dass die TERP1-Genexpression ER $\alpha$-abhängig durch ein ERE vor Exon 5 reguliert wird (Schausi et al. 2003). BP2 ist demnach in der Lage, über ER $\alpha$ die Genexpression von TERP-1 zu stimulieren.

- Uterus: Morphologisch konnten in den Schnitten der E2V-Gruppe verschiedene Veränderungen, die für die Behandlung mit Estrogenen typisch sind, beobachtet werden. Die Zellen des Epithels des Endometriums machen ein deutliches 
Längenwachstum durch. In sehr seltenen Fällen wurde auch ein lokal mehrschichtiges Epithel gefunden. Dies entspricht in der Ratte allerdings einem pathologischen Befund, da im natürlichen Zyklus der Ratte ein mehrschichtiges Epithel nicht vorkommt. Die Zellen des Endometriums (Lamina propria) zeigen Anzeichen einer Polarisierung. Die Zellen und auch die Zellkerne haben eine spindelförmige Form angenommen. Des Weiteren wurde eine Anreicherung von eosinophilen Zellen im Endometrium beobachtet. Dieses Phänomen wurde beim Menschen vor und nach der Menstruation beschrieben (Salamonsen et al. 1999) und auch bei Ratten während des Estrus (Rytomaa 1960). Eine E2-Behandlung induziert das chemotaktisch wirkende Eotaxin, welche zu der Einwanderung der eosinophilen Zellen führt (Tchernitchin et al. 1974). Die Rolle dieser Zellen ist bislang unbekannt, allerdings wird vermutet, dass sie an der Gewebedegradation und -regeneration beteiligt sind (Zhang et al. 2000).

Das Uterusgewicht wurde durch die Behandlung mit E2V im Vergleich zur Kontrollgruppe fast verdreifacht. Auch die Gabe von BP2 führte ab $100 \mathrm{mg} / \mathrm{kg}$ zu einer dosisabhängigen Steigerung des Uterusgewichtes. In der BP2-1000-Gruppe wurde ebenfalls eine Verdreifachung des Uterusgewichtes wie bei E2V beobachtet. Die Reaktion des Uterus, auf Estrogene mit einem vermehrten Wachstum zu reagieren, wurde von Couse und Mitarbeitern beschrieben (Couse et al. 1995). Bei Untersuchungen dieser Reaktion des Uterus in knockout-Mäusen ist festgestellt worden, dass ER $\alpha$ - und ER $\alpha / \beta$-knockout-Mäuse im Gegensatz zu ER $\beta$-knockout-Mäusen auf die Behandlung mit Estrogenen nicht reagieren (Krege et al. 1998). Die Kaskade von zellulären und molekularen Interaktionen, die in dem Gewichtszuwachs des Uterus endet, ist hauptsächlich von der Funktion des ER $\alpha$ abhängig. Da aber ER $\beta$-knockoutMäuse trotz einer intakten Entwicklung der Geschlechtsorgane unter einer starken Subfertilität leiden, ist nicht ausgeschlossen, dass der ER $\beta$ einen wichtigen Einfluss auf die Reproduktion hat (Krege et al. 1998). Zudem können auch selektive ERß-Agonisten einen sehr schwachen, aber dosisabhängigen, induzierenden Einfluss auf das Uterusgewicht ausüben (Frasor et al. 2003). Inwieweit auch synergistische, also von ER $\alpha$ und ER $\beta$ vermittelte Effekte bei knockout-Mäusen eine Rolle spielen, ist bislang unbekannt. 
Die Genexpression von IGF-1 wurde durch die Behandlung mit E2V auf etwa $1000 \%$ gesteigert. Die Behandlung mit BP2 bewirkte in den beiden höchsten Dosierungen nur eine Steigerung der Genexpression auf etwa $500 \%$. IGF-1 und auch der IGF-1-Rezeptor sind beteiligt an der Signaltransduktionskaskade des estrogenen Signals, welche zum Uteruswachstum führt (Richards et al. 1996). In IGF-1-knockoutMäusen konnte das Uteruswachstum nicht durch E2-Gabe induziert werden (Adesanya et al. 1999). Andererseits konnte nach der Gabe von IGF-1 ein Estrogen-ähnliches Uteruswachstum beobachtet werden (Nelson et al. 1991). Verschiedene in vivo- und in vitro-Studien konnten zeigen, dass ER $\alpha$ bei der Induktion der IGF-1-Genexpression eine wichtige Rolle spielt (Ignar-Trowbridge et al. 1992; Curtis et al. 1996; Klotz et al. 2000).

Die C3-Genexpression im Uterus wurde durch die Behandlung mit BP2 deutlich dosisabhängig induziert. Dieser Effekt begann in der BP2-33-Gruppe und setzte sich bis in die BP2-1000-Gruppe fort. Die beiden höchsten Dosierungen von BP2 erreichten eine ähnlich hohe Stimulation der C3-Expression wie E2V. Durch die Behandlung mit E2V konnte die C3-Expression auf über $10.000 \%$ gesteigert werden. Frasor et al. beschrieben die Induktion der C3-Expression nach Gabe von E2 und des ER $\alpha$ Agonisten Propylpyrazoltriol (PPT). Die Gabe des ERß-Agonisten DPN konnte die C3Expression dagegen nicht signifikant stimulieren (Frasor et al. 2003). Da in dieser Studie jedoch nur eine Dosis DPN verwendet wurde, ist es möglich, dass auch ER $\beta$ Agonisten eine stimulierende Wirkung auf die C3-Genexpression ausüben können. BP2 könnte demnach hauptsächlich über ER $\alpha$ seine stimulierende Wirkung ausüben, möglich wäre jedoch auch eine Wirkung über ER $\beta$.

\subsubsection{Auswirkungen von BP2 auf die HPT-Achse}

Estrogene haben einen regulierenden Einfluss auf Metabolismus und Anabolismus des menschlichen Organismus. So hat E2 einen direkten Einfluss auf die hypophysäre TSH-Sekretion. Weibliche Ratten zeigen ein anderes Profil in der Konzentration der TRH-Rezeptoren in der Hypophyse und auch in der 5'-Deiodase-Aktivität (Donda et al. 1990). Eine Behandlung von kastrierten Männchen mit E2 resultiert in der Verweiblichung dieser Merkmale. Physiologische Konzentrationen von E2 $\left(1 * 10^{-11}-1 * 10^{-9} \mathrm{M}\right)$ sind in der 
Lage die TSH-Sekretion in der Hypophysenzellkultur um das 5fache und die intrazelluläre TSH-Konzentrationen um das 2 fache zu erhöhen (Miller et al. 1977). Andere Steroidhormone wie Androgene, Progesteron und Glukokortikoide haben indes keinen Einfluss auf die hypophysäre TSH-Sekretion.

- Hypophyse und Hypothalamus: Der stimulierende Effekt von E2 auf die TSH-Sekretion von Hypophysenzellen wurde in der Zellkultur nachgewiesen. Durch die Koinkubation mit dem ER-Antagonisten ICI 182,780 konnte die Wirkung von E2 aufgehoben werden. Dies zeigt, dass der direkte Effekt von E2 auf die TSH-Sekretion abhängig von funktionsfähigen ERs in der Hypophyse ist. Auch die Testsubstanz BP2 zeigte eine deutliche Induktion der TSH-Sekretion. Diese Induktion war ebenfalls durch ICI hemmbar und belegt somit, das BP2 auf die Funktion der Hypophyse in der HPT-Achse als reines Estrogen agiert. Auch in vivo konnte der stimulierende Effekt von E2 auf die TSH-Sekretion anhand des Serumspiegels beobachtet werden. Wie zu erwarten, hatte BP2 in vivo den gleichen Effekt wie die Positivkontrolle E2V. Zusätzlich zu den Serumspiegeln wurde die Produktion von TSH auf der Ebene der mRNA untersucht. Hier wurde ein hemmender Einfluss von E2 und auch von BP2 auf die Expression der $\alpha$-Untereinheit, welche Bestandteil der drei Hormone LH, FSH und TSH ist, sowie auf die TSH $\beta$-Untereinheit nachgewiesen. Die TSH $\beta$-Untereinheit ist hier der entscheidende Faktor, da die TSH-Expression auf der Proteinebene von der Genexpression der $\alpha$-Untereinheit nahezu unabhängig ist (Gurr et al. 1983). Der Widerspruch zwischen der Regulation des Serumspiegel und der Genexpression wurde schon von Lippman et al. beschrieben. In intakten Ratten führte die Administration von TRH zu einer starken Erhöhung der TSH-Serumspiegel, während die Genexpression der Untereinheiten des Hormon unbeeinflusst waren (Lippman et al. 1986). Daraus resultiert, dass die TSH-Produktion primär durch posttranslationale Glykosylierung und Sekretion aus zellulären Speichern kontrolliert wird. In einem Langzeitversuch mit BP2 über 3 Monate wurde in den BP2-Behandungsgruppen keine Induktion der TSH-Sekretion im Vergleich zu einer unbehandelten Kontrollgruppe gefunden (Seidlova-Wuttke et al. 2005). Bei der Regulation der TSH-Sekretion zeigen sich kurzzeitig Unterschiede in der Reaktion der Konzentration im Serum und der Genexpression, die sich erst nach drei Tagen ausgleichen (Murakami et al. 1991). 
Um zu überprüfen, ob die Induktion der TSH-Sekretion ein direkter Effekt der Testsubstanzen auf die Hypophyse ist oder aber auf eine vermehrte TRH-Sekretion im Hypothalamus zurückzuführen ist, wurde die TRH-Genexpression im MBH gemessen. Es konnte gezeigt werden, dass die Genexpression in der E2V- sowie in den BP2-Behandlungsgruppen unbeeinflusst war. Die erhöhte TSH-Sekretion der Hypophyse ist demnach nicht auf eine Erhöhung der TRH-Expression im Hypothalamus durch die Testsubstanz BP2 zurückzuführen.

- Schilddrüsenhormone: Die Veränderungen, die BP2 auf die Serumspiegel der Schilddrüsenhormone T3 und T4 ausübt, sind abweichend von den bei E2V-Gabe beobachteten Veränderungen der Hormone. Es konnte gezeigt werden, dass BP2 im Gegensatz zu E2V einen hemmenden Einfluss auf die Produktion des T4 hat, während E2V die Konzentration des T3 senkt. Dies wurde im Langzeitversuch bestätigt (Seidlova-Wuttke et al. 2005). Zusätzlich dazu wurden einige Diskrepanzen im Verhältnis von gesamt-T3 bzw. -T4 und freiem Hormon gefunden. Nur ein kleiner Teil der Schilddrüsenhormone liegt in freier Form vor und ist aktiv. BP2 hat einen deutlich von E2V abweichenden, senkenden Effekt auf die fT3-Konzentration, während E2V die Konzentration von fT4, welches in Zielorganen in das aktive T3 umgesetzt werden kann, erhöht. Nur das freie Hormon ist biologisch aktiv, kann die Membran der Zielzelle passieren und im Allgemeinen die Stoffwechselrate und Entwicklungsvorgänge beschleunigen. E2 erhöht die Stoffwechselrate des Organismus und verringert die Nahrungsaufnahme (Young 1986), was zu einem reduzierten Körpergewicht führt. BP2 wiederum senkte das fT3 und verlangsamt somit den Stoffwechsel des Organismus. Das Bild, das BP2 in vivo verursacht, entspricht dem von hypothyreoten Ratten.

- Proteine in der Schilddrüse und der Leber: Das im Serum zirkulierende T3 und T4 wird durch die 5'-Deiodase-Aktivität in der Leber degradiert. Der 5'Deiodase-Assay hat für die Behandlungsgruppen keine erhöhte Aktivität ergeben, so dass eine vermehrte Degradation und Exkretion der Schilddrüsenhormone durch einen Einfluss von BP2 in der Leber ausgeschlossen werden konnte. Bisher konnte in dieser Arbeit gezeigt werden, dass BP2 Effekte verursacht die mit E2V vergleichbar sind. Auf die 
Sekretion der Schilddrüsenhormone entfaltet BP2 jedoch eine nicht-estrogene Aktivität. Der Effekt von BP2 auf die TSH-Sekretion in der Hypophyse ist mit E2V vergleichbar und kann somit nicht für den Schilddrüseneffekt verantwortlich sein. Ein Einfluss auf Transportproteine im Serum würde nur die Diskrepanz zwischen gesamt-T3 bzw. -T4 und den freien Hormonen erklären. Deshalb wurde die Schilddrüsenfunktion anhand von Schlüsselenzymen (Natrium/Iodid-Symporter, Schilddrüsenperoxidase) untersucht.

Basierend auf den Untersuchungen von Carrasco, ist der Natrium/Iodid-Symporter (NIS) kloniert und molekular charakterisiert worden (Carrasco 1993). Der NIS transportiert aktiv Iodid in die Schilddrüsenzellen und hat damit eine Schlüsselposition in der Synthese der Schilddrüsenhormone. Bei der Untersuchung der Proteinexpression des NIS konnte kein Einfluss von BP2 festgestellt werden. Der hemmende Effekt von BP2 auf die Sekretion der Schilddrüsenhormone ist demnach nicht auf eine Störung der Iodid-Aufnahme in die Follikel der Schilddrüse zu erklären.

Die Jod-Atome der Schilddrüsenhormone werden über eine radikalische Reaktion im Inneren der Follikel in das dort gespeicherte Thyreoglobulin eingebaut. Hierfür ist die Schilddrüsenperoxidase (TPO) verantwortlich, die von den Follikelepithelzellen produziert und in das Innere des Schilddrüsenfollikels abgegeben wird. In einem in vitro-TPO-Assay mit rekombinantem humanem Protein inhibierte BP2 bei einer Konzentration von $0,4 \mu \mathrm{M}$ die TPO-Aktivität signifikant (Schmutzler et al. 2006). Damit ist BP2 ein stärkerer Inhibitor der TPO-Aktivität als das bekannte Goitrogen Genistein. In vivo zeigte die Administration von BP2 allerdings ein anderes Bild. BP2 induzierte die TPO-Aktivität und entfaltet die stärkste Wirkung in der BP2-100-Gruppe. Die Serumanalysen ergaben, dass der Serumspiegel des freien BP2 (siehe Abbildung 3-13) in der Gruppe BP2-100 bei 0,44 $\mu \mathrm{M}$ liegt. Die effektive Konzentration von BP2 in vivo und in vitro ist demnach gleich. Der entgegengesetzte Effekt von BP2 auf die TPO-Aktivität in vitro und in vivo ist durch einen zellkulturspezifischen Effekt zu erklären. In in vitro-Zellkulturssays fehlen die Wechselwirkungen mit anderen Systemen des Organismus. Für MMI und PTU wurden ebenfalls Unterschiede in der Modulation der TPO-Aktivität in vivo und 
in vitro gefunden (Davidson et al. 1978). Die Dosis-Wirkungsbeziehung der TPO-Aktivität entspricht nicht den Dosis-Wirkungsbeziehungen der Parameter TSH-, T3- und T4-Sekretion in den BP2-Behandlungsgruppen. Zudem ist die Aktivität der TPO in vivo induziert worden, was nicht in einem Absinken der Schilddrüsenhormone resultieren würde. Deshalb ist es unwahrscheinlich, dass die Veränderung der Synthese der Schilddrüsenhormone durch die Modulation der TPO-Aktivität für die veränderten Serumspiegel verantwortlich ist.

Die in der HPT-Achse erhobenen Daten zeigen einen nicht Estrogen-ähnlichen Effekt in der Schilddrüse. Der Mechanismus konnte allerdings nicht mit den verwendeten Assays aufgeklärt werden. Schon bei der Regulation von ER $\alpha$ und ER $\beta$ zeigte sich ein von E2 abweichendes Bild in der Schilddrüse. Ob ein Zusammenhang zu den Effekten auf die Schilddrüsenhormone besteht, kann anhand dieser Daten nicht eindeutig geklärt werden. BP2 konnte durch Untersuchungen an der HPT-Achse als ein Disruptor der Schilddrüsenaktivität identifiziert werden.

\subsection{Metabolisierung und Kinetik von BP2}

Die Absorption der Testsubstanz nach der oralen Applikation sollte anhand der Serumspiegel verfolgt werden. Dazu wurde das Serum der Tiere mittels HPLC untersucht. Ein der Reinsubstanz entsprechender Peak konnte im Serum identifiziert werden, zudem wurden dosisabhängig zwei weitere Peaks gefunden, die nicht im Serum der Kontrolltiere nachweisbar und somit auf die Behandlung zurückzuführen waren.

Substanzen, die oral appliziert werden, gelangen nach der Absorption im Magen-Darm-Trakt über die Pfortader in die Leber. Dort kommt häufig der first-pass-Effekt zum Tragen (Whitehead et al. 1980). Die Leber ist neben Darm und Niere das zentrale Organ, welches Xenobiotika degradieren kann (Mutschler et al. 2001). Substanzen, die von den Stoffwechselwegen des Organismus nicht verwertet oder abgebaut werden können, werden über die Biotransformation in den Phase-I-Reaktionen transformiert und aktiviert. Dies geschieht bei Säugern häufig durch P450-Isoenzyme der Familien Cyp1 bis Cyp4. Anschließend werden diese aktivierten Substanzen in den Phase-II-Reaktionen mit polaren Resten gekoppelt und können dann in der Regel ausgeschieden werden (Mutschler et al. 2001). 
Über den AhR werden einige wichtige Enzyme der Phase-I der Biotransformation reguliert. Häufig induzieren die Liganden des AhR ihre eigene Biotransformation über diesen Weg. Im EROD-Assay konnte eine schwache Induktion der Aktivität durch die Behandlung mit BP2 gemessen werden (siehe Abbildung 3-4). Dies wurde auf der Ebene der Genexpression anhand der Cypla1-Expression bestätigt (Abbildung 3-29). Da die Induktion jedoch im Vergleich zu 3MC eher gering ausfiel, ist es jedoch auch möglich, dass BP2 hauptsächlich durch andere Enzyme, zum Beispiel Transferasen der Phase-II-Biotransformation metabolisiert wird.

Durch die Behandlung mit Helix pomatia-Glucuronidase können die wichtigsten Aggregate der Biotransformation, die Glucuronide und Sulfate wieder gespalten werden. In der Tat war es möglich, durch die Inkubation der Seren mit diesem Enzym die zwei unbekannten Peaks aus den Chromatogrammen des Serums der BP2 Gruppen zu entfernen. Es war also anzunehmen, dass die oral applizierte Testsubstanz in der Leber zu BP2-Glucuronid und BP2-Sulfat metabolisiert wird.

Um diese Vermutung zu belegen, wurde die Seren der BP2-Tiere einer Massenspektroskopie unterzogen. Dabei konnte für den Peak, welcher die gleiche Retentionszeit wie der Standard aufwies, die Masse des BP2 ermittelt und für die beiden zusätzlichen Peaks die Masse des Glucuronids und des Sulfats gemessen werden. Die Annahme aus dem EROD-Assay wurde hier bestätigt. BP2 wird über die selbst induzierte Biotransformation zu BP2-Glucuronid und BP2-Sulfat metabolisiert.

Mit Hilfe dieser Methode konnte die Konzentration des freien BP2 sowie des gesamt BP2 im Serum der Versuchstiere bestimmt werden. Daraus lässt sich der Anteil des metabolisierten sowie des freien BP2 ermitteln. Der Anteil des freien BP2 und damit des biologisch verfügbaren, liegt durch alle 5 Behandlungsgruppen, also dosisunabhängig, bei etwa $2 \%$ (1,67 - 2,8\%). Eine Ausnahme bildet die BP2-33-Gruppe mit 9,48 \%. Aus der Abbildung 3-13 ist ersichtlich, dass der Mittelwert dieser Gruppe im Kontext aller Behandlungsgruppen unerwartet hoch liegt. Deshalb kann der Wert als Ausreißer angesehen werden. Es gibt zurzeit keine vergleichbaren Daten für Benzophenone oder andere UV-Filter.

Da der Anteil des freien BP2 hier dosisunabhängig zu sein scheint, kann man annehmen, dass die Kapazität der Leber in Bezug auf die Umsetzung der applizierten Substanz nicht ausgeschöpft wurde. Die leichte Induktion der EROD-Aktivität als Indiz für die Aktivität der 
Biotransformation in den hohen Behandlungsgruppen zeigt allerdings schon eine Anpassung und damit Erhöhung der Kapazität der Leber.

Aus den Graphen der Dosiswirkungsbeziehung (Abbildung 3-33) ist eine deutliche Induktion der Effekte in der BP2-333-Gruppe ersichtlich. Dort liegt die Konzentration des freien BP2 bei 1,83 $\mu \mathrm{M}$. Aus den in vitro-Versuchen können die BP2-Konzentrationen abgeleitet werden, die für eine signifikante Induktion des Endpunktes benötigt werden. Im RBA liegt die für eine Verdrängung von E2 benötigte Konzentration bei 0,4 $\mu \mathrm{M}$ BP2, im E-screen zeigt sich eine deutliche Induktion des Wachstums bei $1 \mu \mathrm{M}$ BP2 und im Transaktivierungsassay sind Konzentrationen von 0,1 bzw. 0,3 $\mathrm{MM}$ BP2 nötig, um den Reporter über den jeweiligen ER-Subtyp zu induzieren. Die effektiven Konzentrationen der in vitro-Assays korrelieren mit den Konzentrationen des freien BP2 im Serum der Versuchstiere. Das bedeutet, dass das im Magen-Darm-Trakt resorbierte BP2 in einem first-pass-Effekt in der Leber metabolisiert wird und nur ca. $2 \%$ des feien BP2 das Serum erreichen. Würde mehr freies BP2 die Leber passieren, um erst durch die wiederholten Passagen durch die Leber metabolisiert zu werden, würde der estrogene Effekt in den Behandlungsgruppen viel stärker ausfallen, da schon geringe Belastungszeiten mit estrogenen Substanzen in vivo zu einer Reaktion führen.

Um diese Vermutung zu überprüfen, wurde die Konzentration des BP2 und seiner Metaboliten zeitabhängig nach der Applikation im Serum sowie im Urin der behandelten Tiere gemessen. Die Messung der BP2-Konzentrationen im Serum hat ergeben, dass das Maximum an BP2 und den Metaboliten 30 Minuten nach der Applikation erreicht wurde. Bis 180 Minuten fällt die Konzentration des freien BP2 und die des BP2-Sulfats leicht aber stetig ab, während die Konzentration des BP2-Glucuronids nach 30 Minuten viel höher ist als bei BP2 und innerhalb von 120 Minuten rapide abfällt. Die im Vergleich zu Sulfat hohe Glucuronid-Konzentration im Serum war zu erwarten, da die Bildung des Sulfates, die eine Konkurrenzreaktion zur Glucuronidierung darstellt, durch die verfügbare Menge des endogenen Sulfates begrenzt wird (Coughtrie et al. 1998). Es handelt sich demnach um einen first-pass-Effekt, der für die Metabolisierung des BP2 verantwortlich ist. Der rapide Abfall der Konzentration des BP2-Glucuronids im Serum während der ersten 2 Stunden nach der Applikation deutet auf eine rasche Entfernung durch Exkretion hin. In der Tat ist anhand der Messwerte im Urin zu erkennen, dass das reine BP2 nur in sehr geringen Mengen und die beiden Metaboliten, und besonders das BP2-Glucuronid, in höheren Mengen ausgeschieden 
wurden. Das Maximum der Exkretion liegt bei 120 Minuten, wobei der Messpunkt aber für den Zeitraum von 60 bis 120 Minuten steht, in dem der Urin im Tier produziert wurde.

\subsection{Dosis-Wirkungsbeziehung und Risiko-Bewertung}

Das Erstellen einer Dosis-Wirkungsbeziehung dient der Ermittlung von Schwellenwerten, bei denen ein Parameter einen deutlichen Effekt verursacht $\left(\mathrm{EC}_{50}\right.$ oder lowest observed adverse effect level; LOAEL) oder bei denen ausgeschlossen werden kann, dass ein Effekt verursacht wird (no observed adverse effect level; NOAEL oder CED).

In in vitro-Assays werden Schwellenwerte für einen Mechanismus bzw. biologischen Endpunkt ermittelt, die aber in keinem Verhältnis zu einem Organismus stehen. Deshalb wurde ein in vivo-Versuch durchgeführt, bei welchem die Belastung quantifiziert werden und mit dem Effekt in Korrelation gebracht werden konnte. Anhand der Ergebnisse einer DosisWirkungsbeziehung können Hypothesen aus epidemiologischen Studien bestätigt oder widerlegt werden.

Die aus dem Versuch ermittelten Daten wurden mit Hilfe des Benchmark Approaches analysiert. Eine detaillierte Analyse wurde veröffentlicht (Schlecht et al. 2006). Aus diesem Grund wird hier nur eine Zusammenfassung der wichtigsten Ergebnisse gegeben.

Für die Analyse wurde der Benchmark Approach (Crump 1984) gewählt, da er erhebliche Vorteile gegenüber der Berechnung der NOAEL- und LOAEL-Werte hat. Die aus der Analyse erhaltenen CEDs sind im Gegensatz zu den NOAEL/LOAEL-Werten unabhängig von der Wahl der Dosierungen im Versuch und entsprechen mit einer deutlich höheren Wahrscheinlichkeit dem so genannten "wirklichen" no-adverse-effect-Level. Eine ausführliche Diskussion ist im KemI-Report nachzulesen (KemI 2003).

Es wurde ein CES von einer Standardabweichung gewählt, um die individuellen Schwankungen zwischen einzelnen Individuen innerhalb des Parameters zu berücksichtigen. Die sensitivsten Parameter waren die TERP-1-Genexpression in der Hypophyse mit einem CED von 1,59 mg/kg Kg, die C3-Genexpression im Uterus mit einem CED von 3,24 mg/kg $\mathrm{Kg}$ und der LDL-Serumspiegel bei den metabolischen Parametern mit einem CED von 78,2 $\mathrm{mg} / \mathrm{kg} \mathrm{Kg}$.

Die Analyse zeigt, dass BP2 in vivo bei ovariektomierten weiblichen Ratten eine endokrine Aktivität oberhalb von Dosen von 1,6 bis 3,2 mg/kg Körpergewicht hervorrufen kann. 
Die ermittelten Dosen können mit Hilfe von EU-Richtlinien für Expositionswerte herangezogen werden, um auf ein mögliches Risiko für den Menschen zu schließen. In Schlecht et al. sind die Ergebnisse ausführlich in Bezug auf einige Eventualitäten hinsichtlich der Absorption und Exposition diskutiert (Schlecht et al. 2006).

Für eine Extrapolation der Daten aus dem Tierversuch wurden so genannte Unsicherheitsfaktoren (UF) herangezogen, welche die Differenzen zwischen dem Tiermodell und dem Menschen als exponierte Gruppe berücksichtigen. In diesem Fall kann ein UF von 1440 benutzt werden, der sich aus den Faktoren 10 für die Intraspezies-Varianzen, 48 für die Interspezies-Varianzen und dem Faktor 3 für die Applikationsdauer zusammensetzt. Die maximal akzeptable Exposition berechnet sich aus CED/UF und beträgt somit $1,1 \mu \mathrm{g} / \mathrm{kg} \mathrm{Kg}$.

Die Exposition einer Risikogruppe kann experimentell ermittelt werden. Allerdings liegen hierzu für BP2 noch keine Ergebnisse vor. Die EU Direktive Counsel Directive 95/17EC gibt in einem solchen Fall, speziell für UV-Filter, Richtwerte für die Berechnung der Exposition. Bei einem Gehalt von $0,24 \%$ in kosmetischen Produkten ergibt sich eine systemische Exposition von $40 \mu \mathrm{g} / \mathrm{kg}$ Körpergewicht.

Zusammenfassend kann gesagt werden, dass die europäische und amerikanische Bevölkerung mit einem Effekt rechnen muss, der sich aber möglicherweise nur bei sensitiven Bevölkerungsgruppen wie z.B. bei Kindern auswirkt. In anderen Ländern wie z.B. in Japan ist aufgrund einer anderen Verordnung zu UV-Filtern in Kosmetika ein maximaler Gehalt von $10 \%$ erlaubt. Dadurch ist mit einer höheren Belastung zu rechnen. Dies könnte auch bei gesunden Erwachsenen zu einer Beeinträchtigung führen. In diesem Zusammenhang müssen auch kombinierte Effekte mit anderen EAC, welchen der Mensch ausgesetzt ist, angenommen werden. So konnten Heneweer et al. zeigen, dass gerade UV-Filter in Mischungen additive Effekte verursachen (Heneweer et al. 2005). Außerdem werden Wirkungen chemischer Substanzen in sehr geringen Dosen (low dose-Effekte) diskutiert, die möglicherweise über andere Wirkmechanismen vermittelt werden können (Davis et al. 1990).

BP2 entfaltet in vivo eine estrogene Aktivität und könnte demnach Einfluss auf Estrogenregulierte Systeme wie die Reproduktion, den Metabolismus und die Entwicklung nehmen. Dies stützt die Hypothesen aus vielen epidemiologischen Studien, dass die Belastung mit endokrin aktiven Chemikalien für Beeinträchtigungen der menschlichen Gesundheit verantwortlich sein kann. 


\section{Zusammenfassung}

Das als UV-Filter zum Produktschutz in Kosmetikprodukten enthaltene BP2 ist in den Verdacht geraten, eine EAC zu sein. Aufgrund der Limitierung des von der OECD vorgeschlagenen uterotrophen Assay auf nur ein Estrogen-sensitives Organ wurde zusätzlich $\mathrm{zu}$ den in vitro-Screening-Methoden, ein erweitertes Modell zur Untersuchung der Estrogenität von BP2 eingesetzt. In diesem Modell wurden Parameter der HPG-Achse, der HPT-Achse und des Metabolismus berücksichtigt, um eine mögliche ER-Subtyp-spezifische, SERM- oder ER-unabhängige Aktivität zu erfassen.

In den in vitro-Analysen ist gezeigt worden, dass BP2 ein moderates Estrogen ist. Es verfügt über die Fähigkeit, mit E2 um Bindestellen zu konkurrieren, kann über ERs Reportergene induzieren und induziert Estrogen-regulierte Endpunkte. Obwohl in vitro eine ER $\beta$-Präferenz festgestellt wurde, vermittelt BP2 eine estrogene Aktivität über den ER $\alpha$ in vivo.

Der Metabolismus der Versuchstiere wurde durch BP2 auf eine mit E2 vergleichbare Weise beeinflusst. Dies wurde anhand eines estrogen regulierten Gens in der Leber (IGF-1) und von Serumlipidwerten untersucht. Ein BP2-spezifischer, von der E2-Wirkung abweichender Effekt ist die Induktion der GH-Sekretion in der Hypophyse. BP2 hat möglicherweise noch eine andere über Steroidrezeptoren, beispielsweise den Androgen-Rezeptor, vermittelte Aktivität.

Trotz eines fehlenden Effekts auf den Hypothalamus verursachte BP2 Veränderungen in der Genexpression des ER $\alpha / \beta$-Systems in der Hypophyse, dem Uterus und der Leber, die denen von E2 gleichen. In der Schilddrüse gibt es Anzeichen einer von der E2-Wirkung abweichenden Modulation.

In der Sekretion der Hypophysenhormone zeigt sich bei LH ein von E2 abweichender Effekt. Auch hier ist es möglich, dass BP2 über andere Steroidhormonrezeptoren biologische Prozesse beeinflusst. Auf die Genexpression von TERP1 wirkt BP2 als Estrogen. Die Veränderungen im Uterus, die durch BP2 eingeleitet wurden, sind anhand der Morphologie sowie anhand der Markergene IGF-1 und C3 als rein estrogen bestätigt worden.

Innerhalb der HPT-Achse übt BP2 durch einen direkten Mechanismus auf die Hypophyse einen estrogenen Einfluss aus. Das Bild das BP2 in vivo bei der T3/T4 Sekretion verursacht, entspricht, im Gegensatz zu dem der E2 behandelten Tiere dem Bild von hypothyreoten Ratten. Weder die Degradation in der Leber noch die Schilddrüsenhormonproduktion ist hierfür verantwortlich. Es ist aber wahrscheinlich, dass ein Effekt auf die 
Schilddrüsenfunktion die Ursache ist. Möglicherweise kommt eine Konkurrenzreaktion zwischen BP2 und Tyrosinresten des Thyreoglobulins bei der Iodierung in der Schilddrüse in Frage.

BP2 wird schnell durch den firs-pass-Effekt in der Leber metabolisiert und ausgeschieden. Nur ein geringer Anteil freies BP2 erreicht das Serum. Die Serumkonzentration des freien BP2 in den Gruppen mit einer deutlichen estrogenen Wirkung korreliert mit den effektiven Konzentrationen der in vitro-Assays.

Die Analyse der durch BP2 am stärksten beeinflussten Parameter mit Hilfe des BenchmarkApproaches zur Extrapolation der Effekte auf exponierte Bevölkerungsgruppen hat ergeben, dass eine Beeinflussung gesunder Individuen durch BP2 möglich ist. Eine weitere Risikogruppe sind zum Beispiel Kinder, bei denen aufgrund sensibler Entwicklungsvorgänge und einem in diesem Fall ungünstigen Verhältnis von Körperoberfläche zu Körpervolumen stärkere Effekte zu erwarten sind. Besonders zu erwähnen sind in diesem Fall die Effekte auf die Schilddrüsenfunktionen, die als advers eingestuft werden sollten. Beachtung finden sollten hier auch mögliche Misch-Effeke mit anderen EAC und besondere Effekte bei geringen Dosen. 


\section{Literatur}

Adesanya, O.O., Zhou, J., Samathanam, C., Powell-Braxton, L., Bondy, C.A. (1999). Insulinlike growth factor 1 is required for G2 progression in the estradiol-induced mitotic cycle. Proc Natl Acad Sci U S A 96(6):3287-3291.

Allen, E., Smith, G.M., Garnder, W.U. (1937). Accentuation of the growth effect of theelin on genital tissues of the ovarietcomized mouse by arrest of mitosis with colchicines. Amer J Anat 61:321-341.

Alvaro, D., Alpini, G., Onori, P., Perego, L., Svegliata Baroni, G., Franchitto, A., et al. (2000). Estrogens stimulate proliferation of intrahepatic biliary epithelium in rats. Gastroenterology 119(6):1681-1691.

Anstead, G.M., Carlson, K.E., Katzenellenbogen, J.A. (1997). The estradiol pharmacophore: ligand structure-estrogen receptor binding affinity relationships and a model for the receptor binding site. Steroids 62(3):268-303.

Aronica, S.M., Kraus, W.L., Katzenellenbogen, B.S. (1994). Estrogen action via the cAMP signaling pathway: stimulation of adenylate cyclase and cAMP-regulated gene transcription. Proc Natl Acad Sci U S A 91(18):8517-8521.

Auger, J., Kunstmann, J.M., Czyglik, F., Jouannet, P. (1995). Decline in semen quality among fertile men in Paris during the past 20 years. N Engl J Med 332(5):281-285.

Beato, M., Herrlich, P., Schutz, G. (1995). Steroid hormone receptors: many actors in search of a plot. Cell 83(6):851-857.

Bieglmayer, C., Spona, J., Schoeder, R. (1980). Modulation of LH-RH stimulated gonadotropin release by progestagens and 17 beta-estradiol in primary pituitary cell culture. Endocrinol Exp 14(3):171-182.

Blair, R.M., Fang, H., Branham, W.S., Hass, B.S., Dial, S.L., Moland, C.L., et al. (2000). The estrogen receptor relative binding affinities of 188 natural and xenochemicals: structural diversity of ligands. Toxicol Sci 54(1):138-153.

Blake, C.A. (1977). A medial basal hypothalamic site of synergistic action of estrogen and progesterone on the inhibition of pituitary luteinizing hormone release. Endocrinology 101(4):1130-1134.

Bonde, J.P., Kold Jensen, T., Brixen Larsen, S., Abell, A., Scheike, T., Hjollund, N.H., et al. (1998). Year of birth and sperm count in 10 Danish occupational studies. Scand $J$ Work Environ Health 24(5):407-413.

Bowe, J., Li, X.F., Sugden, D., Katzenellenbogen, J.A., Katzenellenbogen, B.S., O'Byrne, K.T. (2003). The effects of the phytoestrogen, coumestrol, on gonadotropin-releasing hormone $(\mathrm{GnRH})$ mRNA expression in GT1-7 GnRH neurones. J Neuroendocrinol 15(2):105-108. 
Bradford, M.M. (1976). A rapid and sensitive method for the quantitation of microgram quantities of protein utilizing the principle of protein-dye binding. Anal Biochem 72:248-254.

Brash, D.E., Rudolph, J.A., Simon, J.A., Lin, A., McKenna, G.J., Baden, H.P., et al. (1991). A role for sunlight in skin cancer: UV-induced p53 mutations in squamous cell carcinoma. Proc Natl Acad Sci U S A 88(22):10124-10128.

Bray, G.A., Saiduddin, S., York, D.A., Swerdloff, R.S. (1976). Effect of estradiol on uterine weight, thyroid function food intake, and pituitary weight of genetically obese (fattyZucker) and lean rats. Proc Soc Exp Biol Med 153(1):88-91.

Brzozowski, A.M., Pike, A.C., Dauter, Z., Hubbard, R.E., Bonn, T., Engstrom, O., et al. (1997). Molecular basis of agonism and antagonism in the oestrogen receptor. Nature 389(6652):753-758.

Burke, S. (2001). Missing Values, Outliers, Robust Statistics \& Non-parametric Methods. LCGC Europe Online Supplement:19-24.

Cardullo, R.A., Agrawal, S., Flores, C., Zamecnik, P.C., Wolf, D.E. (1988). Detection of nucleic acid hybridization by nonradiative fluorescence resonance energy transfer. Proc Natl Acad Sci U S A 85(23):8790-8794.

Carlsen, E., Giwercman, A., Keiding, N., Skakkebaek, N.E. (1992). Evidence for decreasing quality of semen during past 50 years. Bmj 305(6854):609-613.

Carrasco, N. (1993). Iodide transport in the thyroid gland. Biochim Biophys Acta 1154(1):6582.

Castles, C.G., Oesterreich, S., Hansen, R., Fuqua, S.A. (1997). Auto-regulation of the estrogen receptor promoter. J Steroid Biochem Mol Biol 62(2-3):155-163.

Chen, Z., Zheng, H., Dong, K.W. (2001). Identification of negative and positive estrogen response elements in human GnRH upstream promoter in the placental JEG-3 cells. Mol Cell Endocrinol 184(1-2):125-134.

Chin, W.W., Godine, J.E., Klein, D.R., Chang, A.S., Tan, L.K., Habener, J.F. (1983). Nucleotide sequence of the cDNA encoding the precursor of the beta subunit of rat lutropin. Proc Natl Acad Sci U S A 80(15):4649-4653.

Chu, S., Fuller, P.J. (1997). Identification of a splice variant of the rat estrogen receptor beta gene. Mol Cell Endocrinol 132(1-2):195-199.

Cidlowski, J.A., Black, J.B., Muldoon, T.G., Mahesh, V.B. (1975). Development of thyroidal responsiveness to estrogen in the maturing rat (38471). Proc Soc Exp Biol Med 148(1):33-36.

Clark, J.H., Markaverich, B.M. (1983). The agonistic and antagonistic effects of short acting estrogens: a review. Pharmacol Ther 21(3):429-453. 
Clemons, J.H., Dixon, D.G., Bols, N.C. (1997). Derivation of 2,3,7,8-TCDD toxic equivalent factors (TEFs) for selected dioxins, furans and PCBs with rainbow trout and rat liver cell lines and the influence of exposure time. Chemosphere 34(5-7):1105-1119.

Collingwood, T.N., Urnov, F.D., Wolffe, A.P. (1999). Nuclear receptors: coactivators, corepressors and chromatin remodeling in the control of transcription. $J \mathrm{Mol}$ Endocrinol 23(3):255-275.

Collins, P., Webb, C. (1999). Estrogen hits the surface. Nat Med 5(10):1130-1131.

Colvin, P.L., Jr., Wagner, J.D., Heuser, M.D., Sorci-Thomas, M.G. (1993). Oral contraceptives decrease hepatic cholesterol independent of the LDL receptor in nonhuman primates. Arterioscler Thromb 13(11):1645-1649.

Cooke, B.K., A., S. (1982). Distribution and breakdown of DDT in orchard soil. Pestic Sci 13:545-551.

Coughtrie, M.W., Dajani, R., Kauffmann, F.C., Rubin, G.L., Sharp, S. (1998). Sulfotransferases and the Biology of Sulfation. In: Drug Metabolism - Towards the Next Milennium (Gooderham, N.J., ed). Amsterdam, Berlin, Oxford, Tokyo, Washington DC:I O S Press.

Couse, J.F., Curtis, S.W., Washburn, T.F., Lindzey, J., Golding, T.S., Lubahn, D.B., et al. (1995). Analysis of transcription and estrogen insensitivity in the female mouse after targeted disruption of the estrogen receptor gene. Mol Endocrinol 9(11):1441-1454.

Crump, K.S. (1984). A new method for determining allowable daily intakes. Fundam Appl Toxicol 4(5):854-871.

Curtis, S.W., Washburn, T., Sewall, C., DiAugustine, R., Lindzey, J., Couse, J.F., et al. (1996). Physiological coupling of growth factor and steroid receptor signaling pathways: estrogen receptor knockout mice lack estrogen-like response to epidermal growth factor. Proc Natl Acad Sci U S A 93(22):12626-12630.

Danzo, B.J. (1997). Environmental xenobiotics may disrupt normal endocrine function by interfering with the binding of physiological ligands to steroid receptors and binding proteins. Environ Health Perspect 105(3):294-301.

Davidson, B., Soodak, M., Neary, J.T., Strout, H.V., Kieffer, J.D., Mover, H., et al. (1978). The irreversible inactivation of thyroid peroxidase by methylmercaptoimidazole, thiouracil, and propylthiouracil in vitro and its relationship to in vivo findings. Endocrinology 103(3):871-882.

Davis, J.M., Svendsgaard, D.J. (1990). U-shaped dose-response curves: their occurrence and implications for risk assessment. J Toxicol Environ Health 30(2):71-83.

Degen, G.H., Foth, H., Kahl, R., Kappus, H., Neumann, H.G., Oesch, F., et al. (1999). Hormonell aktive Substanzen in der Umwelt: Xenoöstrogene. 24: DGPT Forum. 
Denison, M.S., Pandini, A., Nagy, S.R., Baldwin, E.P., Bonati, L. (2002). Ligand binding and activation of the Ah receptor. Chem Biol Interact 141(1-2):3-24.

Dich, J., Wiklund, K. (1998). Prostate cancer in pesticide applicators in Swedish agriculture. Prostate 34(2):100-112.

Donda, A., Reymond, F., Rey, F., Lemarchand-Beraud, T. (1990). Sex steroids modulate the pituitary parameters involved in the regulation of TSH secretion in the rat. Acta Endocrinol (Copenh) 122(5):577-584.

Dorgan, J.F., Brock, J.W., Rothman, N., Needham, L.L., Miller, R., Stephenson, H.E., Jr., et al. (1999). Serum organochlorine pesticides and PCBs and breast cancer risk: results from a prospective analysis (USA). Cancer Causes Control 10(1):1-11.

Dorling, A.A., Todman, M.G., Korach, K.S., Herbison, A.E. (2003). Critical role for estrogen receptor alpha in negative feedback regulation of gonadotropin-releasing hormone mRNA expression in the female mouse. Neuroendocrinology 78(4):204-209.

Ebert, B., Seidel, A., Lampen, A. (2005). Induction of phase-1 metabolizing enzymes by oltipraz, flavone and indole-3-carbinol enhance the formation and transport of benzo[a]pyrene sulfate conjugates in intestinal Caco-2 cells. Toxicol Lett 158(2):140151.

Emons, G., Hoffmann, H.G., Brack, C., Ortmann, O., Sturm, R., Ball, P., et al. (1988). Modulation of gonadotropin-releasing hormone receptor concentration in cultured female rat pituitary cells by estradiol treatment. J Steroid Biochem 31(5):751-756.

Emons, G., Ortmann, O., Fingscheidt, U., Ball, P., Knuppen, R. (1986). Short-term effects of oestradiol and 4-hydroxyoestradiol on gonadotrophin-releasing hormone induced luteinizing hormone secretion by rat pituitary cells in culture. Acta Endocrinol (Copenh) 111(3):312-320.

Evans, R.M. (1988). The steroid and thyroid hormone receptor superfamily. Science 240(4854):889-895.

Fan, J.D., Wagner, B.L., McDonnell, D.P. (1996). Identification of the sequences within the human complement 3 promoter required for estrogen responsiveness provides insight into the mechanism of tamoxifen mixed agonist activity. Mol Endocrinol 10(12):16051616.

Fent, K. (2003). Ökotoxikologie 2. überarbeitete und erweiterte Auflage. Stuttgart:Thieme.

Fleming, L.E., Bean, J.A., Rudolph, M., Hamilton, K. (1999). Cancer incidence in a cohort of licensed pesticide applicators in Florida. J Occup Environ Med 41(4):279-288.

Flouriot, G., Brand, H., Denger, S., Metivier, R., Kos, M., Reid, G., et al. (2000). Identification of a new isoform of the human estrogen receptor-alpha (hER-alpha) that is encoded by distinct transcripts and that is able to repress hER-alpha activation function 1. Embo J 19(17):4688-4700. 
Fowler, A.M., Solodin, N.M., Valley, C.C., Alarid, E.T. (2005). Altered Target Gene Regulation Controlled by Estrogen Receptor-\{alpha\} Concentration. Mol Endocrinol.

Frasor, J., Barnett, D.H., Danes, J.M., Hess, R., Parlow, A.F., Katzenellenbogen, B.S. (2003). Response-specific and ligand dose-dependent modulation of estrogen receptor (ER) alpha activity by ERbeta in the uterus. Endocrinology 144(7):3159-3166.

Friend, K.E., Ang, L.W., Shupnik, M.A. (1995). Estrogen regulates the expression of several different estrogen receptor mRNA isoforms in rat pituitary. Proc Natl Acad Sci U S A 92(10):4367-4371.

Gies, A., Gottschalk, C., Greiner, P., Heger, W., Kolossa, M., Rechenberg, B., et al. (2001). Nachhaltigkeit und Vorsorge bei der Risikobewertung und beim Risikomanagement von Chemikalien. Teil II: Umweltchemikalien, die auf das Hormonsystem wirken Belastungen, Auswirkungen, Minderungsstrategien -: Umweltbundesamt.

Giguere, V., Yang, N., Segui, P., Evans, R.M. (1988). Identification of a new class of steroid hormone receptors. Nature 331(6151):91-94.

Godine, J.E., Chin, W.W., Habener, J.F. (1982). alpha Subunit of rat pituitary glycoprotein hormones. Primary structure of the precursor determined from the nucleotide sequence of cloned cDNAs. J Biol Chem 257(14):8368-8371.

Gomez, E., Pillon, A., Fenet, H., Rosain, D., Duchesne, M.J., Balaguer, P., et al. (2005). Estrogenic activity of cosmetic components in reporter cell lines: Parabens, UV screens, and musk. J Toxicol Environ Health A 68(4):239-251.

Green, S., Walter, P., Kumar, V., Krust, A., Bornert, J.M., Argos, P., et al. (1986). Human oestrogen receptor cDNA: sequence, expression and homology to v-erb-A. Nature 320(6058):134-139.

Gronemeyer, H., Laudet, V. (1995). Transcription factors 3: nuclear receptors. Protein Profile 2(11):1173-1308.

Gurr, J.A., Kourides, I.A. (1983). Regulation of thyrotropin biosynthesis. Discordant effect of thyroid hormone on alpha and beta subunit mRNA levels. $J$ Biol Chem 258(17):10208-10211.

Hatoya, S., Torii, R., Kumagai, D., Sugiura, K., Kawate, N., Tamada, H., et al. (2003). Expression of estrogen receptor alpha and beta genes in the mediobasal hypothalamus, pituitary and ovary during the canine estrous cycle. Neurosci Lett 347(2):131-135.

Heneweer, M., Muusse, M., van den Berg, M., Sanderson, J.T. (2005). Additive estrogenic effects of mixtures of frequently used UV filters on $\mathrm{pS} 2$-gene transcription in MCF-7 cells. Toxicol Appl Pharmacol 208(2):170-177.

Herbison, A.E. (1998). Multimodal influence of estrogen upon gonadotropin-releasing hormone neurons. Endocr Rev 19(3):302-330. 
Herbst, A.L. (1987). The effects in the human of diethylstilbestrol (DES) use during pregnancy. Princess Takamatsu Symp 18:67-75.

Herbst, A.L., Ulfelder, H., Poskanzer, D.C. (1971). Adenocarcinoma of the vagina. Association of maternal stilbestrol therapy with tumor appearance in young women. $N$ Engl J Med 284(15):878-881.

Herynk, M.H., Fuqua, S.A. (2004). Estrogen receptor mutations in human disease. Endocr Rev 25(6):869-898.

Holland, P.M., Abramson, R.D., Watson, R., Gelfand, D.H. (1991). Detection of specific polymerase chain reaction product by utilizing the $5^{\prime}----3^{\prime}$ exonuclease activity of Thermus aquaticus DNA polymerase. Proc Natl Acad Sci U S A 88(16):7276-7280.

Hong, H., Tong, W., Fang, H., Shi, L., Xie, Q., Wu, J., et al. (2002). Prediction of estrogen receptor binding for 58,000 chemicals using an integrated system of a tree-based model with structural alerts. Environ Health Perspect 110(1):29-36.

Hooper, S.W., Pettigrew, C.A., Sayler, G.S. (1990). Ecological fate, effects and prospects for elimination of environmental polychlorinated biphenyls (PCBs). Environ Toxicol Chem 9:655-667.

Hoyer, A.P., Grandjean, P., Jorgensen, T., Brock, J.W., Hartvig, H.B. (1998). Organochlorine exposure and risk of breast cancer. Lancet 352(9143):1816-1820.

Hunter, W.M., Greenwood, F.C. (1962). Preparation of iodine-131 labelled human growth hormone of high specific activity. Nature 194:495-496.

IARC. (1992). Solar and Ultraviolet Radiation Volume 55. Lyon: WORLD HEALTH ORGANIZATION, INTERNATIONAL AGENCY FOR RESEARCH ON CANCER (IARC).

Ignar-Trowbridge, D.M., Nelson, K.G., Bidwell, M.C., Curtis, S.W., Washburn, T.F., McLachlan, J.A., et al. (1992). Coupling of dual signaling pathways: epidermal growth factor action involves the estrogen receptor. Proc Natl Acad Sci USA 89(10):4658-4662.

Kanno, J., Onyon, L., Peddada, S., Ashby, J., Jacob, E., Owens, W. (2003). The OECD program to validate the rat uterotrophic bioassay. Phase 2: dose-response studies. Environ Health Perspect 111(12):1530-1549.

Kaye, A.M., Sheratzky, D., Lindner, H.R. (1971). Kinetics of DNA synthesis in immature rat uterus: age dependence and estradiol stimulation. Biochim Biophys Acta 261(2):475486.

Keller-Byrne, J.E., Khuder, S.A., Schaub, E.A. (1997). Meta-analyses of prostate cancer and farming. Am J Ind Med 31(5):580-586. 
KemI. (2003). HUMAN HEALTH RISK ASSESSMENT. Proposals for the use of assessment (uncertainty) factors. Application to risk assessment for plant protection products, industrial chemicals and biocidal products within the European Union. Solna, Sweden: Body for Competence and Methodology Development, National Chemicals Inspectorate and Institute of Environmental Medicine, Karolinska Institutet.

Kerrigan, J.R., Veldhuis, J.D., Rogol, A.D. (1994). Androgen-receptor blockade enhances pulsatile luteinizing hormone production in late pubertal males: evidence for a hypothalamic site of physiologic androgen feedback action. Pediatr Res 35(1):102106.

Klotz, D.M., Hewitt, S.C., Korach, K.S., Diaugustine, R.P. (2000). Activation of a uterine insulin-like growth factor I signaling pathway by clinical and environmental estrogens: requirement of estrogen receptor-alpha. Endocrinology 141(9):3430-3439.

Knobil, E. (1990). The GnRH pulse generator. Am J Obstet Gynecol 163(5 Pt 2):1721-1727.

Korach, K.S., McLachlan, J.A. (1995). Techniques for detection of estrogenicity. Environ Health Perspect 103 Suppl 7:5-8.

Krattenmacher, R., Knauthe, R., Parczyk, K., Walker, A., Hilgenfeldt, U., Fritzemeier, K.H. (1994). Estrogen action on hepatic synthesis of angiotensinogen and IGF-I: direct and indirect estrogen effects. J Steroid Biochem Mol Biol 48(2-3):207-214.

Krege, J.H., Hodgin, J.B., Couse, J.F., Enmark, E., Warner, M., Mahler, J.F., et al. (1998). Generation and reproductive phenotypes of mice lacking estrogen receptor beta. Proc Natl Acad Sci U S A 95(26):15677-15682.

Krieger, N., Wolff, M.S., Hiatt, R.A., Rivera, M., Vogelman, J., Orentreich, N. (1994). Breast cancer and serum organochlorines: a prospective study among white, black, and Asian women. J Natl Cancer Inst 86(8):589-599.

Kuiper, G.G., Enmark, E., Pelto-Huikko, M., Nilsson, S., Gustafsson, J.A. (1996). Cloning of a novel receptor expressed in rat prostate and ovary. Proc Natl Acad Sci U S A 93(12):5925-5930.

Kuiper, G.G., Lemmen, J.G., Carlsson, B., Corton, J.C., Safe, S.H., van der Saag, P.T., et al. (1998). Interaction of estrogenic chemicals and phytoestrogens with estrogen receptor beta. Endocrinology 139(10):4252-4263.

Laden, F., Hankinson, S.E., Wolff, M.S., Colditz, G.A., Willett, W.C., Speizer, F.E., et al. (2001). Plasma organochlorine levels and the risk of breast cancer: an extended follow-up in the Nurses' Health Study. Int J Cancer 91(4):568-574.

Laemmli, U.K. (1970). Cleavage of structural proteins during the assembly of the head of bacteriophage T4. Nature 227(5259):680-685. 
Landel, C.C., Kushner, P.J., Greene, G.L. (1994). The interaction of human estrogen receptor with DNA is modulated by receptor-associated proteins. Mol Endocrinol 8(10):14071419.

Landel, C.C., Kushner, P.J., Greene, G.L. (1995). Estrogen receptor accessory proteins: effects on receptor-DNA interactions. Environ Health Perspect 103 Suppl 7:23-28.

Lechan, R.M., Wu, P., Jackson, I.M., Wolf, H., Cooperman, S., Mandel, G., et al. (1986). Thyrotropin-releasing hormone precursor: characterization in rat brain. Science 231(4734):159-161.

Levine, J.E. (1997). New concepts of the neuroendocrine regulation of gonadotropin surges in rats. Biol Reprod 56(2):293-302.

Leygue, E., Dotzlaw, H., Lu, B., Glor, C., Watson, P.H., Murphy, L.C. (1998). Estrogen receptor beta: mine is longer than yours? J Clin Endocrinol Metab 83(10):3754-3755.

Lin, V.Y., Resnick, E.M., Shupnik, M.A. (2003). Truncated estrogen receptor product-1 stimulates estrogen receptor alpha transcriptional activity by titration of repressor proteins. J Biol Chem 278(40):38125-38131.

Lindberg, M.K., Moverare, S., Skrtic, S., Gao, H., Dahlman-Wright, K., Gustafsson, J.A., et al. (2003). Estrogen receptor (ER)-beta reduces ERalpha-regulated gene transcription, supporting a "ying yang" relationship between ERalpha and ERbeta in mice. Mol Endocrinol 17(2):203-208.

Lippman, S.S., Amr, S., Weintraub, B.D. (1986). Discordant effects of thyrotropin (TSH)releasing hormone on pre- and posttranslational regulation of TSH biosynthesis in rat pituitary. Endocrinology 119(1):343-348.

Liu, M.M., Albanese, C., Anderson, C.M., Hilty, K., Webb, P., Uht, R.M., et al. (2002). Opposing action of estrogen receptors alpha and beta on cyclin D1 gene expression. $J$ Biol Chem 277(27):24353-24360.

Livak, K.J., Flood, S.J., Marmaro, J., Giusti, W., Deetz, K. (1995). Oligonucleotides with fluorescent dyes at opposite ends provide a quenched probe system useful for detecting PCR product and nucleic acid hybridization. PCR Methods Appl 4(6):357362.

Lund, T.D., Munson, D.J., Haldy, M.E., Setchell, K.D., Lephart, E.D., Handa, R.J. (2004). Equol is a novel anti-androgen that inhibits prostate growth and hormone feedback. Biol Reprod 70(4):1188-1195.

Lundeen, S.G., Carver, J.M., McKean, M.L., Winneker, R.C. (1997). Characterization of the ovariectomized rat model for the evaluation of estrogen effects on plasma cholesterol levels. Endocrinology 138(4):1552-1558.

Maruyama, K., Endoh, H., Sasaki-Iwaoka, H., Kanou, H., Shimaya, E., Hashimoto, S., et al. (1998). A novel isoform of rat estrogen receptor beta with 18 amino acid insertion in 
the ligand binding domain as a putative dominant negative regular of estrogen action. Biochem Biophys Res Commun 246(1):142-147.

Menon, M., Peegel, H., Katta, V. (1985). Estradiol potentiation of gonadotropin-releasing hormone responsiveness in the anterior pituitary is mediated by an increase in gonadotropin-releasing hormone receptors. Am J Obstet Gynecol 151(4):534-540.

Metzger, D.L., Kerrigan, J.R. (1993). Androgen receptor blockade with flutamide enhances growth hormone secretion in late pubertal males: evidence for independent actions of estrogen and androgen. $J$ Clin Endocrinol Metab 76(5):1147-1152.

Migliaccio, A., Di Domenico, M., Castoria, G., de Falco, A., Bontempo, P., Nola, E., et al. (1996). Tyrosine kinase/p21ras/MAP-kinase pathway activation by estradiol-receptor complex in MCF-7 cells. Embo J 15(6):1292-1300.

Miller, W.L., Knight, M.M., Gorski, J. (1977). Estrogen action in vitro: regulation of thyroid stimulating and other pituitary hormones in cell cultures. Endocrinology 101(5):14551460 .

Misumi, Y., Sohda, M., Ikehara, Y. (1990). Nucleotide and deduced amino acid sequence of rat complement C3. Nucleic Acids Res 18(8):2178.

Morinaga, H., Yanase, T., Nomura, M., Okabe, T., Goto, K., Harada, N., et al. (2004). A benzimidazole fungicide, benomyl, and its metabolite, carbendazim, induce aromatase activity in a human ovarian granulose-like tumor cell line (KGN). Endocrinology 145(4):1860-1869.

Morley, P., Whitfield, J.F., Vanderhyden, B.C., Tsang, B.K., Schwartz, J.L. (1992). A new, nongenomic estrogen action: the rapid release of intracellular calcium. Endocrinology 131(3):1305-1312.

Morrison, H., Savitz, D., Semenciw, R., Hulka, B., Mao, Y., Morison, D., et al. (1993). Farming and prostate cancer mortality. Am J Epidemiol 137(3):270-280.

Mullis, K.B., Faloona, F.A. (1987). Specific synthesis of DNA in vitro via a polymerasecatalyzed chain reaction. Methods Enzymol 155:335-350.

Murakami, M., Mori, M., Kato, Y., Kobayashi, I. (1991). Hypothalamic thyrotropin-releasing hormone regulates pituitary thyrotropin beta- and alpha-subunit mRNA levels in the rat. Neuroendocrinology 53(3):276-280.

Murata, T., Narita, K., Honda, K., Matsukawa, S., Higuchi, T. (2003). Differential regulation of estrogen receptor alpha and beta mRNAs in the rat uterus during pregnancy and labor: possible involvement of estrogen receptors in oxytocin receptor regulation. Endocr J 50(5):579-587.

Murphy, L.C., Dotzlaw, H., Leygue, E., Coutts, A., Watson, P. (1998). The pathophysiological role of estrogen receptor variants in human breast cancer. J Steroid Biochem Mol Biol 65(1-6):175-180. 
Murphy, L.J., Murphy, L.C., Friesen, H.G. (1987). Estrogen induces insulin-like growth factor-I expression in the rat uterus. Mol Endocrinol 1(7):445-450.

Mutschler, E., Geisslinger, G., Kroemer, H.K., Schäfer-Korting, M. (2001). Arzneimittelwirkungen. Stuttgart:Wissenschaftliche Verlagsgesellschaft mbH.

Nanjee, M.N., Koritnik, D.R., Thomas, J., Miller, N.E. (1990). Hormonal determinants of apolipoprotein B,E receptor expression in human liver. Positive association of receptor expression with plasma estrone concentration in middle-aged/elderly women. Biochim Biophys Acta 1046(2):151-158.

Nelson, K.G., Takahashi, T., Bossert, N.L., Walmer, D.K., McLachlan, J.A. (1991). Epidermal growth factor replaces estrogen in the stimulation of female genital-tract growth and differentiation. Proc Natl Acad Sci US A 88(1):21-25.

Newbold, R. (1995). Cellular and molecular effects of developmental exposure to diethylstilbestrol: implications for other environmental estrogens. Environ Health Perspect 103 Suppl 7:83-87.

Nilsson, S., Makela, S., Treuter, E., Tujague, M., Thomsen, J., Andersson, G., et al. (2001). Mechanisms of estrogen action. Physiol Rev 81(4):1535-1565.

Nishihara, T., Nishikawa, J., Kanayama, T., Dakeyama, F., Saito, K., Imagawa, M., et al. (2000). Estrogenic activities of 517 chemicals by yeast two-hybrid assay. J Health Sci 46(4):282-298.

Oesterreich, S., Zhang, P., Guler, R.L., Sun, X., Curran, E.M., Welshons, W.V., et al. (2001). Re-expression of estrogen receptor alpha in estrogen receptor alpha-negative MCF-7 cells restores both estrogen and insulin-like growth factor-mediated signaling and growth. Cancer Res 61(15):5771-5777.

Okada, A., Ohta, Y., Brody, S.L., Watanabe, H., Krust, A., Chambon, P., et al. (2004). Role of foxj1 and estrogen receptor alpha in ciliated epithelial cell differentiation of the neonatal oviduct. J Mol Endocrinol 32(3):615-625.

Ortmann, O., Asmus, W., Diedrich, K., Schulz, K.D., Emons, G. (1999). Interactions of ovarian steroids with pituitary adenylate cyclase-activating polypeptide and GnRH in anterior pituitary cells. Eur J Endocrinol 140(3):207-214.

Owens, W., Koeter, H.B. (2003). The OECD program to validate the rat uterotrophic bioassay: an overview. Environ Health Perspect 111(12):1527-1529.

Paech, K., Webb, P., Kuiper, G.G., Nilsson, S., Gustafsson, J., Kushner, P.J., et al. (1997). Differential ligand activation of estrogen receptors ERalpha and ERbeta at AP1 sites. Science 277(5331):1508-1510.

Page, R.B. (1983). Directional pituitary blood flow: a microcinephotographic study. Endocrinology 112(1):157-165. 
Pak, T.R., Chung, W.C., Lund, T.D., Hinds, L.R., Clay, C.M., Handa, R.J. (2005). The androgen metabolite, 5alpha-androstane-3beta, 17beta-diol, is a potent modulator of estrogen receptor-beta1-mediated gene transcription in neuronal cells. Endocrinology 146(1):147-155.

Pak, T.R., Chung, W.C., Roberts, J.L., Handa, R.J. (2006). Ligand-independent effects of estrogen receptor beta on mouse gonadotropin releasing hormone $(\mathrm{GnRH})$ promoter activity. Endocrinology.

Palkovits, M. (1973). Isolated removal of hypothalamic or other brain nuclei of the rat. Brain Res 59:449-450.

Pappas, T.C., Gametchu, B., Watson, C.S. (1995). Membrane estrogen receptors identified by multiple antibody labeling and impeded-ligand binding. Faseb J 9(5):404-410.

Parker, A.S., Cerhan, J.R., Putnam, S.D., Cantor, K.P., Lynch, C.F. (1999). A cohort study of farming and risk of prostate cancer in Iowa. Epidemiology 10(4):452-455.

Paxinos, G., Watson, C. (1998). The Rat Brain in Stereotaxic Coordinates. London:Academic Press.

Pike, A.C., Brzozowski, A.M., Hubbard, R.E., Bonn, T., Thorsell, A.G., Engstrom, O., et al. (1999). Structure of the ligand-binding domain of oestrogen receptor beta in the presence of a partial agonist and a full antagonist. Embo $J$ 18(17):4608-4618.

Rachez, C., Freedman, L.P. (2001). Mediator complexes and transcription. Curr Opin Cell Biol 13(3):274-280.

Reid, G., Denger, S., Kos, M., Gannon, F. (2002). Human estrogen receptor-alpha: regulation by synthesis, modification and degradation. Cell Mol Life Sci 59(5):821-831.

Resnick, E.M., Schreihofer, D.A., Periasamy, A., Shupnik, M.A. (2000). Truncated estrogen receptor product-1 suppresses estrogen receptor transactivation by dimerization with estrogen receptors alpha and beta. J Biol Chem 275(10):7158-7166.

Richards, R.G., DiAugustine, R.P., Petrusz, P., Clark, G.C., Sebastian, J. (1996). Estradiol stimulates tyrosine phosphorylation of the insulin-like growth factor-1 receptor and insulin receptor substrate-1 in the uterus. Proc Natl Acad Sci U S A 93(21):1200212007.

Roberts, C.T., Jr., Lasky, S.R., Lowe, W.L., Jr., Seaman, W.T., LeRoith, D. (1987). Molecular cloning of rat insulin-like growth factor I complementary deoxyribonucleic acids: differential messenger ribonucleic acid processing and regulation by growth hormone in extrahepatic tissues. Mol Endocrinol 1(3):243-248.

Roy, D., Angelini, N.L., Belsham, D.D. (1999). Estrogen directly respresses gonadotropinreleasing hormone $(\mathrm{GnRH})$ gene expression in estrogen receptor-alpha (ERalpha)- and ERbeta-expressing GT1-7 GnRH neurons. Endocrinology 140(11):5045-5053. 
Rytomaa, T. (1960). Organ distribution and histochemical properties of eosinophil granulocytes in rat. Acta Pathol Microbiol Scand 50(Suppl 140):1-118.

Sacks, F.M., Walsh, B.W. (1990). The effects of reproductive hormones on serum lipoproteins: unresolved issues in biology and clinical practice. Ann N Y Acad Sci 592:272-285; discussion 334-245.

Safe, S., Wormke, M. (2003). Inhibitory aryl hydrocarbon receptor-estrogen receptor alpha cross-talk and mechanisms of action. Chem Res Toxicol 16(7):807-816.

Salamonsen, L.A., Woolley, D.E. (1999). Menstruation: induction by matrix metalloproteinases and inflammatory cells. J Reprod Immunol 44(1-2):1-27.

Santti, R., Newbold, R.R., Makela, S., Pylkkanen, L., McLachlan, J.A. (1994). Developmental estrogenization and prostatic neoplasia. Prostate 24(2):67-78.

Schausi, D., Tiffoche, C., Thieulant, M.L. (2003). Regulation of the intronic promoter of rat estrogen receptor alpha gene, responsible for truncated estrogen receptor product-1 expression. Endocrinology 144(7):2845-2855.

Schlecht, C., Klammer, H., Jarry, H., Wuttke, W. (2004). Effects of estradiol, benzophenone2 and benzophenone-3 on the expression pattern of the estrogen receptors (ER) alpha and beta, the estrogen receptor-related receptor 1 (ERR1) and the aryl hydrocarbon receptor (AhR) in adult ovariectomized rats. Toxicology 205(1-2):123-130.

Schlecht, C., Klammer, H., Wuttke, W., Jarry, H. (2006). A dose-response study on the estrogenic activity of benzophenone-2 on various endpoints in the serum, pituitary 2 and uterus of female rats. Arch Toxicol im Druck.

Schmutzler, C., Bacinksi, A., Ambrugger, P., Klammer, H., Schlecht, C., Huhne, K., et al. (2006). The UV absorber benzophenone 2 is a more potent inhibitor of thyroid peroxidase than the anti-thyroid drugs propyl-thiouracil and methimazol. In Vorbereitung.

Schreihofer, D.A., Stoler, M.H., Shupnik, M.A. (2000). Differential expression and regulation of estrogen receptors (ERs) in rat pituitary and cell lines: estrogen decreases ERalpha protein and estrogen responsiveness. Endocrinology 141(6):2174-2184.

Seidlova-Wuttke, D., Jarry, H., Christoffel, J., Rimoldi, G., Wuttke, W. (2005). Effects of bisphenol-A (BPA), dibutylphtalate (DBP), benzophenone-2 (BP2), procymidone (Proc), and linurone (Lin) on fat tissue, a variety of hormones and metabolic parameters: a 3 months comparison with effects of estradiol (E2) in ovariectomized (ovx) rats. Toxicology 213(1-2):13-24.

Shupnik, M.A., Gharib, S.D., Chin, W.W. (1988). Estrogen suppresses rat gonadotropin gene transcription in vivo. Endocrinology 122(5):1842-1846.

Slob, W. (2002). Dose-response modeling of continuous endpoints. Toxicol Sci 66(2):298312. 
Smith, E.R., Davidson, J.M. (1974). Location of feedback receptors: effects of intracranially implanted steroids on plasma LH and LRF response. Endocrinology 95(6):1566-1573.

Smith, M.S., Freeman, M.E., Neill, J.D. (1975). The control of progesterone secretion during the estrous cycle and early pseudopregnancy in the rat: prolactin, gonadotropin and steroid levels associated with rescue of the corpus luteum of pseudopregnancy. Endocrinology 96(1):219-226.

Soto, A.M., Sonnenschein, C., Chung, K.L., Fernandez, M.F., Olea, N., Serrano, F.O. (1995). The E-SCREEN assay as a tool to identify estrogens: an update on estrogenic environmental pollutants. Environ Health Perspect 103 Suppl 7:113-122.

Spreafico, E., Bettini, E., Pollio, G., Maggi, A. (1992). Nucleotide sequence of estrogen receptor cDNA from Sprague-Dawley rat. Eur J Pharmacol 227(3):353-356.

Stege, H. (2001). Effect of xenogenic repair enzymes on photoimmunology and photocarcinogenesis. $J$ Photochem Photobiol B 65(2-3):105-108.

Strausberg, R.L., Feingold, E.A., Grouse, L.H., Derge, J.G., Klausner, R.D., Collins, F.S., et al. (2002). Generation and initial analysis of more than 15,000 full-length human and mouse cDNA sequences. Proc Natl Acad Sci U S A 99(26):16899-16903.

Sundstrom, S.A., Komm, B.S., Ponce-de-Leon, H., Yi, Z., Teuscher, C., Lyttle, C.R. (1989). Estrogen regulation of tissue-specific expression of complement C3. J Biol Chem 264(28):16941-16947.

Suzuki, T., Kitamura, S., Khota, R., Sugihara, K., Fujimoto, N., Ohta, S. (2005). Estrogenic and antiandrogenic activities of 17 benzophenone derivatives used as UV stabilizers and sunscreens. Toxicol Appl Pharmacol 203(1):9-17.

Svechnikov, K., Supornsilchai, V., Strand, M.L., Wahlgren, A., Seidlova-Wuttke, D., Wuttke, W., et al. (2005). Influence of long-term dietary administration of procymidone, a fungicide with anti-androgenic effects, or the phytoestrogen genistein to rats on the pituitary-gonadal axis and Leydig cell steroidogenesis. J Endocrinol 187(1):117-124.

Swan, S.H., Elkin, E.P., Fenster, L. (1997). Have sperm densities declined? A reanalysis of global trend data. Environ Health Perspect 105(11):1228-1232.

Swan, S.H., Elkin, E.P., Fenster, L. (2000). The question of declining sperm density revisited: an analysis of 101 studies published 1934-1996. Environ Health Perspect 108(10):961-966.

Takatori, S., Kitagawa, Y., Oda, H., Miwa, G., Nishikawa, J., Nishihara, T., et al. (2003). Estrogenicity of metabolites of Benzophenone derivatives examined by a yeast twohybrid assay. J Health Sci 49(2):91-98.

Tang, L.K., Spies, H.G. (1975). Effects of gonadal steroids on the basal and LRF-induced gonadotropin secretion by cultures of rat pituitary. Endocrinology 96(2):349-355. 
Tchernitchin, A., Roorijck, J., Tchernitchin, X., Vandenhende, J., Galand, F. (1974). Dramatic early increase in uterine eosinophils after oestrogen administration. Nature 248(444):142-143.

Tena-Sempere, M., Navarro, V.M., Mayen, A., Bellido, C., Sanchez-Criado, J.E. (2004). Regulation of estrogen receptor (ER) isoform messenger RNA expression by different ER ligands in female rat pituitary. Biol Reprod 70(3):671-678.

Toppari, J., Larsen, J.C., Christiansen, P., Giwercman, A., Grandjean, P., Guillette, L.J., Jr., et al. (1996). Male reproductive health and environmental xenoestrogens. Environ Health Perspect 104 Suppl 4:741-803.

Vinggaard, A.M., Hass, U., Dalgaard, M., Andersen, H.R., Bonefeld-Jorgensen, E., Christiansen, S., et al. (2006). Prochloraz: an imidazole fungicide with multiple mechanisms of action. Int J Androl 29(1):186-192.

Walsh, B.W., Schiff, I., Rosner, B., Greenberg, L., Ravnikar, V., Sacks, F.M. (1991). Effects of postmenopausal estrogen replacement on the concentrations and metabolism of plasma lipoproteins. $N$ Engl J Med 325(17):1196-1204.

Weihua, Z., Andersson, S., Cheng, G., Simpson, E.R., Warner, M., Gustafsson, J.A. (2003). Update on estrogen signaling. FEBS Lett 546(1):17-24.

Whitehead, M.I., Townsend, P.T., Gill, D.K., Collins, W.P., Campbell, S. (1980). Absorption and metabolism of oral progesterone. Br Med J 280(6217):825-827.

Whyte, J.J., Schmitt, C.J., Tillitt, D.E. (2004). The H4IIE cell bioassay as an indicator of dioxin-like chemicals in wildlife and the environment. Crit Rev Toxicol 34(1):1-83.

Wormke, M., Stoner, M., Saville, B., Walker, K., Abdelrahim, M., Burghardt, R., et al. (2003). The aryl hydrocarbon receptor mediates degradation of estrogen receptor alpha through activation of proteasomes. Mol Cell Biol 23(6):1843-1855.

Woutersen, R.A., Jonker, D., Stevenson, H., te Biesebeek, J.D., Slob, W. (2001). The benchmark approach applied to a 28-day toxicity study with Rhodorsil Silane in rats. the impact of increasing the number of dose groups. Food Chem Toxicol 39(7):697707.

Xu, J.W., Gong, J., Chang, X.M., Luo, J.Y., Dong, L., Jia, A., et al. (2004). Effects of estradiol on liver estrogen receptor-alpha and its mRNA expression in hepatic fibrosis in rats. World J Gastroenterol 10(2):250-254.

Yabusaki, Y., Shimizu, M., Murakami, H., Nakamura, K., Oeda, K., Ohkawa, H. (1984). Nucleotide sequence of a full-length cDNA coding for 3-methylcholanthrene-induced rat liver cytochrome P-450MC. Nucleic Acids Res 12(6):2929-2938.

Yamasaki, K., Takeyoshi, M., Yakabe, Y., Sawaki, M., Takatsuki, M. (2003). Comparison of the reporter gene assay for ER-alpha antagonists with the immature rat uterotrophic assay of 10 chemicals. Toxicol Lett 142(1-2):119-131. 
Young, J.K. (1986). Thyroxine treatment reduces the anorectic effect of estradiol in rats. Behav Neurosci 100(2):284-287.

Yuan, Y.D. (1991). Female reproductive system. In: Handbook of toxicologic pathology (Haschek, W.M., Rousseaux, C.G., eds). London:Academic Press, 891-933.

Zhang, J., Lathbury, L.J., Salamonsen, L.A. (2000). Expression of the chemokine eotaxin and its receptor, CCR3, in human endometrium. Biol Reprod 62(2):404-411.

Zhang, Q.X., Hilsenbeck, S.G., Fuqua, S.A., Borg, A. (1996). Multiple splicing variants of the estrogen receptor are present in individual human breast tumors. J Steroid Biochem Mol Biol 59(3-4):251-260.

Zhang, S., Li, X., Burghardt, R., Smith, R., 3rd, Safe, S.H. (2005). Role of estrogen receptor (ER) alpha in insulin-like growth factor (IGF)-I-induced responses in MCF-7 breast cancer cells. J Mol Endocrinol 35(3):433-447.

Zhou, Y., Watters, J.J., Dorsa, D.M. (1996). Estrogen rapidly induces the phosphorylation of the cAMP response element binding protein in rat brain. Endocrinology 137(5):21632166. 


\section{Anhang}

\subsection{Primersequenzen}

Tabelle 7-1: Primer- und Sondensequenzen der verwendeten TaqMan'TM-Systeme.

\begin{tabular}{|c|c|c|c|c|c|c|c|c|c|c|c|c|c|c|c|c|c|c|c|c|c|}
\hline $\begin{array}{l}N \\
\mathbb{0} \\
\stackrel{0}{0} \\
\stackrel{0}{0} \\
\widetilde{1}\end{array}$ & & 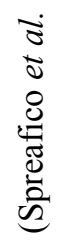 & $\widehat{\sigma}$ & 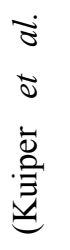 & $\begin{array}{l}\varrho \\
\stackrel{2}{ }\end{array}$ & 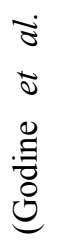 & $\begin{array}{l}\text { बิ } \\
\stackrel{\infty}{\triangle}\end{array}$ & $\begin{array}{l}\vec{\sigma} \\
\check{\sigma} \\
\tilde{\Xi} \\
\tilde{U}\end{array}$ & & 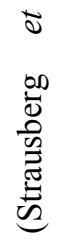 & $\begin{array}{l}\widehat{\widehat{\delta}} \\
\text { } \\
\text { sे }\end{array}$ & 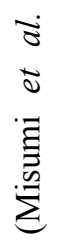 & & 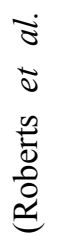 & & 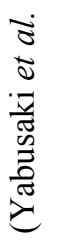 & $\begin{array}{l}\stackrel{\mathscr{I}}{\circ} \\
\stackrel{2}{\varrho}\end{array}$ & 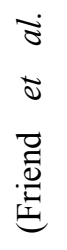 & & $\begin{array}{l}\vec{\sigma} \\
\overleftarrow{v} \\
\tilde{\Xi} \\
\stackrel{\Xi}{0} \\
\stackrel{d}{U}\end{array}$ & \\
\hline $\begin{array}{l}\frac{1}{ \pm} \\
\frac{1}{Z} \\
0 \\
0 \\
0\end{array}$ & 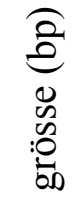 & $\exists$ & & $\underset{g}{\text { g }}$ & & $\stackrel{R}{2}$ & & $\underset{\Xi}{\stackrel{\Xi}{0}}$ & & ల్ల & & Ә & & $\bar{\beth}$ & & $\bar{\sigma}$ & & $\exists$ & & $\stackrel{0}{0}$ & \\
\hline 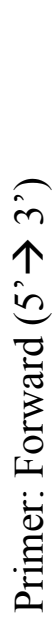 & $\begin{array}{l}\approx \\
\uparrow \\
\uparrow \\
i n \\
0 \\
\tilde{D} \\
\overrightarrow{0} \\
\approx\end{array}$ & 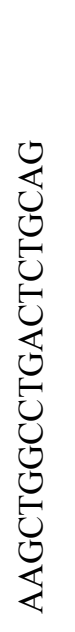 & 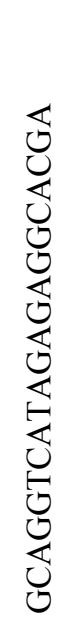 & 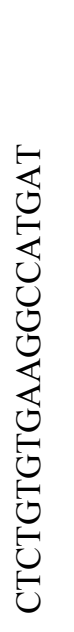 & 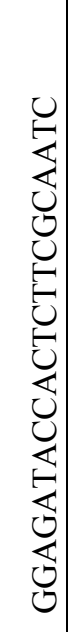 & 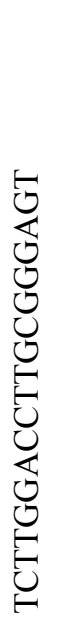 & 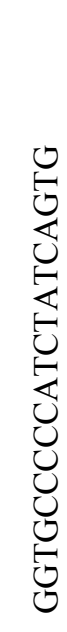 & 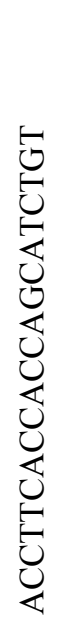 & 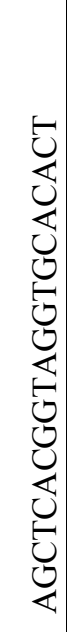 & 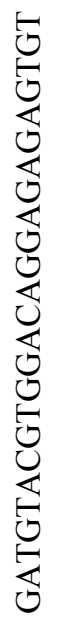 & 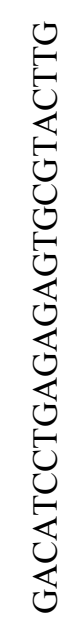 & 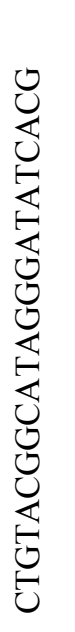 & 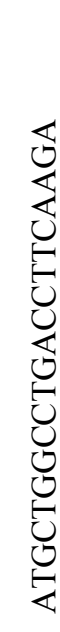 & 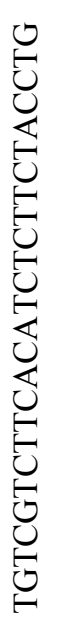 & 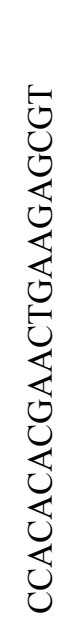 & 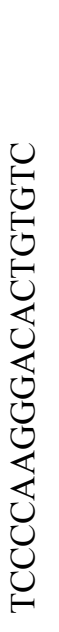 & 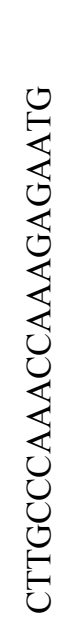 & 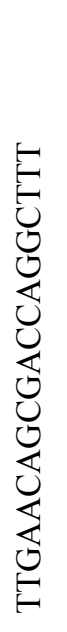 & 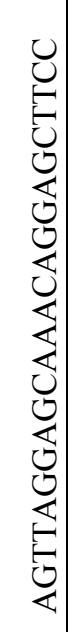 & 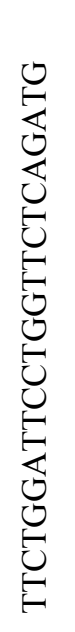 & 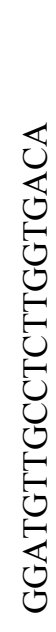 \\
\hline $\begin{array}{l}\tilde{m} \\
\uparrow \\
\text { in } \\
0 \\
\tilde{0} \\
\tilde{0} \\
\text { is }\end{array}$ & 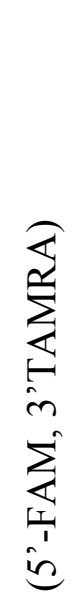 & $\begin{array}{l}0 \\
U \\
0 \\
0 \\
0 \\
0 \\
0 \\
0 \\
0 \\
0 \\
0 \\
0 \\
0 \\
0 \\
0 \\
0 \\
0 \\
0 \\
0 \\
0\end{array}$ & & 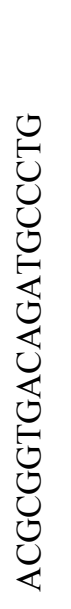 & & 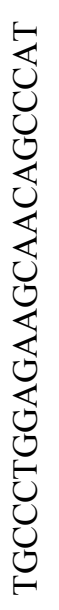 & & 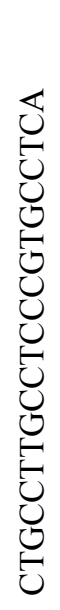 & & 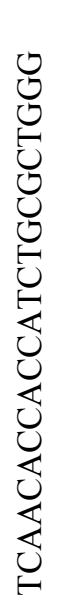 & & 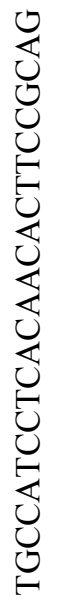 & & 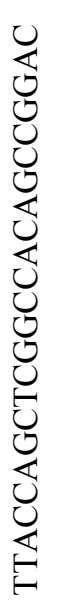 & & 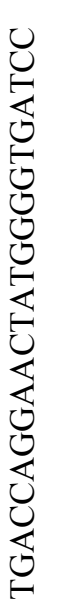 & & 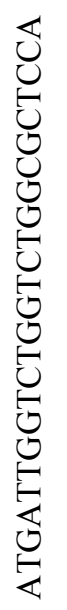 & & 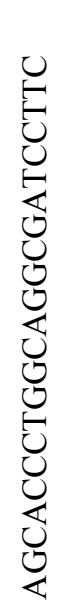 & \\
\hline$\bullet$ & 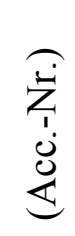 & 當 & 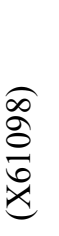 & & ñ & 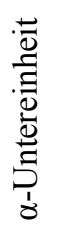 & $\stackrel{E}{n}$ & 亗 & $\vec{\sigma}_{1}$ & & & 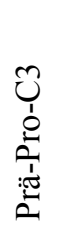 & $\stackrel{乛}{\approx}$ & & & $\frac{\vec{\pi}}{\tilde{3}}$ & إ & $\begin{array}{l}\vec{a} \\
\underline{a} \\
\underline{n}\end{array}$ & 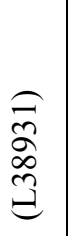 & 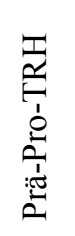 & $\begin{array}{l}0 \\
0 \\
\delta_{0} \\
\underbrace{}_{0} \\
\sigma_{1} \\
s^{\prime}\end{array}$ \\
\hline
\end{tabular}




\section{Danksagung}

Herrn Prof. Dr. R. Hardeland danke ich für die Bereitschaft zur Betreuung dieser externen Arbeit sowie für sein Interesse an deren Fortschritt.

Herrn Prof. Dr. D. Doenecke danke ich für die Übernahme des Korreferates.

Mein Dank gilt Herrn Prof. Dr. W. Wuttke für die freundliche Überlassung des Themas, die Möglichkeit zum freien wissenschaftlichen Arbeiten und sein Interesse am Fortschritt dieser Arbeit. Innerhalb des „EURISKED“-Projektes ermöglichte er mir zudem die Teilnahme an nationalen und internationalen Treffen, wofür ich mich ebenfalls bedanken möchte.

Ebenfalls bedanken möchte ich mich bei Prof. H. Jarry für seine Bereitschaft zur Diskussion, seine zahlreichen Ideen (auch in der Praxis), die wesentlich zur Verbesserung dieser Arbeit beigetragen haben sowie für die kritische Durchsicht dieses Manuskriptes.

Bei Prof. Dr. J. Köhrle, Dr. C. Schmutzler und I. Hamann von der Endokrinologie der Charité in Berlin bedanke ich mich für die Möglichkeit, die TPO- und Deiodase-Aktivitäten in ihrem Labor zu bestimmen.

Mein besonderer Dank gilt Dr. P. Balaguer (INSERM, Montpellier, Frankreich) für seine Bereitschaft den Transaktivierungsassay mit stabil transfizierten MELN-Zellen für diese Arbeit zur Verfügung zu stellen.

Ferner möchte ich mich bei Prof. Dr. W. Slob und Herrn B. Bokkers vom RIVM der Niederlande für die Möglichkeit die PROAST-Software zu benutzen sowie für die freundliche Hilfe und Unterstützung bei der Bedienung des Programms bedanken.

Herrn Dr. H. Frauendorf, Leiter der Abteilung Analytik/Massenspektrometrie des Institutes für organische Chemie der Universität Göttingen, danke ich für die massenspektrometrische Analyse der Seren aus dem Tierversuch.

Allen aktuellen und ehemaligen Mitarbeitern der Abteilung Klinische und Experimentelle Endokrinologie der Universitätsfrauenklinik Göttingen danke ich für die freundliche Unterstützung. Insbesondere möchte ich mich bei Maria Metten für die Hilfe bei den radioaktiven Assays und der HPLC, bei Christel Düls für die Einführung in die Zellkultur und bei Anette Witt und Claudia Neitzel für die Unterweisung und Hilfe am TaqMan bedanken. Allen in der „Umgebung“ des Doktoranden-Zimmers danke ich für viele schöne Momente und interessante Diskussionen.

Meiner Familie und meinem Freund danke ich für die moralische Unterstützung, ohne die diese Arbeit ungleich schwerer gewesen wäre. 


\section{Lebenslauf}

\section{Christiane Schlecht}

Geburtsdatum: $\quad$ 23.04.1979

Geburtsort: $\quad$ Blankenburg (Harz), Sachsen-Anhalt

Nationalität: deutsch

Familienstand: ledig

\section{Schulbildung}

09.1985 - 07.1991 Grundschule „Am Regenstein“ in Blankenburg

09.1991 - 06.1997 Gymnasium „Am Thie“ in Blankenburg

Abschluss: Abitur

\section{Hochschulbildung}

10.1997 - 05.2003 Studium der Biologie an der Georg-August-Universität, Göttingen

Thema der Diplomarbeit: Versuche zur Gewinnung und Charakterisierung der Restriktions-Endonuclease BglI aus einem rekombinanten Bakterienstamm für einen Vergleich mit dem Enzym aus dem Wildtyp.

Abschluss: Diplombiologin

05.2003 - 05.2006 Promotionsstudium an der Georg-August-Universität, Göttingen Thema der Dissertation: „Untersuchung endokriner Effekte von Benzophenon-2 und 17 $\beta$-Estradiol in estrogen-rezeptiven Organen“

\section{Beruflicher Werdegang}

04.2001 - 01.2002 Studentische Hilfskraft im Göttingen Genomics Laboratory

05.2003 - 12.2005 Wissenschaftliche Mitarbeiterin der Abteilung Klinische und Experimentelle Endokrinologie der Universitätsfrauenklinik, Göttingen 


\section{Wissenschaftliche Veröffentlichungen}

Effects of Estradiol, Benzophenone-2 and Benzophenone-3 on the expression pattern of the Estrogen receptors (ER) alpha and beta, the Estrogen receptor related receptor 1 (ERR1) and the Aryl hydrocarbon receptor (AhR) in adult ovariectomized rats.

Christiane Schlecht, Holger Klammer, Hubertus Jarry, Wolfgang Wuttke Toxicology. 2004 Dec 1;205(1-2):123-30.

Multi-organic risk assessment of estrogenic properties of octyl-methoxycinnamate in vivo. A 5 day sub-acute pharmacodynamic study with ovariectomized rats.

Holger Klammer, Christiane Schlecht, Wolfgang Wuttke, Hubertus Jarry Toxicology. 2005 Nov 5;215(1-2):90-6.

A dose-response study on the estrogenic activity of benzophenone- 2 on various endpoints in the serum, pituitary 2 and uterus of female rats.

Christiane Schlecht, Holger Klammer, Wolfgang Wuttke, Hubertus Jarry Archives of Toxicology. Im Druck 